\title{
Exchange rates and risk premia within the European Monetary System
}

Citation for published version (APA):

Vlaar, P. J. G. (1994). Exchange rates and risk premia within the European Monetary System. [Doctoral Thesis, Maastricht University]. Rijksuniversiteit Limburg. https://doi.org/10.26481/dis.19940929pv

Document status and date:

Published: 01/01/1994

DOI:

10.26481/dis.19940929pv

Document Version:

Publisher's PDF, also known as Version of record

\section{Please check the document version of this publication:}

- A submitted manuscript is the version of the article upon submission and before peer-review. There can be important differences between the submitted version and the official published version of record.

People interested in the research are advised to contact the author for the final version of the publication, or visit the DOI to the publisher's website.

- The final author version and the galley proof are versions of the publication after peer review.

- The final published version features the final layout of the paper including the volume, issue and page numbers.

Link to publication

\footnotetext{
General rights rights.

- You may freely distribute the URL identifying the publication in the public portal. please follow below link for the End User Agreement:

www.umlib.nl/taverne-license

Take down policy

If you believe that this document breaches copyright please contact us at:

repository@maastrichtuniversity.nl

providing details and we will investigate your claim.
}

Copyright and moral rights for the publications made accessible in the public portal are retained by the authors and/or other copyright owners and it is a condition of accessing publications that users recognise and abide by the legal requirements associated with these

- Users may download and print one copy of any publication from the public portal for the purpose of private study or research.

- You may not further distribute the material or use it for any profit-making activity or commercial gain

If the publication is distributed under the terms of Article $25 \mathrm{fa}$ of the Dutch Copyright Act, indicated by the "Taverne" license above, 
Exchange Rates and Risk Premia within the European Monetary System 
NWO 


\section{Exchange Rates and Risk Premia within the European Monetary System}

\section{PROEFSCHRIFT}

ter verkrijging van de graad van doctor aan de Rijksuniversiteit Limburg te Maastricht, op gezag van de Rector Magnificus, Prof. dr. H. Philipsen, volgens het besluit van het College van Dekanen, in het openbaar te verdedigen op donderdag

29 september 1994 om 14.00 uur

door

Petrus Johannes Gerardus Vlaar

geboren te Avenhorn 
Promotor: Prof.dr. F.C. Palm

Beoordelingscommissie: Prof.dr. C.G. Koedijk (voorzitter)

Prof. dr. H. Jager (Universiteit van Amsterdam)

Prof. dr. P.C. Schotman

CIP-DATA KONINKLIJKE BIBLIOTHEEK, DEN HAAG

Vlaar, Peter J.G.

Exchange Rates and Risk Premia within the European

Monetary System / Peter J.G. Vlaar. - [S.l. : s.n.].

Thesis Maastricht. - With ref. - With summary in Dutch.

ISBN 90-9007316-7

NUGI 681

Subject headings: exchange rates; risk premia; EMS. 


\section{Preface}

Most chapters in this thesis are revised versions of previously written articles. Chapter 2 is a revised version of Vlaar and Palm (1993a). Chapter 3 originates from Vlaar (1992). Chapter 4 is based on Vlaar and Palm (1993b), whereas chapter 5 originates from Cavaglia, Koedijk and Vlaar (1994). Chapter 6 closely resembles Vlaar (1994) and finally appendix A is a revised version of Vlaar (1993).

\section{Acknowledgements}

This thesis has benefitted from the support of many people. In particular, I wish to thank Franz Palm and Kees Koedijk for their continual interest. Their critical comments substantially contributed to the clearness of this thesis. I would also like to thank the other members of my dissertation committee, Henk Jager and Peter Schotman for their useful comments, and Jean-Pierre Urbain for his help, especially on the subject of cointegration.

The research for this dissertation was sponsored by the Economics Research Foundation, which is part of the Netherlands Organization for Scientific Research (NWO). The financial support of the "Stichting Organisatie van Effectenhandelaren te Rotterdam" is also gratefully acknowledged.

Peter Vlaar

May 1994. 


\section{Contents}

List of figures viii

List of tables $\quad$ ix

1 Introduction 1

1.1 A brief history of the European Monetary System . . . . . . 1

1.2 Empirical modeling of financial assets . . . . . . . . . 5

1.3 The target zone literature . . . . . . . . . . . . . 7

1.4 Outline of this thesis $\ldots \ldots \ldots \ldots \ldots$

2 A time series model for weekly EMS exchange rates $\quad 15$

2.1 Introduction . . . . . . . . . . . . . . . 15

2.2 The data . . . . . . . . . . . . . . . 16

2.3 The model . . . . . . . . . . . . . . . . . . . . 21

2.4 Empirical results . . . . . . . . . . . . . . . . 24

2.5 Conclusions . . . . . . . . . . . . . . 33

3 An EMS exchange rate model with endogenous jumps $\quad 35$

3.1 Introduction . . . . . . . . . . . . . . . . 35

3.2 The model . . . . . . . . . . . . . . 36

3.3 Estimation results . . . . . . . . . . . . . . . . 43

3.4 Model predictions . . . . . . . . . . . . . . . . 49

3.5 Conclusions . . . . . . . . . . . . . . . . 58

4 Modeling weekly excess returns within the EMS 59

4.1 Introduction . . . . . . . . . . . . . . . . 59

4.2 Modeling risk premia . . . . . . . . . . . . 60

4.3 The data . . . . . . . . . . . . . . . . . . . 62

4.4 The model .................... . . . 65 
4.5 Empirical results . . . . . . . . . . . . . . . 68

4.6 Conclusions . . . . . . . . . . . . . . . . . . . 75

$5 \quad$ EMS credibility and risk premia using survey data $\quad \mathbf{7 7}$

5.1 Introduction . . . . . . . . . . . . . . 77

5.2 Data-description . . . . . . . . . . . . . . . 78

5.3 EMS credibility . . . . . . . . . . . . . . . . . . . . . . . . . . 79

5.4 EMS risk premia . . . . . . . . . . . . . . . . 87

5.5 Conclusion . . . . . . . . . . . . . . . . . . . 91

6 German interest rates and the European Monetary System 93

6.1 Introduction . . . . . . . . . . . . . . . . . . 93

6.2 A reaction function for German interest rates . . . . . . . 96

6.2.1 Relevant variables in the reaction function . . . . . . 96

6.2 .2 Econometric issues . . . . . . . . . . . . 98 98

6.2 .3 Empirical results . . . . . . . . . . . . . . 100

6.3 Implications for other EMS countries . . . . . . . . . . 106

6.3.1 The desired interest rate from a domestic perspective . 106

6.3.2 An econometric model for the exchange rate . . . . . 111

6.3 .3 Empirical results . . . . . . . . . . . . . . 113

6.4 Conclusions . . . . . . . . . . . . . . . . 117

$\begin{array}{lll}7 & \text { Summary and conclusions } & 119\end{array}$

A Simple diagnostic tests for likelihood functions 125

A.1 Problem setting . . . . . . . . . . . . 125

A.2 Test statistics . . . . . . . . . . . . . . 126

A.3 The estimated parameters issue . . . . . . . . . . . 128

B Moments of the mixture distributions 133

$\begin{array}{ll}\text { C Data sources } & 137\end{array}$

$\begin{array}{ll}\text { References } & 139\end{array}$

$\begin{array}{ll}\text { Author index } & 149\end{array}$

Samenvatting (Summary in Dutch) 151

$\begin{array}{ll}\text { Curriculum Vitae } & 157\end{array}$ 


\section{List of Figures}

1.1 The weekly French franc / D-mark exchange rate . . . . . 3

2.1 Weekly exchange rates in domestic currency per D-mark ... 18

3.1 Yearly inflation differential with Germany . . . . . . . . 40

3.2 Yearly trade balance surplus as percentage of total exports . . 41

3.3 Jump probabilities . . . . . . . . . . . . . . . 47

$3.495 \%$ forecast intervals and parity changes . . . . . . . 52

4.1 Excess returns and parity changes relative to the D-mark . . 63

4.2 Conditional expectation and variance of excess return . . . 72

4.3 Expected weekly excess return . . . . . . . . . . 74

5.1 Spot exchange rate and one year ahead forecasts: BF/DM . . 81

5.2 Spot exchange rate and one year ahead forecasts: FF/DM . . 81

5.3 Spot exchange rate and one year ahead forecasts: IL/DM . . 81

5.4 Spot exchange rate and one year ahead forecasts: DG/DM . . 83

5.5 Spot exchange rate and one year ahead forecasts: SP/DM . 83

5.6 Spot exchange rate and one year ahead forecasts: BP/DM . 83

6.1 Realized and simulated German call money rate . . . . . . 105

6.2 Realized and simulated call money rates . . . . . . . . 107

6.3 Jump probabilities . . . . . . . . . . . . 115 


\section{List of Tables}

2.1 Summary statistics of $\log \mathrm{D}$-mark rates . . . . . . . . 20

2.2 Coefficients of $\mathrm{MA}(r) \operatorname{GARCH}(p, q)$ models . . . . . . . 25

2.3 Diagnostics of $\mathrm{MA}(r) \operatorname{GARCH}(p, q)$ models . . . . . . . 27

2.4 Schwarz criteria and goodness-of-fit measures for the MA(1)$\operatorname{GARCH}(1,1)$ specification . . . . . . . . . . 30

2.5 The multivariate MA(1)-GARCH(1,1)-Bernoulli-normal model 32

3.1 Summary statistics of $\log$ D-mark rates . . . . . . . . 37

3.2 ERM realignments: Percentage devaluation against D-mark . . 38

3.3 Maximum likelihood results for ERM currencies . . . . . . 44

3.4 LR statistics for models with alternative jump specifications . 15

3.5 One to four weeks ahead forecast errors . . . . . . . . . 50

3.6 Excess returns of investment strategies . . . . . . . . 56

4.1 Summary statistics for weekly excess returns . . . . . . . . 64

4.2 Empirical results for weekly excess returns . . . . . . . . 69

5.1 Actual and expected yearly changes in the D-mark rate and in yearly interest rate differentials, December 1985 to August $1991 \ldots \ldots \ldots \ldots \ldots \ldots$

5.2 Corrclation coefficients between position in the band and expected change in the exchange rate ... . . . . 86

5.3 EMS risk premia and inflation differentials . . . . . . . 89

5.4 EMS risk premia: inflation differentials and survey uncertainty 90

6.I Augmented Dickey-Fuller test statistics . . . . . . . . . . . 99

6.2 Cointegration rank tests . . . . . . . . . . . 101

6.3 Single equation models for the German call money rate . . . 103

6.4 Maximum likelihood results for the exchange rate models . . . 114 


\section{Chapter 1}

\section{Introduction}

This thesis consists of five empirical studies on exchange rates and risk premia within the European Monetary System. It aims to give a better understanding of the consequences of exchange rate bands on exchange rate stability and on interest rate dynamics. By way of introduction and for further reference, a brief hist ory of the EMS will be first given. After that, some background on the empirical modeling of financial assets will be provided. Existing models for financial market will be useful in giving insights into the way in which price formation takes place in the EMS. We will continue with a critical examination of the literature on exchange rate bands. Finally, an outline of the contributions of this thesis will be presented.

\subsection{A brief history of the European Monetary System}

Since the breakdown of the Bretton Woods system of fixed but adjustable exchange rates in the early 1970s, European countries have sought ways to limit mutual exchange rate fluctuations. This was seen as one of the necessary prerequisites to come to a further integration between the countries of the European Community. Also, there were already plans to come to a monetary union in the longer run. In April 1972 the efforts led to the so-called "Snake" arrangement between the six EC countries (Belgium, France, Germany, Italy, Luxembourg and the Netherlands) and three members-in-waiting (Denmark, Ireland and the UK). Within the Snake, bilateral exchange rate movements were limited to stay within relatively small bands (2.25\%). However, es- 
pecially since the first OPEC oil price shock which led to different levels of unemployment and inflation in different European countries, the system started to erode. Devaluations and revaluations became common practice, and some countries even had to leave the Snake.

As the Snake proved incapable of delivering exchange rate stability, it was replaced by the European Monetary System (EMS), in March 1979. The main element of the EMS is its Exchange Rate Mechanism (ERM) in which all EC members except the UK participated. In the ERM each currency has a central rate expressed in the European Currency Unit (ECU). These central rates determine a grid of bilateral central rates (the parities) around which fluctuation margins of $\pm 2.25 \%$ ( $\pm 6 \%$ for the Italian lira) are established. In order to keep the bilateral rates within the margins, the participating countries are obliged to intervene in the foreign exchange market if a bilateral rate hits the boundary of the band. For this purpose, special credit facilities have been established ${ }^{1}$. Instead of defending the parities, it is also possible to adjust them (to realign), but this is only possible if all members agree. In the economic literature, an arrangement as the ERM is called an exchange rate target zone.

In order to illustrate the working of the ERM, the French franc D-mark rate, together with its fluctuation band, is shown in figure 1.1. In the early years of the EMS, the exchange rate mechanism was not very successful. Due to the lack of policy coordination between member states, parity realignments were common practice. Each country pursued its own economic policy and whenever this policy resulted in an exchange rate that was not in line with the central parities, the parities were adjusted. Especially from 1981 to 1983 tensions in the ERM were substantial due to the expansionary economic policy of the French socialist government (the: Mitterand experiment).

After the March 1983 realignment, the ERM entered its second phase. It was agreed on that more emphasis should be laid on policy coordination. In practice, this meant that the ERM became a greater Deutchemark area (see Giavazzi and Giovannini, 1989). Germany, the country with the lowest inflation and the strongest currency, provided a monetary anchor for the

\footnotetext{
${ }^{1}$ A part from the bilateral central rates, the ECU central rates were also given a role in the system. Whenever a currency's ECU price diverges more than $0.75 \%$ rom its agreed central rate, the concerned country is supposed to take action. In practice however, this divergence indicator has not been very important since a policy response is not obliged in these circumstances.
} 
system. The other countries pegged their currencies to the D-mark and started to follow macroeconomic policies required to converge to German economic standards. Thereby, these currencies gained both exchange rate stability and credibility of their monetary policy (see Giavazzi and Pagano, 1988). As a result of the growing economic convergence, both the number and the size of realignments declined.

Figure 1.1: The weekly French franc/D-mark exchange rate

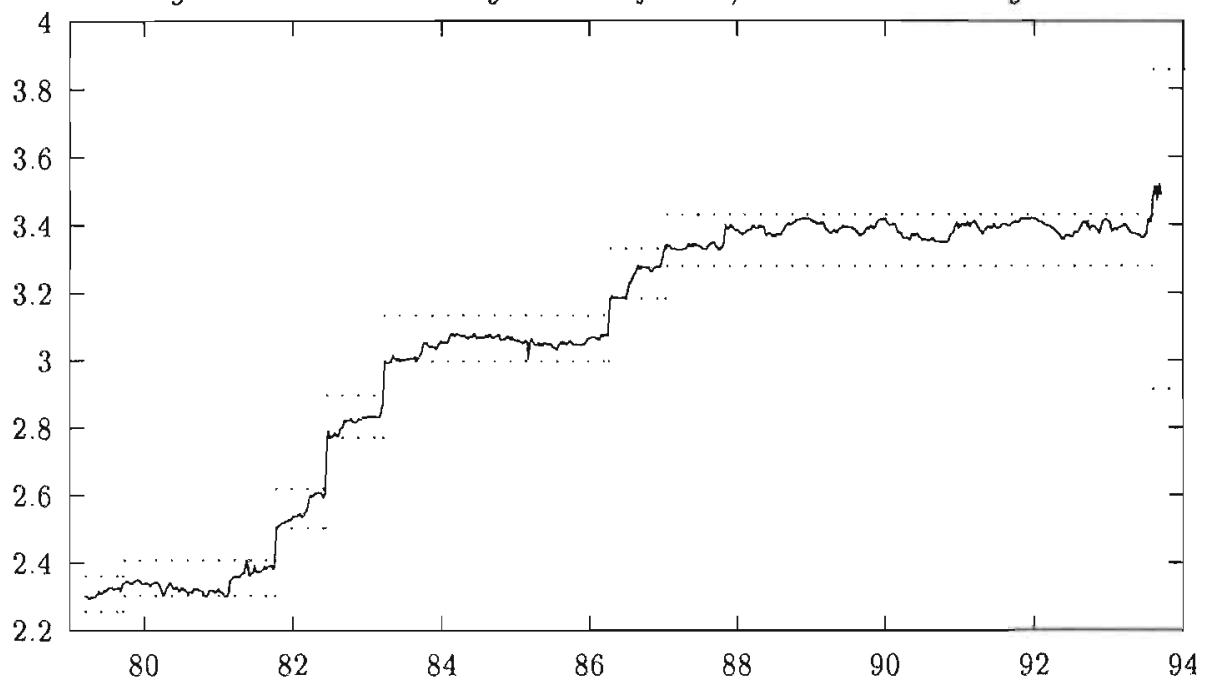

The system was further strengthened in September 1987 with the BasleNyborg agreement. In this agreement, the credit facilities were extended to include intramarginal interventions. Moreover, the ERM members agreed to lay more emphasis on the use of interest differentials to defend the parities and to make fuller use of the fluctuation band. Especially this last point is clearly visible for the French franc. The franc quite often reached the ceiling of the band, whereas before the agreement the French monetary authorities tried to keep the exchange rate in the middle of the band. Apart from the technical devaluation of the Italian lira in January 1990, which was accompanied by a narrowing of its fluctuation band to $\pm 2.25 \%$, no realignments took place until September 1992. In this relatively stable period the Spanish peseta (June 1989), the British pound (October 1990) and the Portuguese escudo (April 1992) also joined the exchange rate mechanism, with wide $( \pm 6 \%)$ fluctuation margins. The perceived success of the system during this 
period led to plans for the realization in three stages of a European Monetary Union (EMU), formulated by the Delors Committee (1989). The optimism reached its peak with the agreement on the Maastricht Treaty in December 1991. In this treaty, among other things, the specific interpretation of the three phases described by the Delors committee and a precise time schedule for their implementation was agreed upon. Also, the conditions under which members could join the monetary union were described.

With the rejection of the Maastricht Treaty in the Danish referendum of June 1992, the optimism on the working of the ERM started to erode. At least three factors contributed to the growing doubts. First, although inflation levels had been converging over the years, some of the currencies were clearly overvalued. The Italian lira for instance, had undergone a real appreciation of almost $40 \%$ relative to the D-mark since 1979 due to the persistently high Italian inflation rates. The British pound was probably also misaligned, due to the too high rate at which the pound had entered the mechanism. Second, the German unification in July 1990 had led to relatively high inflation rates in Germany. In order to prevent even higher inflation rates, the Bundesbank had raised the interest rates. Due to arbitrage, the other ERM members had no other choice but to follow the Bundesbank, which resulted in problematically high interest rates in Europe. Third, the criteria for admission to the EMU gave rise to serious doubts about the feasibility of one EMU for all participating countries. The consequences of these doubts were even enlarged by the recent abolishment of capital controls, which had made the system more vulnerable for speculation. Tensions continued to build up and reached a peak just before the French referendum on the Maastricht Treaty in September 1992, which predicted outcome was also close to rejection. The Italian lira and British pound were forced to leave the system due to severe speculative pressures. Since then, all currencies, except the Dutch guilder and the D-mark, have been under attack. For the Spanish peseta, the Portuguese escudo and the Irish punt these speculative pressures have resulted in devaluations.

On August 2, 1993, the speculative pressures on the system reached their climax. All bands, except those for the guilder - D-mark rate, were enlarged to $\pm 15 \%$, in order to prevent a total collapse of the system. Although this measure was announced as a temporary one, it is unknown when (or if) the old margins will be restored. 


\subsection{Empirical modeling of financial assets}

Most empirical studies on exchange rates are concerned with US dollar rates. These exchange rates, like other asset prices, exhibit leptokurtic behavior (fatter tails than usual), clusters of high and low volatility, but no significant serial correlation. These stylized facts can be reproduced by means of an Auto-Regressive Conditional Heteroskedasticity (ARCH, see Engle, 1982) specification or one of its generalizations. The characteristic of an $\operatorname{ARCH}(q)$ model is the autoregressive structure in the conditional variance of the model

$$
h_{t}^{2}=\alpha_{0}+\sum_{i=1}^{q} \alpha_{i} \varepsilon_{t-i}^{2}
$$

where $h_{t}^{2}$ is the conditional variance of the model and where $\varepsilon_{t-i}^{2}$ is the squared disturbance at time $t-i$. In order to assure that the conditional variance is always positive, the $\alpha_{i}$ parameters are restricted to be positive.

By specifying the current conditional variance as a function of the lagged squared innovations, the persistence in volatility is modeled. Moreover, it can be shown that ARCH-like heteroskedasticity causes the kurtosis of the unconditional distribution to be higher than that of the conditional distribution, thereby explaining the leptokurtic behavior.

The successes of the ARCH specification have led to numerous generalizations to accommodate more facts of the real world (see the survey article by Bera and Higgins, 1993). The most important generalization was the introduction of the Generalized ARCH (GARCH) model by Bollerslev (1986). In this specification, the conditional variance is a linear function of both the past squared innovations and of lagged conditional variances. The $\operatorname{GARCH}(p, q)$ specification looks like

$$
h_{t}^{2}=\alpha_{0}+\sum_{i=1}^{q} \alpha_{i} \varepsilon_{t-i}^{2}+\sum_{j=1}^{p} \beta_{j} h_{t-j}^{2} .
$$

This specification can be interpreted as an ARMA model for the variance.

Another interesting modifical ion is the Exponential-GARCH (EGARCH) specification of Nelson (1991). In this model an asymmetric conditional variance function is specified. This asymmetry takes account of the so called leverage effect: the negative correlation between volatility and past returns, which can be observed especially in the stock market. Large losses easily lead 
to panic reactions in the market, resulting in much volatility. Large gains on the other hand are not likely to result in increased uncertainty. In order to specify the model define $\varepsilon_{t}=\eta_{t} h_{t}$, where $\eta_{t}$ is independent and identically distributed with expectation zero and variance one. To avoid nonnegativity restrictions, the logarithmic specification of Geweke (1986) is used.

$$
\log \left(h_{t}^{2}\right)=\alpha_{0}+\sum_{i=1}^{q} \alpha_{i} g\left(\eta_{t-i}\right)+\sum_{j=1}^{p} \beta_{j} \log \left(h_{t-j}^{2}\right)
$$

where

$$
g\left(\eta_{t}\right)=\theta \eta_{t}+\gamma\left[\left|\eta_{t}\right|-F_{i}\left|\eta_{t}\right|\right]
$$

The first expression on the right hand side of equation (1.4) takes account of the leverage effect ( $\theta$ is expected to be negative), whereas the second term produces the ARCH effect (if $\gamma$ is positive an unexpectedly large innovation results in a higher conditional variance).

This specification turned out be quite successful when applied to stock market data. The interpretation of the leverage effect on exchange rate data is less obvious however. A rise in the exchange rate at the same time implies a positive return for investors on one side of the market and a loss for investors on the other side. Therefore, it is not clear whether a depreciation should be interpreted as a positive or a negative return.

Since their introduction, the ARCH-like specifications have been very popular in econometrics. The recent survey article by Bollerslev, Chou, and Kroner (1992) cited more than 300 papers applying these or closely related techniques. Most of these studies conclude that the GARCH specification is very successful in accounting for the conditional heteroskedasticity, but not so in explaining the high kurtosis, especially when applied to high frequency (daily or weekly) financial data.

That is why other distributions than the normal one, with or without GARCH specification, have been applied (for examples to free-float exchange rate changes see for instance McFarland, Pettit and Sung, 1982, 1987; So, 1987; Boothe and Glassman, 1987; Tucker and Pond, 1988; Akgiray and Booth, 1988; Jorion, 1988; Hsieh, 1989; Baillie and Bollerslev, 1989). Candidate distributions with fatter tails than the normal one are among others the Student- $t$, a normal-Poisson mixture, a discrete mixture of normals, a generalized error distribution, a normal-lognormal distribution and a stable Paretian distribution. Most studies on daily or weekly US dollar data 
conclude that the Student- $t$ distribution together with a $\operatorname{GARCH}(1,1)$ specification captures the stylized facts appropriately.

Since ERM currencies have to stay within a target zone, their statistical properties can be expected to differ from those for free-float rates. As long as no realignment occurs, the changes of the rates have to be small and meanreverting in order to stay within the band. At times of realignments however, large depreciations can occur (see figure 1.1) resulting in much fatter tails of the distribution of the ERM currencies than for the free-float currencies. Moreover, since all realignments within the EMS meant devaluations relative to the Deutsche mark, the distributions of all ERM currencies expressed in terms of the D-mark are positively skewed. Therefore, symmetric distributions such as the Student-t. or the generalized error distribution are unlikely to give appropriate results. The stable Paretian distribution is probably also less suitable as the unconditional variance of this distribution does not exist (except in the limiting case of a normal distribution), so that it can not account for GARCH effects. We will use a normal distribution, combined with a stochastic jump process instead. The jump size will be assumed to be normally distributed and for the jump intensity the Poisson specification (also used in Nieuwland, Verschoor and Wolff, 1991) will be compared to the Bernoulli one. As the sum of normal variates is also normally distributed, the resulting distributions are respectively a normal-Poisson mixture and a discrete mixture of normals.

\subsection{The target zone literature}

In recent years, a large number of studies on target zones has appeared ${ }^{2}$. The theoretical research mainly focuses on the influence of a known intervention policy on expectations. Starting point for this literature is the seminal paper by Krugman (1991). Krugman assumed the exchange rate, like other assets, to be a function of the current aggregate "fundamental" and the expected change in the exchange rate. In order to simplify, this relation was taken to be linear

$$
s(t)=f(t)+\alpha E_{t}[d s(t)] / d t \quad \alpha \geq 0,
$$

${ }^{2}$ See the survey articles by Svensson (1992a) and Bertola (1993). 
where $s(t)$ denotes the exchange rate and $f(t)$ the aggregate fundamental.

The aggregate fundamental incorporates all kinds of economic variables that might influence the exchange rate (like the domestic and foreign money supplies, output levels, price levels, the foreign interest rate, etc.). The target zone literature typically assumes this fundamental to be an unobserved variable ${ }^{3}$, which has two components. The one part, follows a known stochastic process, namely a Brownian motion (a continuous time random walk), whereas the other part is controlled (in a publicly known manner) by the monetary authorities, in order to accommodate the requircments of the exchange rate system. The differences between the proposed models stem from the way the fundamental is regulated by the authorities. All of them assume that both the stochastic process and the way in which regulation occurs is fully known to the market, and believed to hold forever.

In the Krugman model, it is assumed that the monetary authorities only intervene at the margins. Furthermore, it is assumed that the amount of the interventions will always be just enough to keep the spot rate within the band, meaning that the band is fully credible. In this case, the relationship between the fundamentals and the exchange rate will be S-shaped. Due to the forward looking nature of rational agents, the presence of the band and possible interventions by the monetary authorities drive the exchange rate away from the edges towards the center of the band. The asymptotic unconditional distribution of the exchange rate will be U-shaped under these conditions.

Lindberg and Söderlind (1991) on the other hand find an unconditional bell-shaped distribution when considering intra-marginal interventions.

Bertola and Caballero (1992) introduce the probability of a realignment in this framework. In their model, the public knows the exact probability $(p)$ that the monetary authorities support the strong currency if the margin is reached. In that case, a realignment takes place and the spot rate will jump to the new central parity. If the weak currency is supported, interventions will lead to a jump to the old central rate. Within the margins, the probability of a realignment is zero. In this setting the relationship between the exchange rate and the fundamentals can be completely opposite (the inverted $S$ ) to the one in the standard Krugman model. The shape depends on $p$.

\footnotetext{
${ }^{3}$ An exception to this rule is the work of Pesaran and Samiei (1992).
} 
The basic workhorse behind all these models is the no arbitrage argument. If the public knew exactly how the monetary authorities are going to react in each state of the world and if they were risk neutral, the expected arbitrage gains would be immediately exploited. As a consequence, the spot rate would move in such a way that arbitrage opportunities were removed ${ }^{4}$.

Since in reality the intervention policy is not known (and certainly not exactly of the form suggested in these articles, see figure 1.1) and since the models are not robust to a change in this perceived policy, it is not surprising that there is not much empirical support for the target zone model (Flood, Rose and Mathieson, 1991; Meese and Rose, 1990; Beetsma, 1993; De Jong, 1993).

Moreover, as will be shown in chapters 3,4 and 5, it scems that expected opportunities, based on our model predictions, are not always exploited by the market, making the theoretical foundation of these models highly questionable (see also Krugman and Miller, 1992, for a critical evaluation of the assumptions underlying the target zone model).

Since in the real world, fully credible target zones are rather exceptional, more attention has been paid to realignments. The most popular modification of the target zone models has been suggested by Bertola and Svensson (1993) in the so-called second generation target zone models. They introduce a second state variable determining the exchange rate (apart from the previous composite fundamental), namely stochastic devaluation risk. If the stochastic process of this variable is also known to be a Brownian motion (possibly with drift), it can be shown that the relationship between the new composite fundamental and the exchange rate within the band (the deviation of the spot rate from its central parity) is similar to the ones in the fully credible target zone models. In that case, the exchange rate within the band should exhibit mean reversion.

For empirical work, they suggest to deduce the expected rate of realignment (realignment probability times its expected size) as the difference betwcen the total expected depreciation (using the uncovered interest parity)

\footnotetext{
"This argument forms also the main foundation of the speculative attack literature in which the timing of realignments is based on the magnitude of the international reserves, see the review of Blackburn and Sola (1993). For applications of this framework on target. zones, see Krugman and Rotemberg (1990) and Dumas and Svensson (1991).
} 
and the expected depreciation within the band (using a time series model) ${ }^{5}$. However, most empirical applications show that the resulting rate of realignment shows a very volatile behavior, which contradicts the assumption of a Brownian motion. If this second state variable can indeed jump, the resulting expected behavior of the exchange rate within the band can be almost anything, so no similarity with credible target zones is to be expected.

The fact that strong mean-reversion is usually found for the exchange rate within the band is hardly surprising. By construction, this variable is bounded between relatively small margins $( \pm 2.25 \%)$, so this variable can not have a unit root. If the spot rate is currently at the top of the band, it will either appreciate, or devalue, in which case it is not likely to depreciate to the top of the new band immediately. Only if this currency stays at the top forever, "mean"-reversion will not be detected".

Very likely, the expected depreciation within the band is by itself influenced by the probability of a realignment (and not only by the occurrence of a realignment). In figure 1.1 for instance, it can be seen that the French franc D-mark rate jumps to the top of the band, probably in anticipation of an upcoming realignment, just before the devaluations of the French franc in March 1983 and January 1987. In our view, changes within the band and changes of the band should not be separated.

Also, one might question the point in deriving the rate of realignment. The main reason why expected parity changes are of interest is that these might tell us something about the expected future spot rate (which seems to be the ultimate goal). Here however, the exercise is performed the other way around: given the expected depreciation (using UIP) the expected rate of realignment is derived.

A totally different approach to model realignments was followed by Edin and Vredin (1991). They deduce the effects of devaluations for the Nordic countries in a two stage procedure. In the first stage they estimate the probability of a realignment by means of a probit model on some economic fundamentals and in the second stage the effects (the size) of a realignment, condi-

\footnotetext{
${ }^{5}$ Rose and Svensson (1991), Svensson (1993) and Frankel and Phillips (1991) use this framework to estimate the realignment risk for the EMS.

${ }^{6}$ If observations after realigninents are deleted from the sample, mean-reversion will not necessarily be detected.
} 
tional on a realignment. This procedure suggests that realignment weeks are fundamentally different from other weeks. However, for ERM currencies this is doubtful for two reasons. First of all, it is unlikely that the economic conditions in realignment weeks differ fundamentally from the ones in the weeks preceding a realignment. Since a realignment is based on a multilateral political decision, the timing is not only determined by economic circurnstances. Second (and more importantly), if we look at the effects of a devaluation, again it is not certain that weeks in which a realignment took place are that different. A devaluation is not always accompanied by a comparably large depreciation in the same week since the fluctuation margins might be overlapping. Within the ERM most devaluations are anticipated for, and on several occasions a devaluation was even accompanied by an appreciation (see figure 1.1). Since both the reasons for and the effects of realignments are also present in other than realignment weeks, it might be more interesting to integrate exchange rate movements within the band and the movements of the band (realignments).

\subsection{Outline of this thesis}

The starting point of the theoretical target zone literature, as discussed in the previous section, is the publicly known reaction of the monetary authorities to changes in the "fundamentals". In this thesis on the other hand, it will be assumed that the market does not know how the authorities will react. This uncertainty will be the main driving force behind our models. Large changes in the economic fundamentals can only be incorporatced in the exchange rate if the parities are realigned. This means that if a realignment is agreed on, not only the effects of the just announced news itcm are transmitted into the new parity, but also other changes in the economic environment since the last realignment. Therefore, relatively small changes (good or bad) can have large implications for expectations. These implications are even enlarged by the uncertain political dimension of realignments, which make devaluations extremely difficult to predict. As a conscquence, the market easily panics, resulting in sudden large depreciations within the band, even if the politicians are really willing to sustain the parities.

In chapter 2 , these volatile movements within the band are, together with the depreciations resulting from the large devaluations, modeled by 
means of stochastic jumps. The jump size is assumed to be normally distributed with a positive mean (on average a depreciation) and a high variance (much volatility). For the intensity of the jumps, the Poisson distribution, which has been used in empirical work on exchange rates before (see e.g. Jorion, 1988; Nieuwland, Verschoor and Wolff, 1991), is compared with the Bernoulli one, which is far easier to estimate. Other aspects of the model are an MA specification to take account of the stabilizing effects of the intervention policy and a GARCH specification to model the persistence in volatility.

Using weekly data on six ERM currencies in terms of the D-mark, it is shown that these jumps are very important for the model specification. If the jumps are not included, the negative MA term is not always detected and the GARCH specification becomes explosively nonstationary for several currencies. The differences between the Bernoulli and Poisson specifications are negligible. For most currencies, both specifications pass an adjusted goodness-of-fit test (see appendix A). For the other currencies, a discret, mixture of three normals, which can be interpreted as a normal distribution combined with two independent jump processes, is proferred. Finally, the six ERM currencies are estimated in a multivariate setting. Most results are similar to the univariate ones, but, as expected, the efficiency of the parameter estimates improved.

In chapter 3, the Bernoulli jump specification of the models of chapter 2 is endogenized. As the economies of the ERM countries have been converging over the years, one might expect the influence of the jumps in our models to have declined. This is modeled by making the probability of a jump a function of economic fundamentals that influence the realignment probability. It is shown that both a positive inflation differential with Germany and a trade balance deficit significantly increase the probability of a jump. Another modification of the models is the inclusion of an error-correction term, measuring the deviation of the spot rate from its current central parity. These models are estimated from weekly data from April 1979 to December 1990. With the models, predictions are made for the period January 1991 to September 1992. First it is shown that the models outperform the random walk, in mean squared forecast error, when making one to four weeks ahead predictions. Second, the one week ahead $95 \%$ forecast intervals are given. They have decreased substantially over the years, reflecting the increased credi- 
bility. Finally, it is shown that the models can be used to select weeks in which it is save to invest in the weak ERM currencies, thereby exploiting the interest differentials within the EMS.

In order to find an explanation for their existence, these excess returns (deviations from uncovered interest parity) are modeled themselves in chapter 4. As the excess returns incorporate the realized depreciations, the models resemble the ones for the exchange rates. Two modifications are made. First, the conditional standard deviation of the models is incorporated in the mean equation, in order to model the risk return tradeoff. Second, the trade balance is deleted from the jump specification to avoid multicollinearity problems. The results are similar to the ones found for the exchange rate changes, so the interest differential does not compensate for these regularities. Two sources for excess returns are found. First, uncertainty, measured by the conditional standard deviation. The inflation differential is an important source for this uncertainty. Second, changes in the perceived realignment probability. These changes cause the excess returns to be negatively correlated and result in a positive relationship between the position of the spot rate in the band and the expected excess return. Plots of the expected excess returns, which under the assumption of market efficiency and rational agents represent risk premia, show that they are highly volatile and substantial, reflecting the changing uncertainty in the EMS.

In chapter $\mathbf{5}$ survey data on exchange rate expectations are used. It is shown that for most currencies both the survey forecasts and the forward rates were outside the fluctuation band most of the time, until April 1990. Moreover, the survey expectations show very volatile behavior. These findings are in accordance with our assumption of positive and constantly changing perceived realignment risk. Finally, the survey data are used to construct an ex-ante measure of the risk premium, which is not affected by possible systematic forecast errors. A significant relationship is found between this ex-ante measure and the inflation differential with Germany.

Chapter 6 investigates a possible reason for the near collapse of the system in August 1993. Almost all participating countries experienced speculative attacks against their currencies, whereas only some of them were clearly overvalued. In the financial press the high German interest rates were viewed as the main cause. In order to investigate whether these rates were indeed high, a reaction function for the German call money rate in the 
1980s, based only on the domestic German situation, is estimated. By means of a dynamic simulation, it is shown that the German call money rate was indeed $\pm 1.5 \%$ higher than expected from the end of 1991 on. When this reaction function is applied to the other ERM countries, the simulated call money rate, which can be interpreted as the preferred interest rate based only on domestic circumstances, turns out to be substantially lower than the German rate since 1990 - 1991. The difference generally increased sometimes to more than $3 \%$. To investigate its influence on the exchange rate mechanism, the difference between the expected German interest rate and the simulated European country rate, which can be interpreted as an indicator of the cost of losing monetary independence due to the membership of the ERM, is included as an additional explanatory variable for the jump probability in the models of chapter 3 . For two out of four currencies investigated, the difference significantly increases the probability of a jump.

Finally, chapter 7 summarizes the main results and discusses some policy implications. Appendix A reviews the test statistics that are used throughout the thesis, appendix B describes the moments of the Bernoulli and Poisson mixtures of normals and appendix $\mathrm{C}$ provides the data sources. 


\section{Chapter 2}

\section{A time series model for weekly EMS exchange rates}

\subsection{Introduction}

In empirical work, the ERM has not yet received much attention. Most empirical studies on exchange rates are concerned with US dollar rates. These exchange rates exhibit leptokurtic behavior (fatter tails than usual), clusters of high and low volatility, but not significant serial correlation. These stylized facts can be reproduced by means of an ARCH (Engle, 1982) or GARCH (Bollerslev, 1986) specification. However, especially for high frequency financial data, the GARCH specification cum normal innovations can not fully explain the leptokurtic behavior. That is why several authors used other distributions than the normal one, such as the student- $t$, a discrete mixture of normals, a generalized error distribution or a normal-Poisson distribution (e.g. Jorion, 1988; Hsieh, 1989; Baillie and Bollerslev, 1989).

Since the ERM currencies have to stay within a target zone, we should expect their statistical properties to differ from those of the free-float rates. As long as no realignment occurs, the changes of the rates have to be small and mean-reverting in order to stay within the band. At times of realignments however, large depreciations can occur resulting in much fatter tails of the distribution of the ERM currencies than for the free-float currencies. Moreover, since all realignments within the EMS meant a revaluation of the Deutsche mark, the distributions of all ERM currencies expressed in terms of the D-mark are positively skewed. 
In Nieuwland, Verschoor and Wolff (1991) these properties were modeled by means of an $\mathrm{ARCH}(1)$ specification combined with a mixed normalPoisson distribution, as in Jorion (1988). The Poisson process generates jumps, which might reproduce the discontinuities arising from (anticipations of) parity adjustments.

In this chapter, we generalize these models in four directions, using weekly observations on the D-mark rates of the Belgian franc, the Dutch guilder, the French franc, the Danish krone, the Irish punt, the Italian lira and for comparison reason the British pound and the US dollar, for the period April 4, 1979 to March 27, 1991.

First, a moving average (MA) specification is included to allow for the stabilizing effects of the intervention policy. Second, the ARCH(1) specification is replaced by the more general $\operatorname{GARCH}(1,1)$ specification. Third, the normal-Poisson mixture is compared to mixtures of two, three and four normal distributions, respectively which can be more easily estimated and interpreted than a Poisson mixture. The inclusion of a jump process reduces the influence of outliers on the MA-GARCH specification, and accounts for skewness and high excess kurtosis. Economic explanations for the presence of outliers are speculative attacks inside the band and realignments. Fourth, the six ERM currencies are estimated in a multivariate setting. An MA(1)GARCH(1,1)-Bernoulli-normal model is estimated assuming a constant correlation matrix and an identical jump probability for all currencies.

The structure of the chapter is as follows. Section 2.2 describes the data, section 2.3 contains the statistical models, section 2.4 provides empirical results and section 2.5 summarizes the main results.

\subsection{The data}

The data consist of 626 weekly Wednesday closing rat's from the London Eurocurrency market in terms of the Deutsche mark from April 4, 1979 to March 27, 1991. All data are taken from Datastream. As the data series were reported in terms of the UK pound, we computed D-mark rates, assuming perfect arbitrage. The countries under consideration are those participating in the exchange rate mechanism of the EMS since the beginning $(3 / 13 / 79)$, that is Belgium, France, Denmark, Ireland, Italy and the Netherlands, and 
for reason of comparison, the US and the UK. For the UK pound only the free-float period (until October 8,1990 ) is considered.

In figure 2.1, the currencies are shown, together with their fluctuation bands. Several things are striking from these charts. ERM currencies behave very differently from free-float currencies. The target zone limits the exchange rate movements, resulting in much less volatile behavior for the ERM currencies than for the free-float currencies, most of the time. If the parities are realigned however, very large depreciations can occur, especially if the fluctuation bands are not overlapping and/or if the devaluation was not foreseen by the market. Large depreciations sometimes also occur within the band. These movements are probably due to market anticipations of an upcoming devaluation. Since the political willingness to sustain the parities is not known by the market, a small change in the expected probability of a realignment, for instance due to the announcement of an economic indicator or political news, has a relatively large effect on expectations, resulting in volatile behavior within the band. Finally, especially for the Dutch guilder the volatility has declined over the years, reflecting the increased credibility of the guilder D-mark peg.

As can be seen in table 2.1, these different patterns result in quite different statistical properties for the ERM currencies than for the free-float currencies. The devaluations and large movements within the band lead to a very high excess kurtosis for these currencies ${ }^{1}$, especially for the Belgian franc, the French franc and the Irish punt. Moreover, as all parity adjustments in the ERM meant devaluations relative to the D-mark, all currencies expressed in the D-mark are positively skewed.

The first row of table 2.1 shows that the unit root hypothesis is rejected for the deviation of the exchange rate from the central parity, $(s-c)$. However, if we do not account for realignments, the unit root hypothesis can no longer be rejected. That is why the model will be estimated in first differences.

A time-varying second moment might be detected by $Q_{\epsilon^{2}}(25)$ : a BoxPierce test applied to the squared data (Bollerslev, 1988). However, this test statistic requires a finite fourth moment, which might be doubtful for our data given the high kurtosis. That is why we also report the Box-Pierce test for the absolute value of the exchange rate changes $\left(Q_{|e|}(25)\right)$, which

${ }^{1}$ If devaluation weeks are excluded from the sample, the kurtosis remains much higher for these currencies than for free-float currencies. 
Figure 2.1: Weekly exchange rates in domestic currency per D-mark
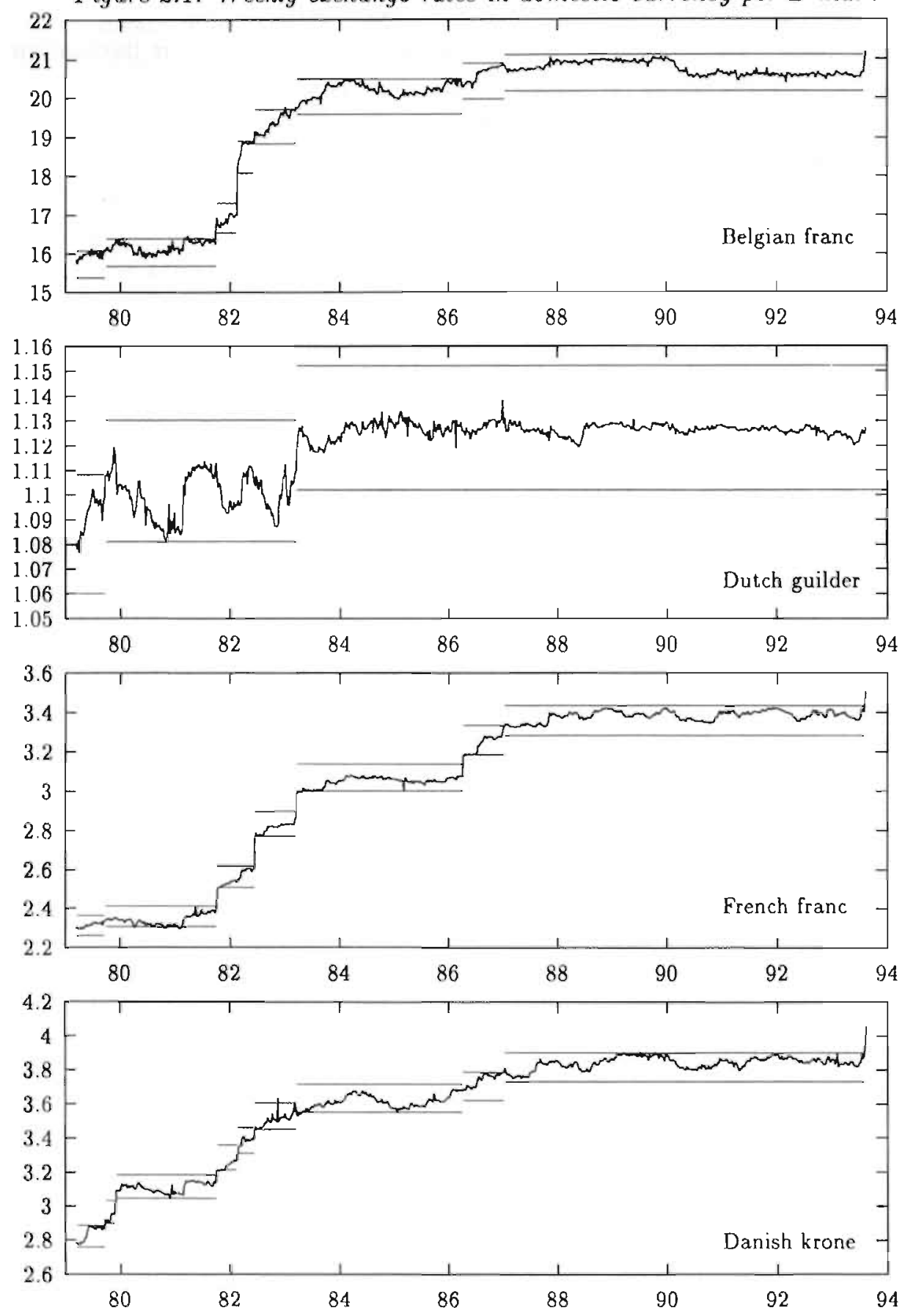
Figure 2.1 continued: Weekly exchange rates in domestic currency per D-mark
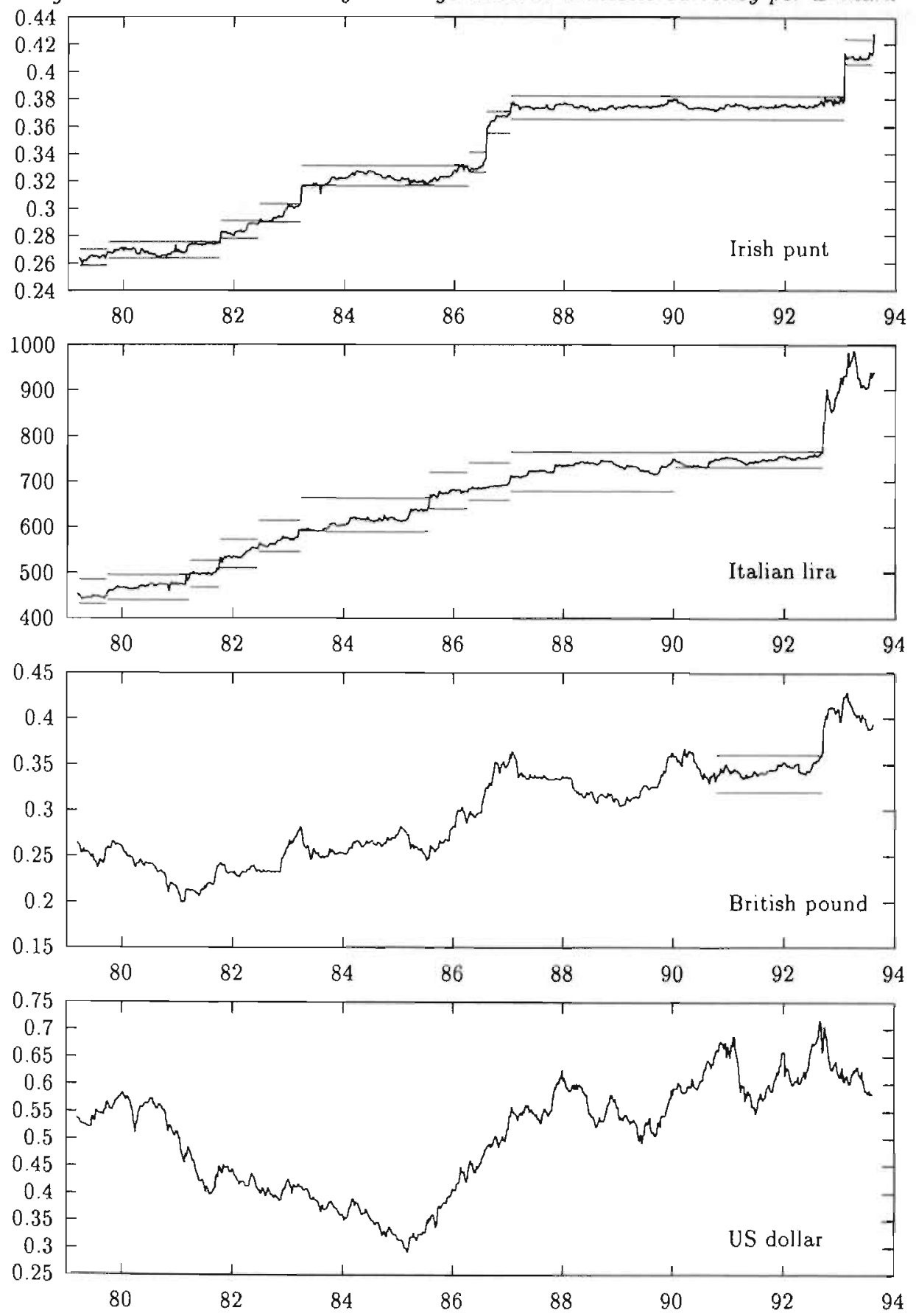
requires only a finite second moment. It turns out that the absolute changes are indeed significantly correlated for all currencies, except the French franc, whereas the null hypothesis of no serial correlation in the squared data was not rejected for the currencies with the highest excess kurtosis.

Table 2.1: Summary statistics of log D-mark rates

\begin{tabular}{||lr|rrrrrrrr||}
\hline Statistics & & BF & DG & FF & DK & IP & IL & BP & USS \\
\hline$A D F$ & $s-c$ & -5.84 & -4.39 & -4.32 & -5.04 & -4.94 & -3.97 & & \\
$A D F$ & $s$ & -2.09 & -2.79 & -1.68 & -3.60 & -1.29 & -1.97 & -.65 & -.86 \\
Mean $\left(\times 10^{2}\right)$ & $\Delta s$ & .04 & .01 & .06 & .05 & .06 & .08 & .04 & .01 \\
St.dev $\left(\times 10^{2}\right)$ & $\Delta s$ & .51 & .24 & .48 & .48 & .49 & .58 & 1.15 & 1.57 \\
Skewness & $\Delta s$ & 5.07 & .26 & 6.17 & 1.41 & 4.29 & 2.08 & .40 & .44 \\
Exc.kurt. & $\Delta s$ & 67.02 & 5.55 & 64.96 & 24.49 & 48.37 & 16.50 & 1.99 & 1.02 \\
$\rho_{e}(1)$ & $\Delta s$ & -.15 & -.19 & .02 & -.21 & -.11 & -.14 & .14 & .07 \\
$Q_{e}(25)$ & $\Delta s$ & 74.56 & 73.67 & 27.90 & 66.78 & 43.34 & 63.90 & 45.46 & 23.30 \\
$Q_{e^{2}}(25)$ & $\Delta s$ & 10.39 & 136.00 & 1.38 & 68.02 & 4.56 & 61.34 & 52.23 & 42.58 \\
$Q_{|e|}(25)$ & $\Delta s$ & 186.21 & 332.80 & 23.52 & 81.99 & 57.16 & 151.24 & 70.90 & 47.50 \\
\hline
\end{tabular}

- The data consist of 626 weekly Wednesday spot rates, expressed in domestic currency per D-mark, from April 4, 1979 to March 27, 1991. For the British pound the sample runs until October 3, 1990.

- $s$ is the $\log \mathrm{D}$-mark rate and $c$ is the $\log$ central parity.

- $A D F$ is the augmented Dickey-Fuller test statistic with a constant and one lag of the differenced series. The $5 \%$ critical value is -2.87 .

- $\rho_{\varepsilon}(1)$ is the first order serial correlation coefficient.

- $Q_{t}(25), Q_{e^{2}}(25)$ and $Q_{|c|}(25)$ are Box-Pierce tests in the raw data, the squared data and the absolute value of the data respectively.

Finally, the first order serial correlation coefficient $\rho_{e}(1)$ and the BoxPierce statistic of the raw data $\left(Q_{e}(25)\right)$ are highly significant for all currencies, except for the French franc and the US dollar, indicating serial correlation in the series. However, these tests assume normality which is clearly rejected for our data. The negative autocorrelation is probably due to the intervention policy of the monetary authorities. The argument goes as follows. Assume that the main objective of the monetary authorities is to stabilize the exchange rate. By defending the parities, the exchange rate movements are already bounded by the boundaries of the fluctuation band. However, 
since this band is quite wide ${ }^{2}$, substantial appreciations or depreciations are also possible within the band. Moreover, if depreciations hold on for several weeks, the monetary authorities might lose credibility, making a speculative attack more probable. To prevent these adverse effects one might expect that the effort made to stop a depreciation this week increases (decreases) in the magnitude of depreciation (appreciation) last week.

Another reason for the negative correlation might be the rapidly changing devaluation expectations. If the market expects a devaluation in the very short term, for instance after an election, the monetary authorities might be forced to intervene heavily if they want to support the curront parity. Just the apparent willingness to make this effort, if the exchange rate is not. devalued, might already decrease the expected realignment probability for the next week.

\subsection{The model}

The results for the ERM countries presented in section 2.2 differ from those for the free-float currencies. First of all, first differences of ERM rates exhibit significant negative autocorrelation, due to the stabilizing effects of the intervention policy. In the model this is accounted for by moving average parameters, denoted by $\psi_{i}$.

A second aspect in which ERM exchange rates differ from free-float series concerns the skewness. ERM exchange rates in terms of the D-mark are not symmetric. As a consequence, symmetric distributions such as the normal, student- $t$ or generalized error distribution are unlikely to give appropriate results. We combine normal distributions and a stochastic jump process to account for skewness and leptokurtosis. For the jump intensity $(\lambda)$ we concentrate on the Bernoulli distribution (Ball and Torous, 1983) while the Poisson distribution is also computed for comparison reason. The jump size is assumed to be normally distributed with expectation $\theta$ and variance $\delta^{2}$. As the sum of normally distributed variables is also normally distributed,

\footnotetext{
${ }^{2}$ Over our sample period, the fluctuation band was $4.5 \%$ for all the currencies discussed here except the Italian lira which had a fluctuation band of $12 \%$ until January 1990 . This wider band was also used for the new currencies in the ERM: the Spanish peseta, the British pound and the Portuguese escudo. In September 1992, the British pound and the Italian lira abandoned the system, and in August 1993 the bands for all exchange rates except the guilder D-mark were enlarged to $30 \%$.
} 
this combination results in discrete mixtures of normals. These distributions can explain the skewness and the leptokurtic behavior of a series as will be shown in appendix $B$.

It should be noticed that jumps are not the same as realignments. The jumps are part of the stochastic process, and it is not possible to separate observations with jumps from those without. The jumps model the outliers in the data and, as can be seen from figure 2.1, these large movements do not necessarily coincide with devaluations, but can also occur for instance as a result of expected policy changes after an election (Ungerer et.al., 1990, table 1), speculative attiacks or changes in interest rates. If the fluctuation margins before and after a devaluation are overlapping, a realignment need not be accompanied by a large depreciation, especially if the timing of this devaluation was rightly predicted by the market. The March 1983 realignment for instance, was forescen for all currencies except the Dutch guilder. As a consequence, this realignment was not accompanied by a large depreciation (by a jump) for the Belgian franc, the Danish krone and the Italian lira.

A third feature of our models is a $\operatorname{GARCH}(p, q)$ specification (Bollerslev, 1986) which takes account of the presence of conditional heteroskedasticity in the data.

Finally, we should consider the interpretation of an intercept denoted by $\mu$. Since we estimate the model in first differences, this parameter represents the slope of a deterministic time trend. Within the ERM, the presence of a time trend would require frequent parity adjustments, or jumps in the opposite direction within the band. Although it is unlikely that a time trend is significant, we estimate the models with intercept because it represents part of the first moment of the data. If we would not include this term into our specification, this first moment would affect $\theta$. In that case, $\theta$ could not fully explain the third moment and first and third moments would not be variation-free.

In order to specify the $\log$-likelihood functions, we first write the model as

$$
\Delta s_{t}=\mu+\lambda \theta+\varepsilon_{t}+\sum_{i=1}^{r} \psi_{i} \varepsilon_{t-i}
$$

where $\varepsilon_{t}$ is the disturbance, which has expectation 0 (see appendix B). The 
normal-Bernoulli log-likelihood function $\left(\ln \left(L_{B e r n}\right)\right)$ has the following form

$$
\begin{array}{r}
\ln \left(L_{B e r n}\right)=-\frac{T}{2} \ln (2 \pi)+ \\
\sum_{t=1}^{T} \ln \left\{\frac{1-\lambda}{h_{t}} \exp \frac{-\left(\varepsilon_{t}+\lambda \theta\right)^{2}}{2 h_{t}^{2}}+\right. \\
\left.\frac{\lambda}{\sqrt{h_{t}^{2}+\delta^{2}}} \exp \frac{-\left(\varepsilon_{t}-(1-\lambda) \theta\right)^{2}}{2\left(h_{t}^{2}+\delta^{2}\right)}\right\} .
\end{array}
$$

The normal-Poisson $\log$-likelihood $\left(\ln \left(L_{P_{\text {ois }}}\right)\right)$ can be written as

$$
\begin{aligned}
\ln \left(L_{P_{\text {ois }}}\right)= & -T \lambda-\frac{T}{2} \ln (2 \pi)+ \\
& \sum_{t=1}^{T} \ln \left\{\sum_{j=0}^{\infty} \frac{\lambda^{j}}{j ! \sqrt{h_{t}^{2}+j \delta^{2}}} \exp \frac{-\left(\varepsilon_{t}-(j-\lambda) \theta\right)^{2}}{2\left(h_{t}^{2}+j \delta^{2}\right)}\right\} .
\end{aligned}
$$

The $\operatorname{GARCH}(p, q)$ specification is the same for the two models

$$
h_{t}^{2}=\alpha_{0}+\sum_{i=1}^{q} \alpha_{i} \varepsilon_{t-i}^{2}+\sum_{j=1}^{p} \beta_{j} h_{t-j}^{2} .
$$

In the economic literature stochastic jumps are mostly modeled by means of a Poisson distribution (Ball and Torous, 1985; Fcinstone, 1987; Akgiray and Booth, 1988; Tucker and Pond, 1988; Jorion, 1988; Hsieh, 1989; Nieuwland et al., 1991; Ball and Roma, 1993). As can be seem from formula (2.3), a difficulty with a Poisson function is that it contains an infinite sum. This sum has to be truncated for the process to become estimable. Ball and Torous (1985) give an upper limit for the truncation error. A truncation after eleven terms seems to be appropriate for most applications ${ }^{3}$. Given an appropriate truncation, we can estimate model (2.3), together with the mean and variance specifications (2.1) and (2.4), by maximum likelihood. Even if we truncate after only five terms maximum likelihood estimation (combining (2.1), (2.3) and (2.4)) is quite complicated. The solution turns out to be sensitive to the choice of the starting values. Ball and Torous (1985) suggested to use the Bernoulli distribution to get starting values for the Poisson distribution. This procedure is followed here.

\footnotetext{
${ }^{3}$ The error increases with $\lambda$. In our application we truncate the sum after eleven terms, but a truncation after five terms gave similar results.
} 
Both the GARCH specification and the jump process (see appendix B) can explain the leptokurtic behavior of the series. Since the statistical and economic motivations for GARCH effects and jumps are quite different we choose a model specification that accounts for the two simultaneously. After a jump has taken place (for instance a parity adjustment) volatility will be high but gradually it will return to normal values when a new equilibrium is reached. If we would not include GARCH, the large volatility following a jump would mistakenly be taken for additional jumps. The jump intensity would rise ${ }^{4}$.

\subsection{Empirical results}

The lengths of the lag structures for the MA and GARCH specifications have been determined using a likelihood-ratio test with a $5 \%$ marginal significance level. The critical values of this statistic are adjusted because nonnegativity constraints (Kodde and Palm, 1986) of the GARCH parameters lead to a test of a one-sided hypothesis.

Positivity of $\alpha_{i}$ and $\beta_{j}$ is enforced by estimating their square root, although this is not strictly necessary for GARCH models of order higher than $(1,1)$ (Nelson and Cao, 1992). For the Bernoulli model $\lambda$ is forced between 0 and 1 by estimating $k$ in the expression $\lambda=(1+\exp (k))^{-1}$.

Tables 2.2 and 2.3 contain the empirical results of $\operatorname{MA}(r)-\operatorname{GARCH}(p, q)$ models for each currency. Three different distributions are used to estimate these models. The first is a normal distribution, the second a normalBernoulli mixture and the last distribution is a normal-Poisson mixture. All models are estimated with the maximum likelihood routine from the software package Gauss using the algorithm of Broyden, Fletcher, Goldfarb and Shano (see Broyden, 1965).

In the models without stochastic jumps, negative autocorrelation is not always present. For the French franc and the Italian lira, the MA parameter is even positive, although not significant, whereas we expected a negative sign from economic theory. These positive coefficients are probably caused by two subsequent outliers with the same sign. By including jumps, the influence of these outliers on the model specification declines.

\footnotetext{
${ }^{4}$ Empirical examples of this phenomenon can be found for instance in Jorion (1988), tables 3 and 4, and in Nieuwland et al. (1991), tables 4 and 6.
} 
Table 2.2: Coefficients of MA(r) GARCH(p,q) models

\begin{tabular}{|c|c|c|c|c|c|c|c|c|}
\hline Distribution & $\begin{array}{c}\mu \\
\left(\times 10^{4}\right)\end{array}$ & $\psi_{1}$ & $\begin{array}{c}\alpha_{0} \\
\left(\times 10^{6}\right)\end{array}$ & $\alpha_{1}$ & $\beta_{1}$ & $\lambda$ & $\begin{array}{c}\theta \\
\left(\times 10^{2}\right)\end{array}$ & $\begin{array}{c}\delta^{2} \\
\left(\times 10^{4}\right)\end{array}$ \\
\hline BF normal & $\begin{array}{r}1.277 \\
(1.43)\end{array}$ & $\begin{array}{r}-.363 \\
(8.19)\end{array}$ & $\begin{array}{r}.000 \\
(.00)\end{array}$ & $\begin{array}{r}.094 \\
(3.53)\end{array}$ & $\begin{array}{r}.926 \\
(47.30)\end{array}$ & & & \\
\hline Bern/normal & $\begin{array}{l}-.423 \\
(.47)\end{array}$ & $\begin{array}{r}-.365 \\
(8.05)\end{array}$ & $\begin{array}{r}.537 \\
(1.73)\end{array}$ & $\begin{array}{r}.149 \\
(2.07)\end{array}$ & $\begin{array}{r}.769 \\
(7.93)\end{array}$ & $\begin{array}{r}.023 \\
(2.25)\end{array}$ & $\begin{array}{r}1.264 \\
(1.66)\end{array}$ & $\begin{array}{r}3.608 \\
(1.21)\end{array}$ \\
\hline Pois/normal & $\begin{array}{l}-.595 \\
(.67)\end{array}$ & $\begin{array}{r}-.358 \\
(7.95)\end{array}$ & $\begin{array}{r}.817 \\
(1.92)\end{array}$ & $\begin{array}{r}.198 \\
(2.94)\end{array}$ & $\begin{array}{r}.683 \\
(6.58)\end{array}$ & $\begin{array}{r}.036 \\
(2.01)\end{array}$ & $\begin{array}{r}.850 \\
(1.47)\end{array}$ & $\begin{array}{r}1.589 \\
(1.12)\end{array}$ \\
\hline DG normal & $\begin{array}{l}-.011 \\
(.02)\end{array}$ & $\begin{array}{r}-.245 \\
(3.69)\end{array}$ & $\begin{array}{r}.065 \\
(.97)\end{array}$ & $\begin{array}{r}.298 \\
(2.25)\end{array}$ & $\begin{array}{r}.763 \\
(8.72)\end{array}$ & & & \\
\hline Bern/normal & $\begin{array}{r}-.485 \\
(1.02)\end{array}$ & $\begin{array}{r}-.332 \\
(6.38)\end{array}$ & $\begin{array}{r}.096 \\
(1.20)\end{array}$ & $\begin{array}{r}.263 \\
(3.43)\end{array}$ & $\begin{array}{r}.651 \\
(6.04)\end{array}$ & $\begin{array}{r}.075 \\
(2.32)\end{array}$ & $\begin{array}{r}.120 \\
(1.39)\end{array}$ & $\begin{array}{r}.222 \\
(2.16)\end{array}$ \\
\hline Pois/normal & $\begin{array}{l}-.501 \\
(1.04)\end{array}$ & $\begin{array}{r}-.333 \\
(6.47)\end{array}$ & $\begin{array}{r}.079 \\
(1.12)\end{array}$ & $\begin{array}{r}.259 \\
(3.34)\end{array}$ & $\begin{array}{r}.661 \\
(6.12)\end{array}$ & $\begin{array}{r}.082 \\
(2.04)\end{array}$ & $\begin{array}{r}.112 \\
(1.39)\end{array}$ & $\begin{array}{r}.199 \\
(1.87)\end{array}$ \\
\hline FF normal & $\begin{array}{r}2.857 \\
(1.16)\end{array}$ & $\begin{array}{r}249 \\
(.39)\end{array}$ & $\begin{array}{l}1.661 \\
(.58)\end{array}$ & $\begin{array}{r}1.051 \\
(1.92)\end{array}$ & $\begin{array}{r}.527 \\
(2.55)\end{array}$ & & & \\
\hline Bern/normal & $\begin{array}{l}1.144 \\
(1.31)\end{array}$ & $\begin{array}{r}-.138 \\
(3.96)\end{array}$ & $\begin{array}{c}4.212 \\
(8.51)\end{array}$ & $\begin{array}{r}.157 \\
(2.88)\end{array}$ & & $\begin{array}{r}.036 \\
(2.90)\end{array}$ & $\begin{array}{r}.964 \\
(2.16)\end{array}$ & $\begin{array}{c}3.436 \\
(2.21)\end{array}$ \\
\hline Pois/normal & $\begin{array}{r}1.129 \\
(1.29)\end{array}$ & $\begin{array}{r}-.139 \\
(3.97)\end{array}$ & $\begin{array}{r}4.196 \\
(8.32)\end{array}$ & $\begin{array}{r}.156 \\
(2.87)\end{array}$ & & $\begin{array}{r}.037 \\
(2.61)\end{array}$ & $\begin{array}{r}.932 \\
(2.06)\end{array}$ & $\begin{array}{r}3.227 \\
(1.88)\end{array}$ \\
\hline DK normal & $\begin{array}{r}3.157 \\
(2.36)\end{array}$ & $\begin{array}{r}-.131 \\
(1.70)\end{array}$ & $\begin{array}{r}675 \\
(.99)\end{array}$ & $\begin{array}{r}.150 \\
(1.83)\end{array}$ & $\begin{array}{r}.847 \\
(11.67)\end{array}$ & & & \\
\hline Bern/norma! & $\begin{array}{l}.584 \\
(.53)\end{array}$ & $\begin{array}{r}-.156 \\
(3.19)\end{array}$ & $\begin{array}{r}7.078 \\
(11.11)\end{array}$ & $\begin{array}{r}.151 \\
(3.98)\end{array}$ & & $\begin{array}{r}.041 \\
(3.09)\end{array}$ & $\begin{array}{r}1.076 \\
(3.38)\end{array}$ & $\begin{array}{r}1.312 \\
(2.76)\end{array}$ \\
\hline Pois/normal & $\begin{array}{l}.542 \\
(.49)\end{array}$ & $\begin{array}{r}-.155 \\
(3.17)\end{array}$ & $\begin{array}{c}7.053 \\
(10.82)\end{array}$ & $\begin{array}{r}.151 \\
(3.97)\end{array}$ & & $\begin{array}{r}.043 \\
(2.72)\end{array}$ & $\begin{array}{r}1.031 \\
(3.06)\end{array}$ & $\begin{array}{r}1.198 \\
(2.16)\end{array}$ \\
\hline normal & $\begin{array}{c}1.263 \\
(1.10)\end{array}$ & $\begin{array}{r}-.358 \\
(4.62)\end{array}$ & $\begin{array}{r}9.955 \\
(3.71)\end{array}$ & $\begin{array}{r}1.051 \\
(2.32)\end{array}$ & & & & \\
\hline Bern/normal & $\begin{array}{r}1.211 \\
(1.18)\end{array}$ & $\begin{array}{r}-.213 \\
(5.33)\end{array}$ & $\begin{array}{r}4.782 \\
(5.41)\end{array}$ & $\begin{array}{r}.305 \\
(2.61)\end{array}$ & $\begin{array}{r}.115 \\
(1.68)\end{array}$ & $\begin{array}{r}.034 \\
(1.80)\end{array}$ & $\begin{array}{r}.614 \\
(1.44)\end{array}$ & $\begin{array}{r}3.189 \\
(1.40)\end{array}$ \\
\hline Pois/normal & $\begin{array}{c}1.164 \\
(1.09)\end{array}$ & $\begin{array}{c}-.212 \\
(5.25)\end{array}$ & $\begin{array}{c}4.679 \\
(3.40)\end{array}$ & $\begin{array}{r}.296 \\
(2.04)\end{array}$ & $\begin{array}{r}.121 \\
(1.30)\end{array}$ & $\begin{array}{r}.039 \\
(.83)\end{array}$ & $\begin{array}{r}.575 \\
(1.12)\end{array}$ & $\begin{array}{l}2.640 \\
(.61)\end{array}$ \\
\hline normal & $\begin{array}{c}5.142 \\
(2.03)\end{array}$ & $\begin{array}{r}.003 \\
(.06)\end{array}$ & $\begin{array}{c}8.519 \\
(2.35)\end{array}$ & $\begin{array}{r}.315 \\
(1.75)\end{array}$ & $\begin{array}{r}.485 \\
(3.74)\end{array}$ & & & \\
\hline Bern/normal & $\begin{array}{l}-.772 \\
(.57)\end{array}$ & $\begin{array}{c}-.144 \\
(3.56)\end{array}$ & $\begin{array}{r}2.897 \\
(2.43)\end{array}$ & $\begin{array}{r}.180 \\
(2.58)\end{array}$ & $\begin{array}{r}.396 \\
(2.76)\end{array}$ & $\begin{array}{r}.094 \\
(2.93)\end{array}$ & $\begin{array}{r}.674 \\
(3.29)\end{array}$ & $\begin{array}{r}1.380 \\
(2.26)\end{array}$ \\
\hline Pois/normal & $\begin{array}{r}-1.493 \\
(.90)\end{array}$ & $\begin{array}{r}-.146 \\
(3.63)\end{array}$ & $\begin{array}{r}2.467 \\
(2.17)\end{array}$ & $\begin{array}{r}.157 \\
(2.49)\end{array}$ & $\begin{array}{r}.428 \\
(3.07)\end{array}$ & $\begin{array}{r}138 \\
(2.19)\end{array}$ & $\begin{array}{r}547 \\
(3.11)\end{array}$ & $\begin{array}{r}841 \\
(1.66)\end{array}$ \\
\hline BP normal & $\begin{array}{r}5.073 \\
(1.04)\end{array}$ & $\begin{array}{r}.144 \\
(2.82)\end{array}$ & $\begin{array}{r}6.767 \\
(1.53)\end{array}$ & $\begin{array}{r}.071 \\
(2.40)\end{array}$ & $\begin{array}{r}.877 \\
(18.48)\end{array}$ & & & \\
\hline Bern/normal & $\begin{array}{l}-5.048 \\
(1.21)\end{array}$ & $\begin{array}{r}.068 \\
(1.33)\end{array}$ & $\begin{array}{r}.000 \\
(.01)\end{array}$ & $\begin{array}{r}.084 \\
(1.87)\end{array}$ & $\begin{array}{r}.834 \\
(8.57)\end{array}$ & $\begin{array}{r}.363 \\
(2.70)\end{array}$ & $\begin{array}{r}.285 \\
(1.88)\end{array}$ & $\begin{array}{r}1.771 \\
(4.41)\end{array}$ \\
\hline Pois/normal & $\begin{array}{l}-7.309 \\
(1.73)\end{array}$ & $\begin{array}{r}.065 \\
(1.30)\end{array}$ & $\begin{array}{l}1.226 \\
(.43)\end{array}$ & $\begin{array}{r}.143 \\
(1.84)\end{array}$ & $\begin{array}{r}.585 \\
(1.49)\end{array}$ & $\begin{array}{r}815 \\
(1.88)\end{array}$ & $\begin{array}{r}.159 \\
(1.40)\end{array}$ & $\begin{array}{r}991 \\
(2.80)\end{array}$ \\
\hline US\$ normal & $\begin{array}{l}1.323 \\
(.22)\end{array}$ & & $\begin{array}{l}35.115 \\
(2.79)\end{array}$ & $\begin{array}{r}.135 \\
(3.25)\end{array}$ & $\begin{array}{r}.727 \\
(10.88)\end{array}$ & & & \\
\hline Bern/normal & $\begin{array}{c}-29.744 \\
(1.79)\end{array}$ & & $\begin{array}{l}15.925 \\
(1.52)\end{array}$ & $\begin{array}{r}.121 \\
(2.71)\end{array}$ & $\begin{array}{r}.721 \\
(9.71)\end{array}$ & $\begin{array}{r}500 \\
(1.78)\end{array}$ & $\begin{array}{r}.646 \\
(2.00)\end{array}$ & $\begin{array}{r}1.493 \\
(3.19)\end{array}$ \\
\hline Pois/normal & $\begin{array}{r}-40.777 \\
(1.15)\end{array}$ & & $\begin{array}{c}10.475 \\
(.58)\end{array}$ & $\begin{array}{r}118 \\
(2.58)\end{array}$ & $\begin{array}{r}.717 \\
(9.45)\end{array}$ & $\begin{array}{l}1.553 \\
(.78)\end{array}$ & $\begin{array}{r}.280 \\
(2.23)\end{array}$ & $\begin{array}{r}.620 \\
(1.21) \\
\end{array}$ \\
\hline
\end{tabular}

- Absolute asymptotic heteroskedasticity-consistent $t$-values are in parentheses. 
Furthermore, the estimated GARCH parameters for the Belgian franc, the Dutch guilder and the French franc seem to be too high since they indicate nonstationarity. The strict stationarity condition is not fulfilled for these currencies: $E\left[\ln \left(\beta_{1}+\alpha_{1} Z^{2}\right)\right]>0$ with $Z \sim N(0,1)$ (Nelson, 1990, figure 1). The $\alpha_{1}$ parameter for the Irish punt is also greater than one, violating the weak stationarity condition, but the strict stationarity condition is fulfilled for this currency. The high values for the GARCH parameters can be explained from misspecification. In these models, the increased volatility resulting from a jump is probably captured by the high values of $\alpha_{1}$ or $\beta_{1}$.

When jumps are taken into account, the MA parameter becomes negative and significant for all ERM currencies and the GARCH specification is weakly stationary for all currencies with $r, p$ and $q$ being at most equal to one. The GARCH $(1,1)$ specification is appropriate for all series, except for the French franc and the Danish krone, for which an $\mathrm{ARCH}(1)$ specification is sufficient. In none of these specifications the intercept is significant.

The Bernoulli and Poisson specifications give similar results for all ERM currencies. The estimated jump intensities are slightly higher for the Poisson model, resulting in a lower jump size. For the Bernoulli model the jump intensity $(\lambda)$ ranges from $2.3 \%$ (Belgian franc) to $9.4 \%$ (Italian lira). Since we have 626 observations this means the estimated expected number of jumps lies between 14 and 59. Given the fact that there have only been 12 parity adjustments during the sample period, part of the jumps must have taken place within the band, for instance, as a result of speculative attacks.

For the British pound and the US dollar the differences between the two jump specifications are larger. However, the other parameters in these models are very similar for both specifications.

For all currencies the expected jump size $(\theta)$ is positive, which is in accordance with the positive skewness. It is significantly different from zero (at the $5 \%$ level) for the French franc, the Danish krone, the Italian lira and the US dollar.

Furthermore, it is interesting to notice that the standard deviation of the jump size $(\delta)$ is always much bigger than its mean $(\theta)$. From this, we may conclude that apart from large depreciations, jumps might also represent large appreciations, for instance after an important policy announcement (German unification). The influence on volatility is most important.

In order to check for the appropriateness of the model (which assumes 
normally distributed jump sizes and innovations), an adjusted Pearson chisquare goodness-of-fit test (see appendix A) is performed on the residuals of the estimated models. The adjustment concerns the classifying mechanism. As the (standardized) residuals of a combined GARCH - jump model are neither identically nor independently distributed (which is required for the

\section{Table 2.3: Diagnostics of MA(r) GARCH $(p, q)$ models}

\begin{tabular}{|c|c|c|c|c|c|c|c|}
\hline Distribution & $\ln (L)$ & $\chi^{2}(19)$ & $Q_{e}(25)$ & $Q_{e^{2}}(25)$ & $Q_{|e|}(25)$ & Skewness & Exc.kurt. \\
\hline normal & 2560.2 & $66.5^{* * *}$ & 29.5 & 11.4 & 31.8 & $2.29^{* * *}$ & $21.31^{* * *}$ \\
\hline Bern/normal & 2654.2 & 20.5 & $35.0^{*}$ & 21.3 & 27.6 & -.05 & .22 \\
\hline Pois/normal & 2654.7 & 18.7 & $35.2^{*}$ & 22,4 & 27.7 & -.02 & $.57^{* * *}$ \\
\hline DG normal & 3010.8 & $53.8^{* * *}$ & 32.0 & 14.9 & 26.7 & $.59^{* * *}$ & $5.09^{* * *}$ \\
\hline Bern/normal & 3063.6 & 13.4 & 32.2 & 15.6 & 18.9 & .06 & .10 \\
\hline Pois/normal & 3065.8 & 10.5 & 31.7 & 15.0 & 17.6 & .06 & .11 \\
\hline FF normal & 2522.6 & $210.0^{* * * *}$ & $34.6^{*}$ & 1.9 & 18.9 & $4.36^{* * *}$ & $43.77^{* * *}$ \\
\hline Bern/normal & 2802.5 & $38.9^{* * *}$ & 24.2 & 22.0 & 27.8 & .11 & $.33^{*}$ \\
\hline Pois/normal & 2802.6 & $38.7^{* * *}$ & 24.2 & 22.0 & 27.8 & .11 & $.33^{*}$ \\
\hline DK normal & 2534.1 & $110.2^{* * *}$ & 28.1 & 21.8 & 33.2 & $1.92^{* * *}$ & $9.84^{* * *}$ \\
\hline Bern/normal & 2656.3 & 21.8 & 25.0 & $40.4^{* *}$ & $36.3^{*}$ & .08 & .20 \\
\hline Pois/normal & 2656.4 & 21.8 & 25.0 & $40.3^{* *}$ & $36.4^{*}$ & .07 & .20 \\
\hline normal & 2534.8 & $139.8^{* * *}$ & $47.6^{* * * *}$ & 4.4 & 27.3 & $2.81^{* * *}$ & $22.77^{* * *}$ \\
\hline Bern/normal & 2675.4 & $36.5^{* * *}$ & $40.0^{* *}$ & $41.0^{* *}$ & $42.2^{* *}$ & .13 & $.46^{* *}$ \\
\hline Pois/normal & 2675.6 & $34.8^{* *}$ & $40.0^{* *}$ & $40.4^{* *}$ & $42.1^{* *}$ & .13 & $.49^{* *}$ \\
\hline normal & 24013 & $149.1^{* * *}$ & 34.2 & $36.6^{*}$ & 19.2 & $2.35^{* * *}$ & $20.31 * * *$ \\
\hline Bern/normal & 2561.9 & $27.5^{*}$ & $35.9^{*}$ & 20.2 & 22.2 & .13 & $.33^{*}$ \\
\hline Pois/normal & 2563.8 & 18.7 & $36.2^{*}$ & 22.5 & 22.6 & .10 & $.51^{* * *}$ \\
\hline BP normal & 1856.4 & $47.8^{* * *}$ & 32.3 & 16.6 & 26.9 & $.39^{* * *}$ & $2,01^{* * *}$ \\
\hline Bern/normal & 1887.4 & 18.9 & 33.9 & 27.0 & 25.0 & .07 & .07 \\
\hline Pois/normal & 1887.8 & 14.7 & $35.3^{*}$ & 26.0 & 22.5 & .05 & .05 \\
\hline US\$ normal & 1727.8 & $29.0^{*}$ & 25.7 & 22.1 & 23.8 & $.28^{* * *}$ & $45^{* *}$ \\
\hline Bern/normal & 1731.1 & 23.4 & 26.5 & 22.6 & 23.8 & .08 & .09 \\
\hline Pois/normal & 1731.4 & 23.6 & 26.6 & 23.7 & 23.6 & .06 & .03 \\
\hline
\end{tabular}

- The data consist of 626 weekly Wednesday spot rates from April 4, 1979 to March 27, 1991. For the British pound the sample runs until October 3, 1990.

- $\chi^{2}(19)$ is an adjusted Pearson goodness-of-fit test (see appendix A), performed on a classification in 20 cells.

- The Box-Pierce statistics $Q_{e}(25), Q_{\epsilon^{2}}(25)$ and $Q_{|\epsilon|}(25)$ and the skewness and excess kurtosis are computed on normalized residuals (see appendix $\mathrm{A}$ ).

- * $\left.{ }^{* *}\right)\left[{ }^{* *}\right]$ indicates significance at the $10 \%(5 \%)[1 \%]$ level. 
chi-square test), we classify the residuals according to the value of the cumulative distribution function, for each residual. That is to say, we compute the probability of getting a smaller value, than the one observed, for each residual.

In the second column of table 2.3 , the results of this test are shown for a classification in 20 cells. The first row for each currency clearly shows the inappropriateness of the MA-GARCH normal model for FRM currencies. The smallest value of this $\chi^{2}(19)$ statistic, that for the Dutch guilder, is still 54. Also noticeable is the rejection according to this statistic of the model for the British pound. Although the excess kurtosis and skewness for this currency are much less extreme than for ERM currencies (see table 2.1), normality is still rejected. The null hypothesis is not rejected for the US dollar.

When stochastic jumps are included, the results improve tremendously. Using the goodness-of-fit test, the mixture models are not rejected at the $5 \%$ level for 6 out of 8 currencies. The only models that are rejected are those for the French franc and the Irish punt. Notice also that the difference in terms of fit between the Bernoulli and Poisson processes are negligible for most currencies. All models that are accepted at the $5 \%$ level for the Poisson distributed jumps are also accepted for the Bernoulli mixture.

The improvement of the fit for ERM currencies can also be seen from the first column of table 2.3. The log-likelihood function increases by values between 53 (Dutch guilder) and 280 (French franc) points when stochastic jumps are included. Again the differences between the Poisson and Bernoulli jump specifications are negligible. The largest difference between the two log-likelihood values is 2.2 (Dutch guilder). The same is true for the British pound and the US dollar, despite the large values for $\lambda$ for these currencies. This indicatess that $\lambda$ does not have to be small for the Bernoulli jump specification to be appropriate (as suggested by Ball and Torous, 1985).

Correlation in the residuals, the squared residuals and the absolute residuals can be detected using the Box-Pierce statistics $Q_{e}(25), Q_{e^{2}}(25)$ and $Q_{|c|}(25)$. Notice that these tests assume normality. For the MA-GARCHnormal models we can compute these test statistics for the standardized residuals. For the normal mixtures however, this procedure will not be of help. For these models we compute "normalized" residuals by means of the cumulative distribution function (see appendix A). Given the values of the 
cumulative distribution function for the mixture models, we can compute the normalized residuals by means of the inverse of the cumulative normal distribution function.

Under the assumption of a correctly specified model, the residuals should be independent. This can be checked by means of the Box-Pierce tests on the normalized residuals. It turns out that the MA(1) specification appropriately accounts for the correlation in the mean. The resulting autocorrelations in the residuals are insignificant for all currencies, except the Irish punt. The time-varying volatility seems to be correctly modeled as well, since both the correlations in the squared residuals, and in the absolute residuals are insignificant for most currencies.

The skewness and excess kurtosis statistics were also computed on normalized residuals. These test statistics are asymptotically normally distributed with expectation 0 and variance $6 / T$ and $24 / T$ respectively. The hypothesis of normality is clearly rejected for all the MA-GARCH normal models, even for the US dollar. For the MA-GARCH Bernoulli-normal models however, the results are much better. Only for the Irish punt, the excess kurtosis of the normalized residuals is significant at the $5 \%$ level.

From these results we conclude that the mixture distributions perform rather well for the weekly ERM exchange rates data, except for the French franc and the Irish punt. One possible reason for the failure of the normalBernoulli distribution to pass the goodness-of-fit test for these currencies might be that the number of two normal distributions included in the mixture is too low. A possible reason for adding a third normal distribution to the mixture could be that the jump sizes at realignment dates are much larger than for the jumps inside the band.

Table 2.1 shows the results of MA-GARCH models for mixiures of up to 4 normal distributions and for the normal-Poisson mixture. The mixtures of normals are estimated as "models with jumps" in the sense that the mean of the jump size $\theta_{i}$ can vary with $i$ and the variances of the second to fourth distribution are estimated as $V A R_{i t}=h_{i}^{2}+\delta_{i}^{2}$. This procedure is preferred to that of specifying independent variances, since it seems reasonable to assume that the same GARCH effect is present in all variances. The weights of the separate distributions are determined by estimating $k_{i}$ in $\lambda_{i}=\operatorname{abs}\left(k_{i}\right) /\left(\sum_{j} \operatorname{abs}\left(k_{j}\right)\right)$, with $k_{1}=1$.

Two different criteria are used to discriminate between the alternative 
Table 2.4: Schwarz criteria and goodness-of-fit measures for the MA(1)-GARCH(1,1) specification

\begin{tabular}{||ll|rrrrr||}
\hline \multirow{2}{*}{ Currency } & & 1 normal & 2 normals & 3 normals & 4 normals & $\begin{array}{r}\text { Poisson- } \\
\text { normal }\end{array}$ \\
\hline BF & $S C$ & -5088.8 & -5256.9 & -5260.2 & -5247.6 & -5257.9 \\
& $P$ & .000 & .364 & .521 & .534 & .474 \\
DG & $S C$ & -5989.4 & -6075.7 & -6062.6 & -6043.8 & -6080.1 \\
& $P$ & .000 & .820 & .942 & .949 & .940 \\
FF & $S C$ & -5013.0 & -5553.5 & -5556.6 & -5546.8 & -5553.7 \\
& $P$ & .000 & .005 & .183 & .840 & .005 \\
DK & $S C$ & -5036.0 & -5261.1 & -5248.4 & -5233.4 & -5261.3 \\
& $P$ & .000 & .295 & .474 & .577 & .295 \\
IP & $S C$ & -5043.8 & -5299.3 & -5317.6 & -5299.4 & -5299.7 \\
& $P$ & .000 & .009 & .780 & .806 & .015 \\
IL & $S C$ & -4770.4 & -5072.3 & -5075.6 & -5056.4 & -5076.1 \\
& $P$ & .000 & .093 & .564 & .516 & .474 \\
BP & $S C$ & -3681.2 & -3723.6 & -3713.8 & -3697.4 & -3724.4 \\
& $P$ & .000 & .465 & .861 & .870 & .739 \\
US\$ & $S C$ & -3429.8 & -3417.1 & -3400.0 & -3381.5 & -3417.7 \\
& $P$ & .066 & .220 & .308 & .546 & .210 \\
\hline
\end{tabular}

- $S C$ represents the Schwarz criterion which is given by: $S C=-2 \ln (L)+$ $n \ln (T), n=$ number of parameters.

- $P$ represents the p-value of the $\chi^{2}(19)$ goodness-of-fit tist.

distributions. As the mixtures of two, three or four normals are not nested in the Poisson-normal model, a standard likelihood ratio test cannot be applied to compare the models. We use the Schwarz (1978) criterion instead: $S C=-2 \ln (L)+n \ln (T)$, where $n$ is the number of parameters in the model. This criterion formally requires independently and identically distributed observations and linear models. Tucker and Pond (1988) showed, by means of a simulation experiment, that the criterion can also be used to discriminate between mixtures of normals and Poisson-normal models. The second criterion is the adjusted Pearson chi-square goodness-of-fit test.

The models with the lowest Schwarz criterion also pass the goodness-offit test. For four out of eight currencies the Poisson mixture has the lowest $S C$-value, but for these the Bernoulli mixture gives almost identical results. For three currencies the mixture of three normals performs best, according the $S C$ criterion. Not surprisingly, these three currencies (plus the Italian lira for which the mixture of three was also preferred to the mixture of two normals) were exactly those which experienced large devaluations during the sample period (see figure 2.1). In the mixture of three normals, these large 
devaluations were modeled by a separate jump process. For the US dollar the normal distribution shows the lowest $S C$ criterion.

The results in table 2.2 to 2.4 do not indicate any strong reasons why the Poisson-normal mixture should be preferred to the Bernoulli-normal one. Since the Bernoulli-normal mixture is much easier to estimate than the Poisson-normal mixture and does not require choosing a truncation point, we prefer the first. Moreover, the economic interpretation of the compound normal distribution is more appealing than the Poisson-normal one. The Poisson-normal mixture models large changes as a sequence of several jumps occurring within one week. However, within the ERM the largest weekly changes in the exchange rate originate from large devaluations, which can hardly be seen as a sum of smaller changes.

These results differ from the results of Tucker and Pond (1988) and Akgiray and Booth (1988), who concluded that, for daily US dollar data, the normal-Poisson mixture always performed better than a discrete mixture of up to five normals. The differences in log-likelihood values they found are also much larger than those found in our study. This finding might be the result of including a GARCH specification in our models. The Poisson-jump specification generates a mixture of normal distributions at the price of just including three parameters. For the other models, the compound normal distribution needs three additional parameters for each normal distribution included in the mixture. Since in the absence of a GARCH specification, part of the changing variance over time has to be taken into account by including additional normals in the mixture, the more parsimoniously parametrized Poisson specification might perform better.

Finally, we jointly estimate the MA(1)-GARCH $(1,1)$ model with Bernoullinormal mixture distribution for the six ERM currencies, assuming a constant correlation matrix (see e.g. Bollerslev, 1990) and an identical jump probability for all six currencies. Since these currencies participate in the ERM and are expressed in terms of the D-mark, it is plausible to assume their disturbances to be correlated. When for instance the D-mark is strong compared to the US dollar, all ERM currencies are expected to be affected. Similarly, a stochastic shock leading to a jump is likely to simultaneously affect all the currencies in the system. Therefore, we restrict the jump probability to be the same for the currencies. The size of the jump however is allowed to differ across them. As the univariate models estimated above are consistent 
with this multivariate model, the results for the multivariate model provide information on the appropriateness of the univariate models. In addition, for the composition of an efficient portfolio of ERM currencies, information on the cross-correlations is required.

The resulting multivariate model has the following form

$$
\Delta s_{i t}=\mu_{i}+\lambda \theta_{i}+\psi_{i} \varepsilon_{i t-1}+\varepsilon_{i t}
$$

with $i$ denoting the country and the vector $\varepsilon_{t}$ having the distribution

$$
\varepsilon_{t} \sim(1-\lambda) N\left(-\lambda \theta, \tilde{h}_{t}^{\prime} \Omega \tilde{h}_{t}\right)+\lambda N\left((1-\lambda) \theta,\left(\tilde{h}_{t}+\tilde{\delta}\right)^{\prime} \Omega\left(\tilde{h_{t}}+\tilde{\delta}\right)\right),
$$

where $\varepsilon_{t}$ and $\theta$ are $6 \times 1$ vectors with typical element $\varepsilon_{i t}$ and $\theta_{i}$ and where $\check{h}_{t}$ and $\hat{\delta}$ are diagonal matrices with typical elements $h_{i t}$ and $\delta_{i}$ respectively, with $h_{i t}^{2}=\alpha_{i 0}+\alpha_{i 1} \varepsilon_{t-1}^{2}+\beta_{i 1} h_{t-1}^{2}$. To restrict the elements of the correlation matrix $\Omega$ to be smaller than one in absolute value, we estimate them by estimating $k_{i j}$ in $\Omega_{i j}=2 \arctan \left(k_{i j}\right) / \pi$. The jump probability $\lambda$ is corumon to all countries.

\begin{tabular}{|c|c|c|c|c|c|c|}
\hline \multicolumn{7}{|c|}{ Log-likelihood value : $16,704.5$} \\
\hline \multirow[t]{2}{*}{$\lambda$} & .0625 & (3.14) & & & & \\
\hline & $\mathrm{BF}$ & DG & $\mathrm{FF}$ & DK & IP & IL \\
\hline \multirow[t]{2}{*}{$\delta^{2}\left(\times 10^{4}\right)$} & $\begin{array}{c}.399 \\
(1.57) \\
1.918 \\
(1.25)\end{array}$ & $\begin{array}{r}.107 \\
(1.37) \\
0.214 \\
(2.72)\end{array}$ & $\begin{array}{r}.444 \\
(1.86) \\
2.585 \\
(2.02)\end{array}$ & $\begin{array}{r}.503 \\
(2.51) \\
1.354 \\
(2.10)\end{array}$ & $\begin{array}{r}.294 \\
(1.58) \\
1.772 \\
(1.42)\end{array}$ & $\begin{array}{r}.709 \\
(2.77) \\
1.857 \\
(2.95)\end{array}$ \\
\hline & \multicolumn{6}{|c|}{ Correlation matrix } \\
\hline $\mathrm{BF}$ & 1 & $\begin{array}{r}.333 \\
(8.49)\end{array}$ & $\begin{array}{r}.384 \\
(9.10)\end{array}$ & $\begin{array}{r}341 \\
(8.41)\end{array}$ & $\begin{array}{r}.320 \\
(6.40)\end{array}$ & $\begin{array}{c}.366 \\
(7.37)\end{array}$ \\
\hline DG & & 1 & $\begin{array}{r}333 \\
(7.93)\end{array}$ & $\begin{array}{r}.249 \\
(6.44)\end{array}$ & $\begin{array}{r}219 \\
(4.67)\end{array}$ & $\begin{array}{r}.324 \\
(6.66)\end{array}$ \\
\hline FF & & & 1 & $\begin{array}{r}323 \\
(8.29)\end{array}$ & $\begin{array}{r}.332 \\
(7.40)\end{array}$ & $\begin{array}{r}459 \\
(12.45)\end{array}$ \\
\hline DK & & & & 1 & $\begin{array}{r}.253 \\
(6.19)\end{array}$ & $\begin{array}{r}.284 \\
(7.88)\end{array}$ \\
\hline IP & & & & & 1 & $\begin{array}{r}.231 \\
(5.51)\end{array}$ \\
\hline IL & & & & & & 1 \\
\hline
\end{tabular}

Table 2.5: The multivariate $M A(1)-G A R C H(1,1)$-Bernoulli-normal model

- Heteroskedasticity-consistent $t$-values are in parentheses. 
The results for this model are given in table 2.5. A selection of the coefficients estimates is included in this table since many parameters are essentially the same as for the univariate models, a finding which is expected to occur when both the univariate and multivariate models are correctly specified. The point estimate of $\lambda$ is 0.0625 . The estimated jump sizes differ somcwhat from those of the univariate models. These differences reflect the differences between the estimates of $\lambda_{i}$ for the univariate models. All elements of the correlation matrix range between .22 and .46 and are highly significant suggesting that the ERM rates should be jointly modeled.

The value of the log-likelihood function is $16,704.5$ which is 290.5 points larger than the sum of the values of the log-likelihood functions for the univariate models. Although the models are not nested, the increase of the log-likelihood function by 290.5 resulting from adding 10 extra parameters seems to be sufficient to conclude that the exchange rates in the ERM are highly interrelated. The joint model presented above yields a satisfactory description of the interrelationships.

\subsection{Conclusions}

In this chapter the time series properties of weekly exchange rates participaling in the ERM of the European Monetary System were examined. One feature of the ERM is that the central banks of the participating countries intervene whenever a bilateral exchange rate deviates more than $2.25 \%$ from its agreed central rate. This intervention policy is likely to stabilize the exchange rate.

There have been several parity adjustments in the last twelve years, resulting in discontinuities in the time series. Since at times of a realignment the change in the spot rate can be very large compared to the usual variations within the band, the market easily panics resulting in sudden large depreciations within the band. The large devaluations together with the panic reactions cause the excess kurtosis for ERM currencies to be much larger than for free-float currencies such as the US dollar or the British pound. Moreover, since all realignments within the ERM in fact have been revaluations of the D-mark, all ERM rates in terms of the D-mark are positively skewed.

These features have been modeled using an MA(1)-GARCH(1,1)-jump 
model. The stabilizing effects of the intervention policy are captured by negative moving average parameters, which turn out to be highly significant for all models. The parity adjustments and sudden depreciations within the band are taken into account by means of a stochastic jump process. We compare the Bernoulli and Poisson specification. For most currencies, the two give similar results. A GARCH specification accounts for the changing volatility over time.

If we do not allow for stochastic jumps, the MA-GARCH specification changes dramatically. For three out of six currencies, the GARCH specification becomes explosive and for two the MA parameter has the wrong sign, although they are not significant. These findings can be explained from the influence of outliers, resulting from parity adjustments, on the model. For the US dollar, jumps are not significant.

The models are checked by means of an adjusted Pearson chi-squared goodness-of-fit test. For 4 out of 6 ERM exchange rates both the Bernoulli and the Poisson specification pass the test. For the other two, a mixture of three normal distributions, which can be interpreted as a normal distribution plus two independent jump specifications, performs best.

Finally joint estimates of an MA(1)-GARCH $(1,1)$ normal-Bernoulli model with constant contemporaneous correlation matrix have been obtained. The results for the joint model were found to be very much in line with the findings for the single processes, but as expected, the efficiency of the estimates improved.

In this chapter, the jump intensity was assumed to be constant. Since the economic performance of the ERM countries has become more similar and, as a consequence, frequency and size of realignments have been declining, we should expect the influence of the jumps in our models to have been declined as well. Estimates of the model over three sub-periods did indeed indicate that the importance of the jump process has diminished, especially since 1987. In the next chapter, this will be modeled by making the jump intensity a function of economic indicators, such as trade deficits, inflation differentials or interest differentials. 


\section{Chapter 3}

\section{An EMS exchange rate model with endogenous jumps}

\subsection{Introduction}

In the previous chapter, it was shown that ERM exchange rates could be modeled by means of a combined MA(1)-GARCH(1,1) jump model. The MA(1) specification models the stabilizing effects of the intervention policy, the GARCH specification accounts for the changing volatility over time, whereas the jump process models the large parity changes and sudden volatile behavior within the band, due to changes in the perceived realignment probability.

It was shown that the Poisson and Bernoulli jump specifications gave similar results. Since the Bernoulli jump specification is far easier to estimate than the Poisson one (which is usually used in econometric models with jumps), this similarity has created the opportunity to model an endogenous jump probability. This will indeed be the main innovation of this chapter.

As the ERM has gained credibility over the eighties (Frankel and Phillips, 1991; Weber, 1991), we expect the influence of the realignment probability to have declined. This is incorporated into our model by making the jump probability a function of economic fundamentals. If the inflation differential with Germany or the trade deficit increases, the probability of a jump increases. It is shown that inflation rates and trade deficits are significant determinants in ERM exchange rates, if incorporated in this indirect way.

Another modification concerns the inclusion of an error correction term 
in the models, measuring the percentage deviation of the spot rate from its central parity. This term establishes the parity reversion, necessary to keep the spot rate within the margins most of the time (Koedijk, Stork and De Vries, 1993).

The models are estimated using weekly observations on the D-mark rates of the Belgian franc, the Dutch guilder, the French franc, the Danish krone, the Irish punt and the Italian lira for the period April 4, 1979 to December 26,1990 . With these models we compute one to four weeks ahead predictions both for the sample period and for a forecasting period from January 2, 1991 to September 23, 1992. It turns out that the models outperform the random walk (Meese and Rogoff, 1983) both within and out-of-sample. Furthermore the $95 \%$ forecast intervals are shown. The intervals are much smaller in the later years of the EMS reflecting the higher credibility. Finally we investigate whether or not our model can predict in which weeks it is safe to invest in the weak currency (Koedijk and Kool, 1993; Koedijk et al., 1993), thereby exploiting the interest differentials that exist within the EMS. Using different investment strategies we show that significant profits can be made in the foreign exchange market and that the results improve if the forecasts of our model are used, again both within and out-of-sample.

The structure of the chapter is as follows. Section 3.2 describes the models, section 3.3 contains the empirical estimation results, section 3.4 provides the results of the forecasting and the investment strategies and section 3.5 summarizes the main results.

\subsection{The model}

Table 3.1 gives some summary statistics of the log D-mark rates. The first row of the table shows that the unit root hypothesis for the exchange rate within the band, $(s-c$, where $s$ and $c$ are the logarithms of the spot rate and central parity respectively) is rejected. However, if we do not compensate for realignments the unit root hypothesis can no longer be rejected at the $5 \%$ level. That is why we will estimate our model in first differences. The parity reversion will be taken into account by including the error correction term $(s-c)_{t-1}$ into our specification.

The skewness is significantly positive for all currencies. This might be the result of asymmetric movernents in the parity adjustments. The excess 
kurtosis is extremely high for all ERM currencies, especially for the Belgian franc, the French franc and the Irish punt. These high values are the result of large devaluations, and also of large movements within the band due to a changing realignment probability. Both skewness and excess kurtosis can be modeled by means of jumps (see appendix B).

Table 3.1: Summary statistics of log D-mark rates

\begin{tabular}{|c|c|c|c|c|c|c|c|}
\hline & & $B F$ & DG & FF & DK & IP & IL \\
\hline$A D F$ & $s-c$ & $-5.055^{* *}$ & $-3.844^{* *}$ & $-4.965^{* *}$ & $-4.696^{* *}$ & $-4.973^{* *}$ & $-3.659^{* *}$ \\
\hline$A D F$ & $s$ & -.679 & $-3.168^{*}$ & -.423 & -2.270 & -1.328 & -.942 \\
\hline Mean $\left(\times 10^{2}\right)$ & $\Delta s$ & .043 & .007 & .063 & .054 & .059 & .084 \\
\hline St.dev. $\left(\times 10^{2}\right)$ & $\Delta s$ & .512 & .244 & .481 & .487 & .494 & .581 \\
\hline Skewness & $\Delta s$ & $5.048^{* *}$ & $.252^{* *}$ & $6.166^{* *}$ & $1.404^{* *}$ & $4.261^{* *}$ & $2.053^{* *}$ \\
\hline Exc.kurt. & $\Delta s$ & $66.082^{* *}$ & $5.396^{* *}$ & $64.429^{* *}$ & $24.334^{* *}$ & $47.628^{* *}$ & $16.199^{\circ *}$ \\
\hline$\rho_{e}(1)$ & $\Delta s$ & $-.155^{* *}$ & $-.189^{* *}$ & .026 & $-.206^{*}$ & $-.109^{*}$ & $-.143^{*}$ \\
\hline$Q_{e}^{A}(24)$ & $\Delta s$ & $48.121^{* *}$ & $37.810^{* *}$ & 33.135 & 29.832 & $35.394^{*}$ & 20.825 \\
\hline$Q_{c^{2}}(24)$ & $\Delta s$ & 10.106 & $129.363^{* *}$ & 1.330 & $66.175^{* *}$ & 4.431 & $59.049^{* *}$ \\
\hline
\end{tabular}

- The sample consists of 613 weekly Wednesday observations from April 1979 to December 1990.

- $A D F$ is an Augmented Dickey-Fuller test with a constant, a trend and 4 lags of the differenced series.

- $s$ is the logarithm of the spot rate, expressed in units of domestic currency per D-mark; $c$ is the logarithm of the central parity.

- $\rho_{e}(1)$ is the first order autocorrelation coefficient; $Q_{e}^{A}(24)$ is a Box-Pierce test, adjusted for ARCH-like heteroskedasticity (see Diebold, 1987); $Q_{e^{2}}(24)$ is a BoxPierce statistic in the squared data.

- * $\left.{ }^{* *}\right)$ indicates significance at the $10 \%(5 \%)$ level.

First order autocorrelation $\left(\rho_{e}(1)\right)$ is significantly negative for all currencies except the French franc. Significant autocorrelation is also detected by the Box-Pierce test up to 24 lags $\left(Q_{e}^{A}(24)\right)$. Since these test statistics are influenced by heteroskedasticity, they are adjusted to allow for ARCH like heteroskedasticity, see Diebold (1987). However, these tests assume normality which is clearly rejected for our data. The negative autocorrelation is probably due to the intervention policy of the monetary authorities. In our model the negative autocorrelation is represented by a (ncgative) moving average term.

Finally, the Box-Pierce test statistic for the squared data $\left(Q_{e^{2}}(24)\right)$ is sig. 
nificant for three out of six currencies. However, as this test statistic requires a finite fourth moment, it might be unreliable for our data. Autocorrelation in the squared data detects changes of the variance. These are modeled by means of a GARCH (Bollerslev, 1986) specification.

In our model, large movements are modeled by means of jumps. The statistical meaning of a jump is a draw from the second normal distribution in a compound normal distribution, with a higher mean (more depreciations than appreciations) and higher variance (more volatility) than the first. Economic explanations of the jumps are the large devaluations and volatile behavior within the band, primarily due to changes in the perceived realignment probabilities. As the timing of a devaluation is extremely difficult to predict (ser Obstfeld, 1991), and since the consequences of these devaluations can be scvere (large speculative losses), market expectations are very much affected by all kinds of economic or political news.

The influence of news on market expectations will be higher if the general economic condition of the country is weak, since the expected devaluation probability/size will be greater in these circumstances. As a consequence, the market, will be more likely to panic, resulting in volatile behavior.

As the economic performance of the ERM countries has become more similar (see for instance (riavazzi and Giovannini, 1989; Ungerer, Hauvonen, Lopez-Claros and Mayer. 1990 or Weber, 1991), we expect the influence of the ralignment probability to have declined. This is reflected in the diminished volatility of the exchange rates in recent years, shown in figure 2.1, and also in table 3.2, where the dates and magnitudes of the realignments are shown. Both the number and the average size of realignments had diminished in recent years (until September 1992).

Table 3.2: ERM realignments: Percentage devaluation against $D$-mark

\begin{tabular}{|c|c|c|c|c|c|c|c|c|c|c|c|c|}
\hline & \multicolumn{2}{|c|}{1979} & 1981 & \multicolumn{2}{|c|}{1982} & \multirow{2}{*}{$\begin{array}{l}1983 \\
21 / 3 \\
\end{array}$} & \multirow{2}{*}{$\begin{array}{l}1985 \\
22 / 7 \\
\end{array}$} & \multicolumn{2}{|c|}{1986} & \multirow{2}{*}{$\begin{array}{l}1987 \\
12 / 1 \\
\end{array}$} & \multirow{2}{*}{$\begin{array}{r}1990 \\
8 / 1 \\
\end{array}$} & \multirow{2}{*}{$\begin{array}{l}1992 \\
13 / 9 \\
\end{array}$} \\
\hline & $24 / 9$ & $30 / 1123 / 3$ & $5 / 10$ & $22 / 2$ & $14 / 6$ & & & $7 / 4$ & $4 / 8$ & & & \\
\hline $\mathrm{BF}$ & 1.98 & & 5.35 & 8.88 & 4.16 & 3.86 & & 1.96 & & 0.98 & & \\
\hline DG & 1.98 & & & & & 1.91 & & & & & & \\
\hline FF & 1.98 & & 8.40 & & 10.08 & 7.89 & & 6.00 & & 2.96 & & \\
\hline DK & 4.88 & 4.88 & 5.35 & 3.05 & 4.16 & 2.88 & & 1.96 & & 2.96 & & \\
\hline $\mathrm{IP}$ & 1.98 & & 5.35 & & 4.16 & 8.92 & & 2.96 & 8.34 & 2.96 & & \\
\hline IL & 1.98 & 6.19 & 8.40 & & 6.95 & 7.89 & 8.17 & 2.96 & & 2.96 & 3.75 & 7.25 \\
\hline
\end{tabular}

- Source: Ungerer et al. (1990) table 4, appended by the author. 
In our model the increased credibility due to the economic convergence is modeled by making the jump probability a function of economic fundamentals, i.e. the yearly inflation differential with Germany and the trade balance surplus. These variables are shown in figure 3.1 and 3.2 respectively. For almost all countries, the inflation differential with Germany has diminished over the years, reflecting the grown convergence between the ERM members. For most countries, this has resulted in an improvement of the trade balance as shown in figure 3.2 .

The resulting jump probability has the following familiar logit form

$$
\lambda_{t}=1-\left(1+\exp \left(\lambda_{0}+\lambda_{\text {infd }} i n f d_{t-8}+\lambda_{t b} t b_{t-8}\right)\right)^{-1},
$$

where

- $\lambda_{t}=$ the probability of a jump at time $t$,

- $\quad$ infd $d_{t-8}=$ the one year inflation differential with Germany, and

- $t b_{t-8}=$ the country's trade balance surplus in the last year (scaled by exports).

Both trade balance and inflation data are only available on a monthly basis. In order to get weekly data a linear interpolation was used. Both the trade balance surplus and the inflation differential are lagged by eight weeks, since the information on these variables is not known to the market immediately.

The inflation differential is included in (3.1) for two reasons. First of all, if the domestic inflation is substantially higher than foreign inflation, domestic firms will lose competitiveness. In the long run this will have to lead to a devaluation, since domestic goods become too expensive compared to import ${ }^{1}$. Second, a decreasing inflation differential with Germany can be seen as a sign that the government and the monetary authorities are really willing to sustain the parity. For these two reasons, a positive sign for $\lambda_{\text {infd }}$ is expected.

\footnotetext{
${ }^{1}$ This argument suggests that the cumulative inflation differential, reflecting the purchasing power parity, might be a better candidate. A problem with this measure however, is that you need an "equilibrium" real exchange rate to start with, and the propre price indexes. In our model this cumulative effect is modeled by means of the trade balance.
} 
Figure 3.1: Yearly inflation differential with Germany
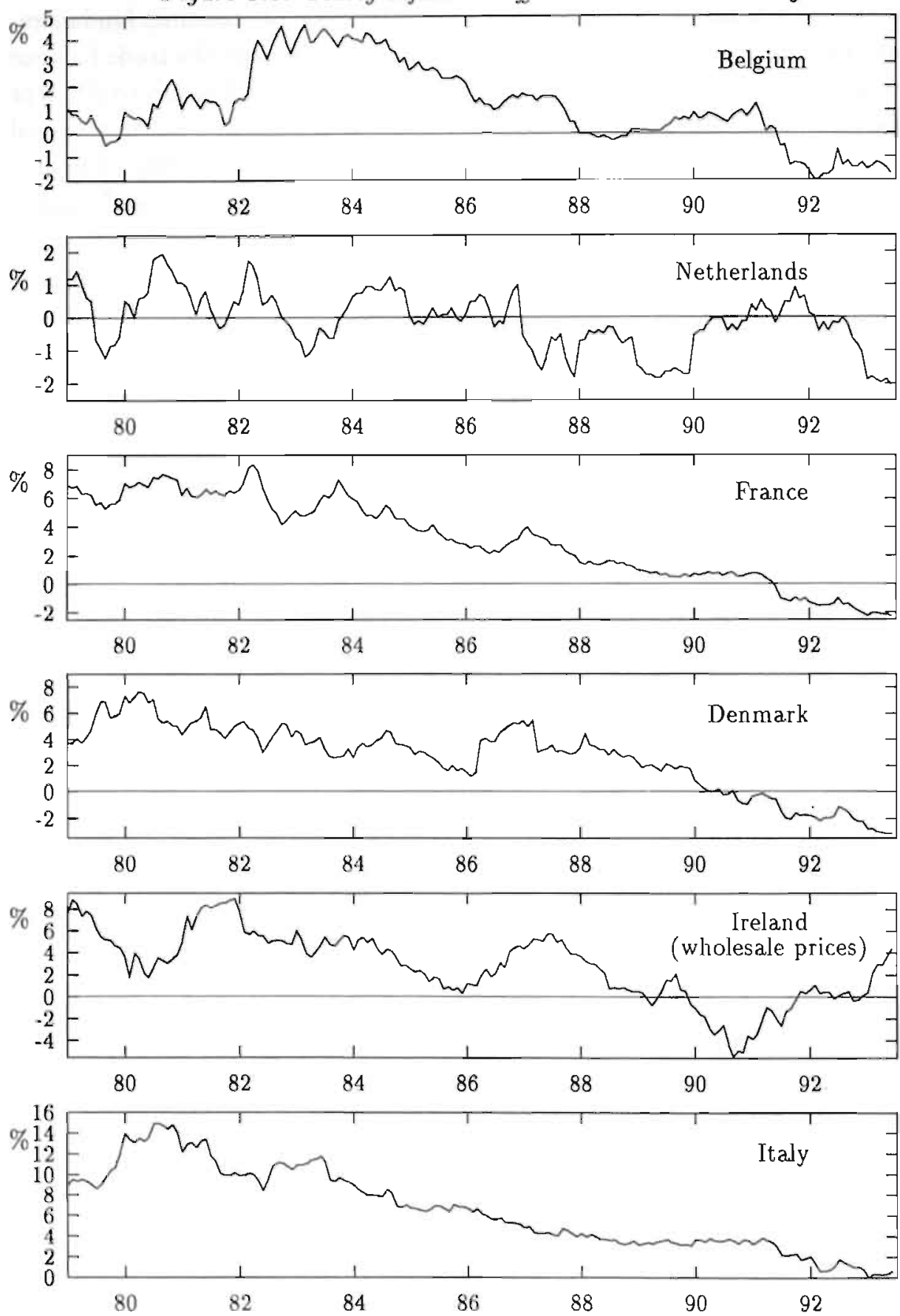
Figure 3.2: Yearly trade balance surplus as percentage of total exports
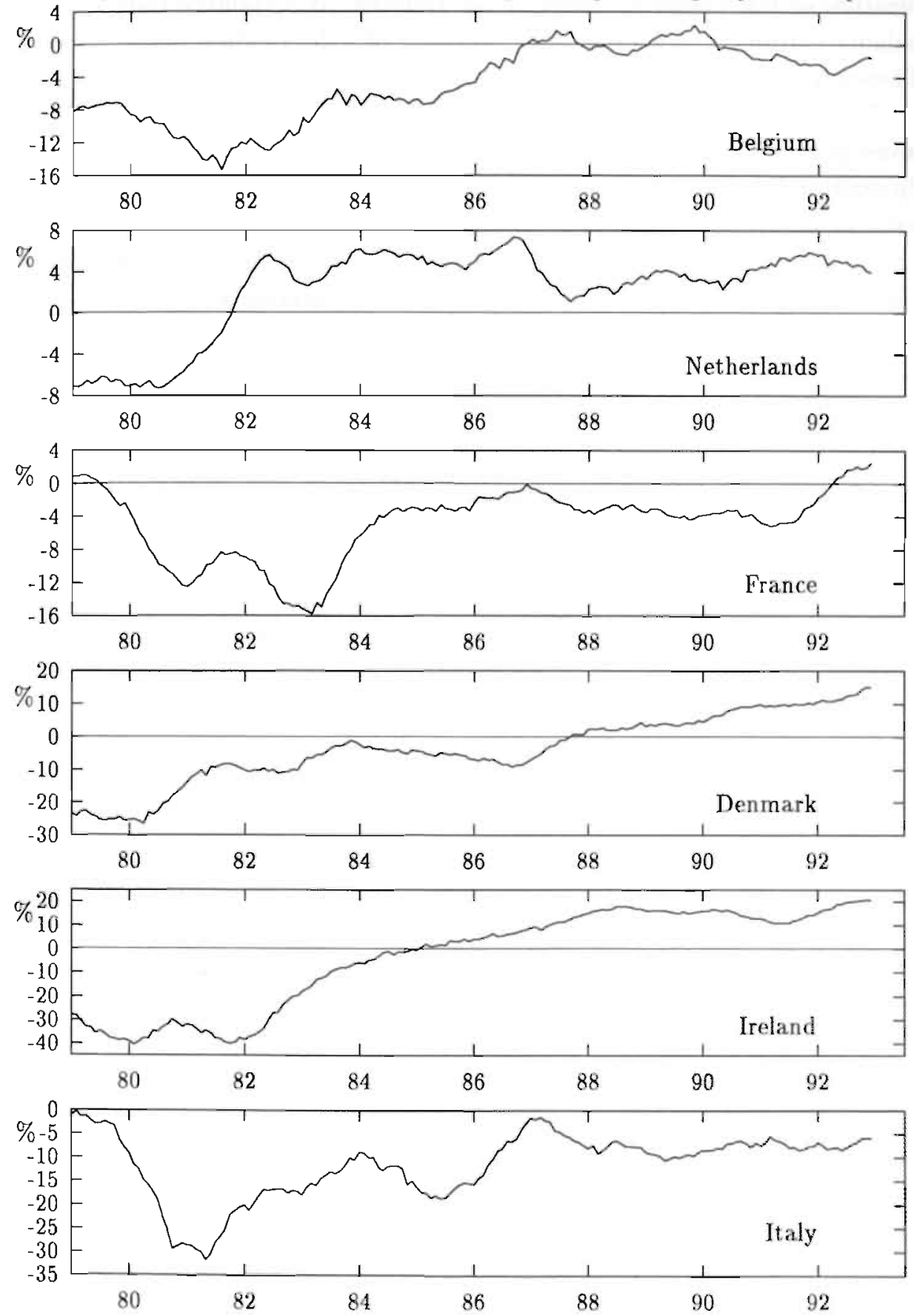
The trade balance is included in the specification since it is a direct measure of the competitiveness of the country. If a country runs a trade balance surplus, a direct economic necessity of a devaluation is not present. Therefore, we expect a negative sign for $\lambda_{t b}$.

One might also consider other variables in this specification. We also investigated the influence on the jump probability of the position in the fluctuation band, of a recent realignment and of the intcrest rate differential with Germany. The effects of the position of the spot rate in the band turned out to be insignificant for all the currencies. Moreover, the sign of the coefficient was negative for most currencies, meaning an increased jump probability if the spot rate is near the strong margin (below the parity). Since most of the devaluations took place when the spot rate was near the weak margin, this result indicates that the jumps have more to do with anticipation of devaluations, than with devaluations themselves.

The influence of a recent realignment was taken into account, to model the diminished realignment probability directly after a realignment. The time span between two realignments was always at least several months, so one might expect there was less reason for the market to panic in these weeks. Although this variable had some statistical significance, we decided to drop it since the Italian lira had to leave the system in September 1992 several days after the devaluation of the lira.

The short term interest rate differentials reflect the market expectation of a realignment, so it might be a leading indicator for the realignment probability. However, only for the French franc the variable turned out to be a significant variable for the jump probability. There are probably three reasons for the lack of significance of this variable. First, jumps not only represent devaluations, but also large changes within the band, for instance in anticipation of a devaluation. The interest rate differential is no leading indicator for these depreciations, since movements in the spot rate and in the interest differential occur simultaneously if the market panics. Second, the timing of large devaluations is not always rightly predicted by the market. There are large interest differentials (over $2 \%$ on a weekly basis) that are not followed by devaluations, and there are large devaluations, not preceded by high interest rate differentials. And third, even if a devaluation is foreseen by the market, the fluctuation bands might be overlapping, so that a devaluation is not necessarily accompanied by a large depreciation (by a 
jump).

The other equations of the model are very similar to the ones presented in chapter two

$$
\Delta s_{t}=\mu+\phi(s-c)_{t-1}+\lambda_{t} \theta+\psi D_{t-1} \varepsilon_{t-1}+\varepsilon_{t},
$$

where $\lambda_{t}$ is the jump probability as defined in (3.1), $\theta$ is the mean jump size, $\phi$ is the error correction term necessary to kcep the spot rate within the band, $\mu$ is the intercept and $\psi$ is the moving average parameter. $D_{t-1}$ is a dummy variable that takes the value 0 if that currency was realigned in period $t-1$, and 1 otherwise. This dummy variable is included since the moving average term accounts for the stabilizing effects of the intervention policy. As the spot rate has to stay within the fluctuation margins, one might expect that the effort made to stop a devaluation this week increases (decreases) with the magnitude of depreciation (appreciation) last week, thereby partly offsetting the changes of the last week. Movements that result from parity changes however, are not expected to be compensated the next week.

The error term $\varepsilon_{t}$ has the following mixture distribution

$$
\varepsilon_{t} \sim\left(1-\lambda_{t}\right) N\left(-\lambda_{t} \theta, h_{t}^{2}\right)+\lambda_{t} N\left(\left(1-\lambda_{t}\right) \theta, h_{t}^{2}+\delta^{2}\right) .
$$

Conditional on no jump, which has probability $\left(1-\lambda_{t}\right)$, see equation $(3.1), \varepsilon_{t}$ is normally distributed with expectation $-\lambda_{t} \theta$ and variance $h_{t}^{2}$. Conditional on a jump its expectation is $\theta$ higher (the mean jump size) and its variance is $\delta^{2}$ higher (the variance of the jump size). Finally, the variance of the first normal distribution, $h_{\ell}^{2}$, is modeled according to the familiar $\operatorname{GARCH}(1,1)$ structure (Bollerslev, 1986) to model the persistence in volatility

$$
h_{t}^{2}=\alpha_{0}+\alpha_{1} \xi_{t-1}^{2}+\beta h_{t-1}^{2} .
$$

\subsection{Estimation results}

We estimated this model, combining equations (3.1) to (3.4), for the six ERM exchange rates using the maximum likelihood routine of the software package GAUSS. Positivity of the variance was enforced by estimating the square root of the variance parameters. We tried different sets of starting values, and obtained the same optimum for all of them.

In table 3.3, the estimation results are shown. Most results are similar to the ones presented in chapter two. The MA(1)-GARCH( 1,1$)$ specification 
Table 3.3: Maximum likelihood results for ERM currencies

\begin{tabular}{|c|c|c|c|c|c|c|}
\hline & BF & DG & FF & DK & IP & IL \\
\hline$\mu\left(\times 10^{4}\right)$ & $\begin{array}{l}2.978^{* *} \\
(2.47)\end{array}$ & $\begin{array}{l}-.422 \\
(0.95)\end{array}$ & $\begin{array}{l}0.969 \\
(1.16)\end{array}$ & $\begin{array}{l}1.184 \\
(1.06)\end{array}$ & $\begin{array}{l}1.086 \\
(1.15)\end{array}$ & $\begin{array}{l}-.631 \\
(0.45)\end{array}$ \\
\hline$\phi$ & $\begin{array}{l}-.027^{* *} \\
(2.82)\end{array}$ & $\begin{array}{l}-.014 \\
(0.73)\end{array}$ & $\begin{array}{l}-.015^{*} \\
(1.72)\end{array}$ & $\begin{array}{l}-.026^{* *} \\
(3.30)\end{array}$ & $\begin{array}{l}-.025^{\text {** }} \\
(2.42)\end{array}$ & $\begin{array}{l}-.007 \\
(1.39)\end{array}$ \\
\hline$\psi$ & $\begin{array}{l}-.355^{* *} \\
(7.69)\end{array}$ & $\begin{array}{l}-.311^{* *} \\
(5.63)\end{array}$ & $\begin{array}{l}-.149^{* *} \\
(3.61)\end{array}$ & $\begin{array}{l}-.169^{* *} \\
(3.53)\end{array}$ & $\begin{array}{l}-.224^{* *} \\
(5.54)\end{array}$ & $\begin{array}{l}-.156^{* *} \\
(3.51)\end{array}$ \\
\hline$\alpha_{0}\left(\times 10^{4}\right)$ & $\begin{array}{c}.009^{* *} \\
(2.26)\end{array}$ & $\begin{array}{c}.00 \mathrm{l}^{*} \\
(1.34)\end{array}$ & $\begin{array}{c}.038^{* *} \\
(8.11)\end{array}$ & $\begin{array}{c}.068^{* *} \\
(10.82)\end{array}$ & $\begin{array}{c}.045^{* *} \\
(5.71)\end{array}$ & $\begin{array}{c}.033^{* *} \\
(2.52)\end{array}$ \\
\hline$\alpha_{1}$ & $\begin{array}{c}.185^{* *} \\
(2.78)\end{array}$ & $\begin{array}{c}.245^{* *} \\
(3.58)\end{array}$ & $\begin{array}{l}.189^{* *} \\
(2.90)\end{array}$ & $\begin{array}{l}.141^{* *} \\
(3.64)\end{array}$ & $\begin{array}{l}.327^{* *} \\
(2.55)\end{array}$ & $\begin{array}{l}.174^{* * *} \\
(1.85)\end{array}$ \\
\hline$\beta$ & $\begin{array}{c}.685^{* *} \\
(7.91)\end{array}$ & $\begin{array}{c}.622^{* *} \\
(5.35)\end{array}$ & $\begin{array}{l}.025 \\
(.79)\end{array}$ & $\begin{array}{l}.000 \\
(.00)\end{array}$ & $\begin{array}{l}.130^{* *} \\
(1.95)\end{array}$ & $\begin{array}{l}.363^{* *} \\
(2.20)\end{array}$ \\
\hline$\lambda_{0}$ & $\begin{array}{c}-5.563^{* *} \\
(3.15)\end{array}$ & $\begin{array}{c}-2.004^{*} \\
(2.83)\end{array}$ & $\begin{array}{c}-6.212^{* *} \\
(4.98)\end{array}$ & $\begin{array}{c}-3.597^{* *} \\
(5.70)\end{array}$ & $\begin{array}{c}-4.088^{* *} \\
(5.30)\end{array}$ & $\begin{array}{c}-3.102^{* *} \\
(4.83)\end{array}$ \\
\hline$\lambda_{\text {in } \int d}$ & $\begin{array}{r}11.009 \\
(0.50)\end{array}$ & $\begin{array}{c}77.803^{* *} \\
(2.09)\end{array}$ & $\begin{array}{c}42.143^{* *} \\
(2.19)\end{array}$ & $\begin{array}{r}-3.680 \\
(0.21)\end{array}$ & $\begin{array}{l}7.714 \\
(0.56)\end{array}$ & $\begin{array}{l}2.142 \\
(0.29)\end{array}$ \\
\hline$\lambda_{16}$ & $\begin{array}{r}-24.336^{*} \\
(1.94)\end{array}$ & $\begin{array}{r}-5.817 \\
(0.78)\end{array}$ & $\begin{array}{r}-11.066^{*} \\
(1.65)\end{array}$ & $\begin{array}{c}-7.866^{* *} \\
(2.35)\end{array}$ & $\begin{array}{r}-4.088^{*} \\
(1.89)\end{array}$ & $\begin{array}{c}-5.475 \\
(1.32)\end{array}$ \\
\hline$\theta\left(\times 10^{2}\right)$ & $\begin{array}{c}.948 \\
(1.30)\end{array}$ & $\begin{array}{c}.076 \\
(1.04)\end{array}$ & $\begin{array}{c}986 \\
(1.56)\end{array}$ & $\begin{array}{l}.806^{* *} \\
(2.78)\end{array}$ & $\begin{array}{c}.814 \\
(1.63)\end{array}$ & $\begin{array}{c}.659^{* *} \\
(3.15)\end{array}$ \\
\hline$\delta^{2}\left(\times 10^{4}\right)$ & $\begin{array}{l}3.160 \\
(1.09)\end{array}$ & $\begin{array}{c}.160^{* *} \\
(1.80)\end{array}$ & $\begin{array}{l}3.430^{* *} \\
(2.21)\end{array}$ & $\begin{array}{l}1.383^{* *} \\
(2.64)\end{array}$ & $\begin{array}{l}3.056^{*} \\
(1.47)\end{array}$ & $\begin{array}{l}1.385^{* *} \\
(2.15)\end{array}$ \\
\hline$\chi^{2}(29)$ & $\begin{array}{l}22.68 \\
{[.791]}\end{array}$ & $\begin{array}{l}36.97 \\
{[.147]}\end{array}$ & $\begin{array}{l}32.07 \\
{[.317]}\end{array}$ & $\begin{array}{l}41.27^{*} \\
{[.065]}\end{array}$ & $\begin{array}{l}40.20^{*} \\
{[.081]}\end{array}$ & $\begin{array}{l}21.80 \\
{[.829]}\end{array}$ \\
\hline$Q_{e}(24)$ & $\begin{array}{l}30.47 \\
{[.170]}\end{array}$ & $\begin{array}{l}25.81 \\
{[.363]}\end{array}$ & $\begin{array}{l}18.95 \\
{[.755]}\end{array}$ & $\begin{array}{l}26.81 \\
{[.313]}\end{array}$ & $\begin{array}{l}42.25^{* *} \\
{[.012]}\end{array}$ & $\begin{array}{l}29.30 \\
{[.209]}\end{array}$ \\
\hline$Q_{\varepsilon^{\jmath}}(24)$ & $\begin{array}{l}18.99 \\
{[.753]}\end{array}$ & $\begin{array}{l}14.45 \\
{[.936]}\end{array}$ & $\begin{array}{l}21.05 \\
{[.636]}\end{array}$ & $\begin{array}{l}28.55 \\
{[.238]}\end{array}$ & $\begin{array}{l}46.38^{* *} \\
{[.004]}\end{array}$ & $\begin{array}{l}10.90 \\
{[.990]}\end{array}$ \\
\hline Skew. & $\begin{array}{r}-0.040 \\
{[.687]}\end{array}$ & $\begin{array}{l}0.073 \\
{[.463]}\end{array}$ & $\begin{array}{l}0.148 \\
{[.134]}\end{array}$ & $\begin{array}{l}0.145 \\
{[.141]}\end{array}$ & $\begin{array}{l}0.049 \\
{[.621 .]}\end{array}$ & $\begin{array}{l}0.140 \\
{[.158]}\end{array}$ \\
\hline Exc kur. & $\begin{array}{l}0.259 \\
{[.190]}\end{array}$ & $\begin{array}{l}0.111 \\
{[.576]} \\
\end{array}$ & $\begin{array}{l}0.341^{*} \\
{[.085]}\end{array}$ & $\begin{array}{l}0.075 \\
{[.705]}\end{array}$ & $\begin{array}{l}0.561^{*} \\
{[.005]}\end{array}$ & $\begin{array}{l}0.220 \\
{[.265]}\end{array}$ \\
\hline
\end{tabular}

- The estimation period covers April 4, 1979 to December 26, 1990 (613 weeks).

- * $\left(^{* *}\right)$ indicates significance at the $10 \%(5 \%)$ level.

- $P$-values and absolute asymptotic heteroskedasticity consistent $t$-values are betwcen square brackets and parentheses receptively.

- $\chi^{2}(29)$ is an adjusted chi-square goodness-of-fit test, performed on a classification in 30 cells (see appendix $\mathrm{A}$ ).

- The statistics $Q_{c}(24), Q_{e^{z}}(24)$, Skew and Exc.kur. are computed on normalized residuals (see appendix $A$ ). 
is very significant, although an $\mathrm{ARCH}(1)$ specification would do just as well for the French franc and the Danish krone. We did not exclude $\beta$ for these currencies since we wanted to estimate the same specification in all models.

The parity reversion parameter $(\phi)$ is in the order of $0.7 \%$ (Italian lira) to $2.7 \%$ (Belgian franc) per week. The coefficient is not significantly different from zero at any conventional level for the Dutch guilder and the Italian lira. Especially for the Dutch guilder this is remarkable since this currency hardly deviated from its parity for years.

Table 3.4: LR statistics for models with alternative jump specifications

\begin{tabular}{|c|c|c|c|c|c|}
\hline $\begin{array}{l}\lambda_{\text {infd }}=0 \\
\lambda_{t b}=0\end{array}$ & $\begin{array}{l}\text { Rest } \\
\text { Rest }\end{array}$ & Rest & Rest & $\begin{array}{l}\text { Both } \\
\text { Rest }\end{array}$ & $\begin{array}{l}\text { Rest } \\
\text { Both }\end{array}$ \\
\hline$B F$ & $9.31^{* * *}$ & $7.13^{* * *}$ & 0.43 & $8.87^{* * *}$ & 2.17 \\
\hline DG & $8.71^{* *}$ & 0.73 & $5.68^{* *}$ & $3.03^{*}$ & $7.98^{* * *}$ \\
\hline $\mathrm{FF}$ & $17.51^{* * *}$ & $3.30^{*}$ & $5.40^{* *}$ & $12.11^{* * *}$ & $14.22^{* * *}$ \\
\hline DK & $8.09^{* *}$ & 2.67 & 0.00 & $8.09^{* * *}$ & $5.42^{* \bar{*}}$ \\
\hline IP & $8.14^{* *}$ & $3.19^{*}$ & 0.32 & $7.82^{* * *}$ & $4.95^{* *}$ \\
\hline IL & $6.82^{* *}$ & $2.99^{*}$ & 0.03 & $6.79^{* * *}$ & $3.83^{*}$ \\
\hline
\end{tabular}

- The estimation period covers April 4, 1979 to December 26, 1990 (613 weeks).

- The "Rest" and "Both" headings indicate whether a parameter is only restricted under $H_{0}$ or also under the alternative.

- * $\left({ }^{* *}\right)[* * *]$ indicates significance at the $10 \%(5 \%)[1 \%]$ level.

Most of the parameters determining the jump probability have the expected sign. The exception is the inflation effect on the Danish krone. The negative sign for the inflation coefficient of the Danish krone has to do with multicollinearity. If either the inflation or the trade balance variable is dropped from the equation, the other becomes significant with the proper sign. Multicollinearity is also the main reason for the insignificant coefficients for the other currencies. In table 3.4, the likelihood-ratio statistics are shown for models with alternative jump specifications. For all the models inflation differentials and trade surpluses are jointly significant at the $5 \%$ level $^{2}$. With the exception of the French franc however, one of the two variables could

\footnotetext{
${ }^{2}$ The results for a Wald statistic were similar.
} 
be deleted from the specification without significantly changing the results. Since we wanted to estimate the same model for all the currencies, we did not exclude any of the variables in the models.

Although not all the coefficients are significant, these models clearly show the significance of inflation differentials and trade deficits. Despite the role played by these variables in the theoretical exchange rate models, the empirical evidence on these variables had been only meager so $\mathrm{far}^{3}$. The most likely reason for this lack of empirical evidence is the loose relationship between prices and trade balances on the one hand, and exchange rates on the other. In the short run, exchange rates are mostly affected by speculative forces. As long as the interest rate on a weak currency is sufficiently higher than for a strong currency, this weak currency is wanted. This means that a. weak currency, e.g. a currency of a country with a high inflation rate and/or a large trade deficit, will only strongly depreciate if the monetary and political authorities allow this. Within a target zone there is actually only one important (latent) variable determining the exchange rate namely the willingness of the authorities to support the parities. As a consequence, there is no direct relationship (as can be estimated by a regression model) between these economic fundamentals and the exchange rate.

There is, however, an indirect relation between those variables. If the economic situation of a country is weak, the authorities are more likely to realign. That is why we measure the effects of economic fundamentals via the increased probability of a large depreciation and of volatile behavior, instead of via a direct, one to one relationship between the exchange rate and the economic fundamentals.

In figure 3.3, the jump probabilities resulting from equation (3.1) are shown. The graphs clearly show the diminished jump probability in the later years of the ERM. For the Belgian and French francs the jump probability is almost zero from 1987 on. But also for the the 1)anish krone and the Irish punt, the probability has decreased substantially to $1 \%$ or less.

For the Dutch guilder and Italian lira on the other hand, the jump probability is still quite high (about $8 \%$ ). For the lira this can be explained by the slow rate of convergence between Italian and German inflation rates, especially since 1987 (see figure 3.1). Although politicians had dropped the word

\footnotetext{
${ }^{3}$ Koedijk and Schotman (1990) find significant parameters for prices by pooling exchange rate data.
} 
Figure 3.3: Jump probabilities
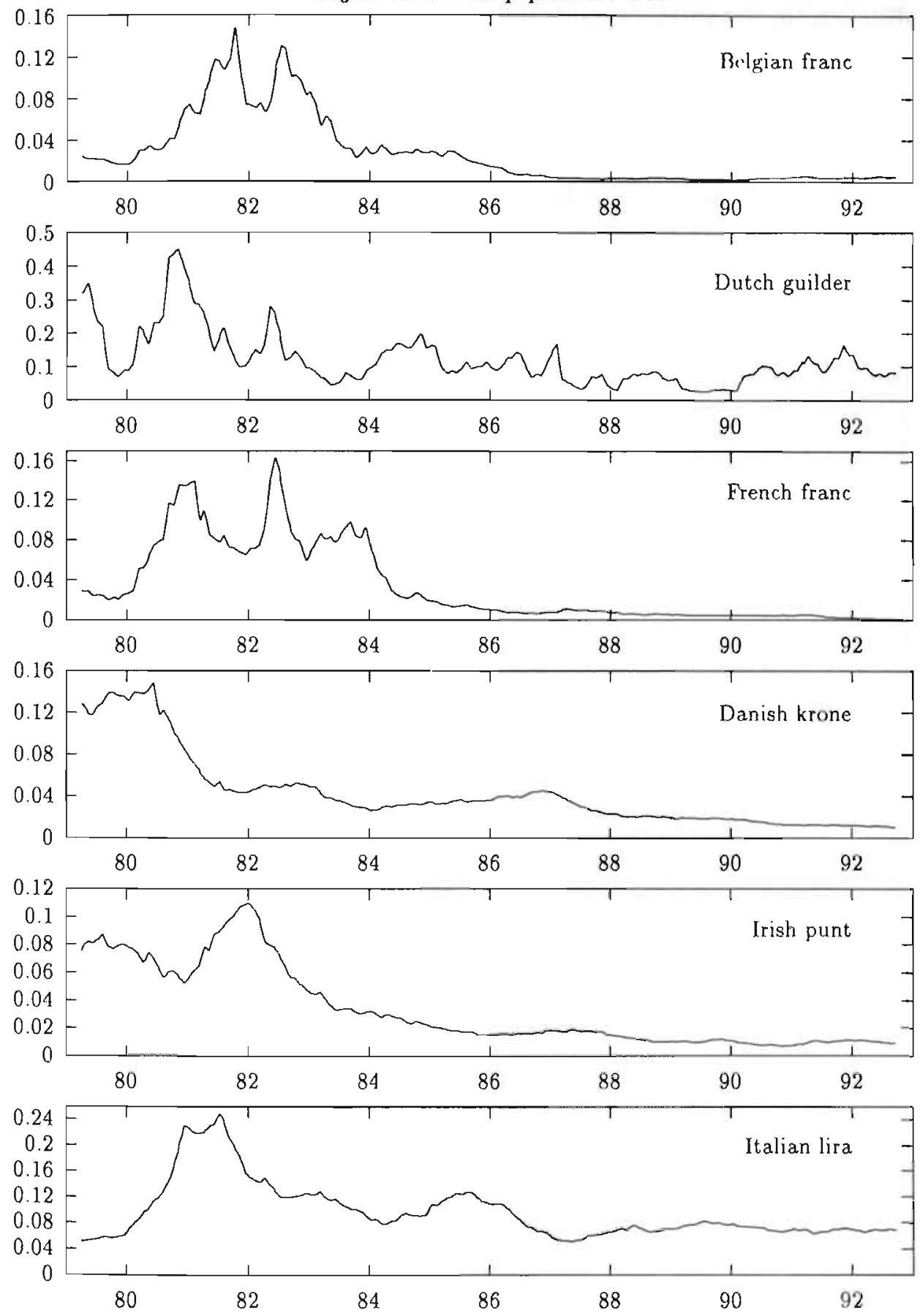
realignment from their vocabulary, the real rate of the lira called for one. The situation for the guilder is quite different. Since the economic differences between Germany and the Netherlands, in terms of inflation, were never very big (see figure 3.1), the convergence with Germany was less profound for the guilder than for the other currencies. Moreover, since the Dutch trade balance is influenced to a large extent by the exports of natural gas, the trade balance does not give a good indication of the strength of the Dutch economy ${ }^{4}$. As a consequence, the diminished volatility for the Dutch guilder was not well explained by these economic fundamentals.

The main reasons for the diminished fluctuations of the guilder D-mark rate are not economical but political. The Dutch central bank has chosen the D-mark ratc as its main policy target. Our model does not contain this political dimension, apart from its economic consequences, because it is very difficult to implement. We can of course include a dummy variable for the increased credibility of the system, for instance starting at the Basle-Nyborg agreement of September $1987^{5}$. But there is no way to be sure that this credibility remains high, or even whether it is justified right now ${ }^{6}$. Instead we use the inflation differential as a proxy for the effort made to make fixed parities lasting.

The average jump size $(\theta)$ is positive for all currencies. This is in agreement with the positive skewness found in the data (appendix B). For the Dutch guilder, both the mean and the variance of the jump size $\left(\delta^{2}\right)$ is considerably smaller than for the other currencies. Given the credibility of the guilder D-mark parity, jumps have probably not so much to do with devaluation expectations for this currency. Furthermore, it is interesting to notice that the standard deviation of the jump size is always much bigger than its mean. From this, we may conclude that apart from large depreciations, jumps might also represent large appreciations, for instance after an important policy announcement (such as the German unification).

\footnotetext{
${ }^{4}$ It suffers from the so called Dutch disease (Van Wijnbergen, 1984).

${ }^{5}$ In this agreement, the EMS countries agreed to lay emphasis on the use of interest rate differentials to defend the stability of the parity grid and to make fuller use of the fluctuation band. Furthermore, the credit facilities were extended to include intramarginal interventions. Dominguez and Kenen (1992) find that exchange rates behave differently after the agreement, than they did before.

${ }^{6}$ The turbulent times around the French referendum in September 1992 on the Maastricht treaty clearly showed that political resistance to realignments is not enough to ensure full credibility.
} 
Turning to the model diagnostics, we see that the models perform reasonably well. Table 3.3 shows that the null hypothesis of the adjusted goodness of fit test $\left(\chi^{2}(29)\right.$, see appendix $\left.A\right)$ is not rejected at the $5 \%$ level for any of the models. For the Danish krone and the Irish punt it is rejected at the $10 \%$ level however. Since the goodness-of-fit test requires independent observations, a rejection of the null might be due to dependence in the data, which might be remedied by modifications in the MA - GARCH specification. Therefore, we also computed Box-Pierce statistics. As these statistics assume a normal distribution, the residuals are normalized (appendix A). Only for the Irish punt, the condition of independence is not fulfilled since the null hypothesis of the Box-Pierce test is rejected at the $5 \%$ level both for the residuals $\left(Q_{e}(24)\right)$ and for the squared residuals $\left(Q_{e^{2}}(24)\right)$. Normalized residuals were also used to compute the skewness and excess kurtosis. Both skewness and kurtosis are modeled quite successfully since only the excess kurtosis for the Irish punt is significant at the $5 \%$ level.

\subsection{Model predictions}

In this section, the prediction properties of the model are investigated. Among others, Meese and Rogoff (1983) found that the out-of-sample prediction power of both structural and time series models of exchange rates is very poor. Even if the parameter values were updated every period, the models did not outperform the random walk without drift. Although one might expect ERM exchange rates to be better predictable than free float currencies, the comparison with the random walk might be an interesting starting point. However, since our maximum likelihood model can not easily be updated every period, we restrict ourselves to the parameter values just given.

Table 3.5 gives the one to four weeks ahead mean (squared) prediction errors of the model and the percentage improvement relative to the random walk without drift for both the sampling period and an out-oi-sample forecasting period running from January 2, 1991 to September 23, 1992. The forecasting period is chosen this way to include the devaluation of the Italian lira on September 13, 1992 but to exclude forecasts that were made after the lira had to leave the ERM (September 17, 1992).

The expectations are formed on the basis of information known at that moment. That is to say, inflation rates, trade balances and central parities 
Table 3.5: One to four weeks ahead forecast errors

\begin{tabular}{||l|rrrr|rrrr||}
\hline & \multicolumn{4}{|c|}{ Within Sample } & \multicolumn{4}{c||}{ Out-of-Sample } \\
\hline Week & \multicolumn{1}{|c}{1} & \multicolumn{1}{c|}{2} & \multicolumn{1}{c|}{3} & \multicolumn{1}{c|}{4} & \multicolumn{1}{c|}{1} & \multicolumn{1}{c|}{2} & \multicolumn{1}{c|}{3} & \multicolumn{1}{c|}{4} \\
\hline \multirow{4}{*}{ BF } & .243 & .407 & .553 & .730 & .091 & .115 & .123 & .135 \\
& 7.989 & 9.627 & 8.722 & 12.296 & 18.121 & 18.033 & 10.941 & 6.637 \\
& -.776 & -1.781 & -2.756 & -3.879 & 6.975 & 10.943 & 14.842 & 18.586 \\
DG & .057 & .093 & .128 & .158 & .005 & .006 & .007 & .009 \\
& 4.628 & 3.992 & 4.955 & 5.681 & 17.388 & 7.490 & 3.828 & 5.529 \\
& .022 & -.039 & -.017 & .051 & .994 & 1.517 & 1.920 & 2.529 \\
FF & .229 & .465 & .673 & .873 & .038 & .059 & .092 & .115 \\
& 2.370 & 5.039 & 7.758 & 10.184 & 5.447 & .864 & 4.642 & 4.910 \\
& -1.155 & -2.654 & -4.191 & -5.792 & -1.418 & -1.423 & -2.088 & -2.428 \\
DK & .220 & .347 & .455 & .560 & .061 & .106 & .125 & .155 \\
& 8.198 & 10.435 & 12.902 & 15.962 & 3.941 & 8.571 & 7.283 & 8.047 \\
& -.589 & -1.420 & -2.283 & -3.279 & -1.242 & -2.645 & -3.658 & -4.616 \\
IP & .237 & .439 & .651 & .904 & .088 & .107 & .099 & .114 \\
& 3.877 & 1.959 & 1.669 & 3.863 & 11.505 & 14.736 & 13.371 & 11.018 \\
& -2.000 & -4.059 & -6.015 & -8.115 & -.775 & -1.040 & -1.168 & -1.951 \\
IL & .323 & .555 & .715 & .940 & .728 & 2.107 & 4.726 & 7.502 \\
& 6.343 & 8.542 & 11.198 & 12.958 & 1.279 & 1.089 & .965 & 1.127 \\
& -2.216 & -4.474 & -6.852 & -9.247 & -8.105 & -21.373 & -37.987 & -52.189 \\
\hline
\end{tabular}

- The sample period runs from April 1979 to December 1990 (613 weeks), and the forecast period from January 1991 to September 23, 1992 (91 weeks).

- For each currency the first row is the mean squared forecast error $\left(\times 10^{4}\right)$, the second row the percentage improvement in mean squared forecast error relative to the random walk, and the last row the mean forecast error $\left(\times 10^{4}\right)$.

are assumed to be constant over the forecast horizon.

For all currencies the mean squared forecast error within sample is greater for the random walk than for our model ${ }^{7}$. Especially for the one week ahead predictions this is not surprising since the same data were used to fit the model. However, it is interesting to see that the improvement relative to the random walk, in terms of the mean squared forecast error, is growing with the length of the forecast horizon (within sample).

Out-of-sample the models still outperform the random walk at all forecast

\footnotetext{
${ }^{7}$ The model also outperformed the random walk when applied to three sub-periods where the second period started after the 1983 realignment and ended after the BasleNyborg agreement of September 1987 (see section 1.1).
} 
horizons ${ }^{8}$. The extent to which several models outperform the random walk is indeed surprising, given the fact that the parities have not changed for most currencies. The mean squared forecast error for the Irish punt model for instance, outperforms the random walk by more than $11 \%$ at all horizons. For the Belgian franc the improvement decreases for longer horizons. This is probably due to the large intercept. The long run equilibrium level for the Belgian franc according to our model ( $\mu / \phi$ if the jumps are negligible) is about $1.1 \%$ above the parity. This is probably too conservative (the mean forecast error is positive, see the third row). For all currencies except the Italian lira, the mean squared forecast error is much smaller for the forecast period than for the sample period. The increased credibility of the system and the fact that these currencies were not realigned in the forecast period make the volatility in this period far less pronounced.

These findings are much better than the results of Meese and Rose (1990) among others, who find that a locally weighted regression does not lead to an improvement in out-of-sample predictive power in EMS exchange rates vis-a-vis the random walk.

However, as the distributional properties are very important in our model, it might be more interesting to look at forecast intervals. Figure 3.4 gives the one week ahead $95 \%$ forecast intervals for both the sampling and the forecast period. Two interesting items can be deduced from these graphs.

First of all, the forecast interval is much larger for the early years of the EMS than for later years, especially for the currencies with large changes in the jump probability, e.g. the Belgian franc, the French franc, the Danish krone and the Irish punt. This is due both to the decrease in the jump probability over the years and the GARCH effect.

Second, a measure of the realignment probability can be deduced. Values outside the fluctuation band can only be realized if the parities are changed. This means that the probability that the exchange rate takes a value which is larger than the upper margin is a lower limit of the expected devaluation

\footnotetext{
${ }^{8}$ For most currencies, the results are robust to a change in the forecast period. The results for the Italian lira however, are influenced to a large extent by its devaluation and abandonment of the system in September 1992. If these events were not included in the forecast period, the random walk without trend would have outperformed the model. This dependence on the period reflects the "Peso problem" (Krasker, 1980).
} 
Figure 3.4: 95\% forecast intervals and parity changes
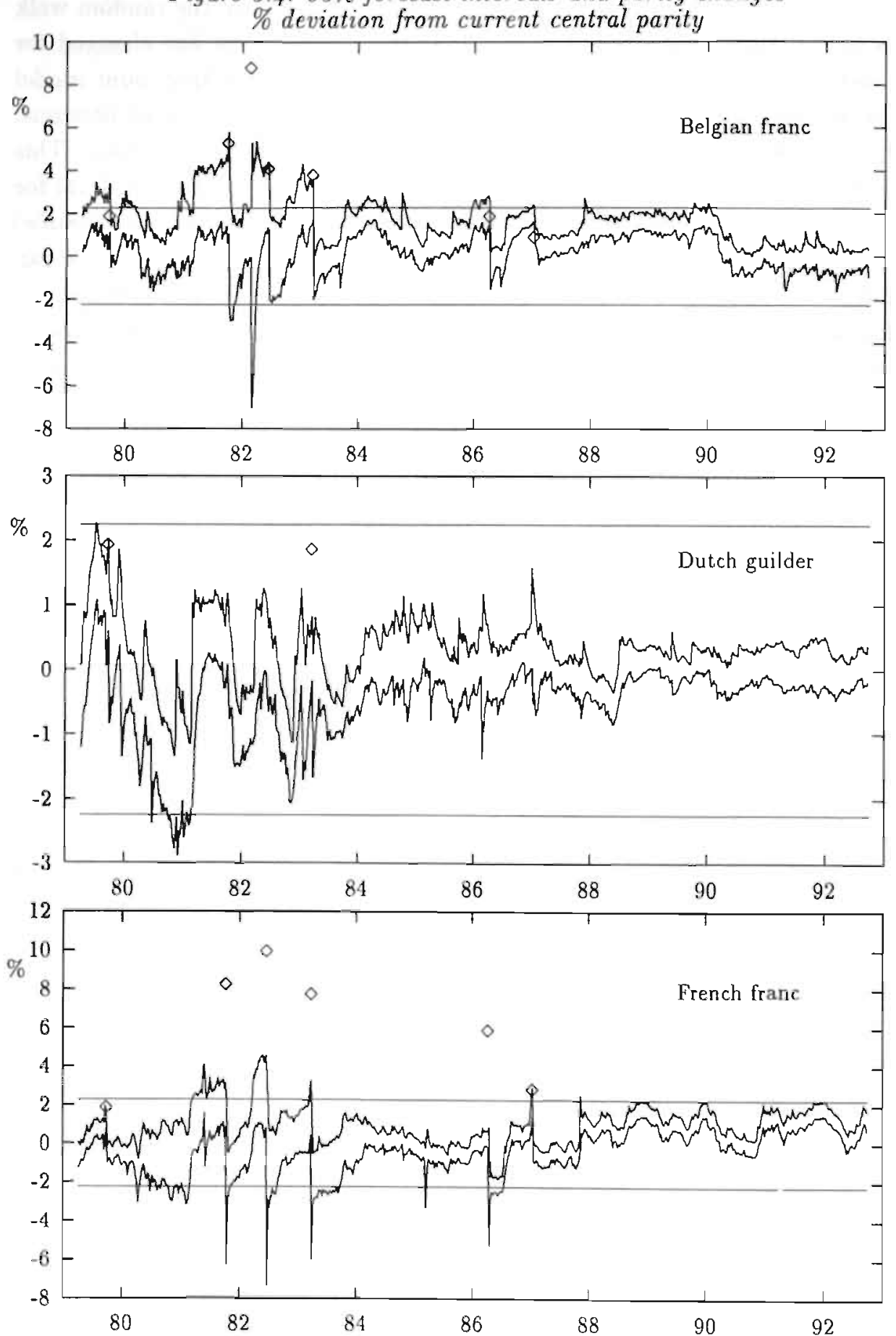
Figure 3.4 continued: $95 \%$ forecast intervals and parity changes
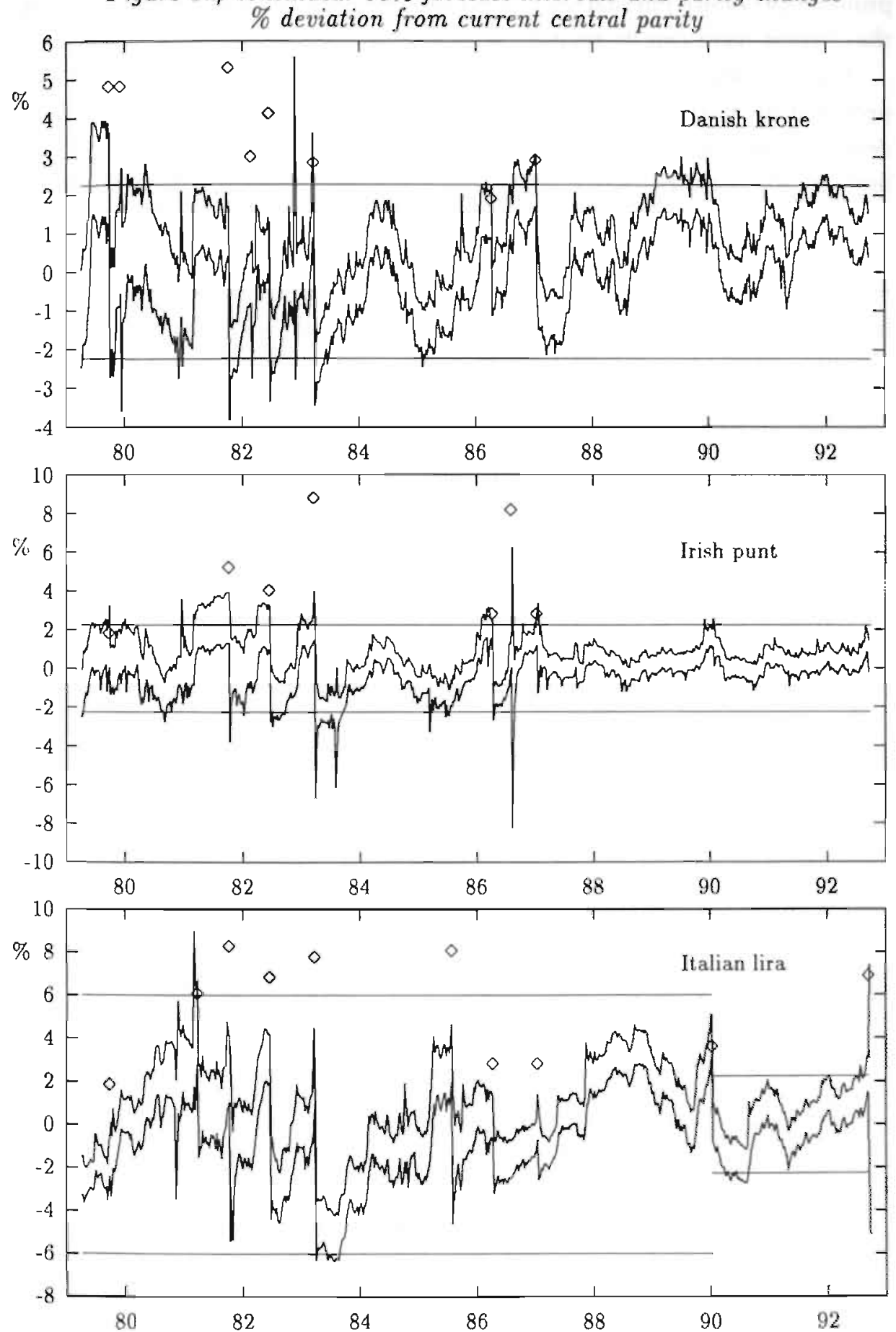
probability ${ }^{9}$ (since fluctuation bands might be overlapping, also values inside the current band can be realized after a devaluation).

For the Belgian franc all devaluations, indicated by the diamonds, are preceded by a crossing of the fluctuation band. However, the timing of the devaluations is not clearly foreseen since on several occasions, the confidence interval was already partly above the fluctuation band for months, before a devaluation took place. For the Dutch guilder both devaluations, especially the last one, came as a complete surprise. For the French franc most realignments were expected although the first (September 1979) and, more importantly, the fifth (April 1986) were not. Especially the occurrence of the fifth devaluation is surprising since the forecast interval was quite small at the time, and in the middle of the band. The devaluations of the Danish krone were only foreseen on three out of eight occasions. The devaluations for the Irish punt were foreseen, except for the sixth one. In August 1986 the US dollar and the British pound depreciated considerably in terms of the D-mark (see figure 2.1). Since the US and the UK were the most important trading partners of Ireland, its currency was devalued by $8.34 \%$. Finally, the forecast interval for Italian lira crossed its fluctuation band only before the March 1981 and September 1992 devaluations. On several occasions the lira devalued together with other currencies, although the position of the lira gave no indication for an upcoming devaluation. If we assume the Italian authorities used an implicit fluctuation margin of only $4.5 \%$, at least until the Basle-Nyborg agreement (see section 1.1), the third, fourth, fifth and sixth devaluation are foreseen as well by our model.

Our final analysis concerns the use of the models to evaluate investment strategies (Koedijk and Kool, 1993; Koedijk et al., 1993). According to the efficient market hypothesis, excess returns are explained in terms of a greater risk associated with the investment. We consider the investment of borrowing D-marks (at the one week offer rate) on the London Eurocurrency market, converting them to one of the other currencies, lending this other currency (at the bid rate) out for one week and convert back the next week (if one does not invest the subsequent week). The transaction cost for converting currencies are not included. By comparing mean excess returns, defined as the return averaged over investment weeks, of investment rules (which weeks to invest)

\footnotetext{
${ }^{9}$ This is the way Koedijk et al. (1993) estimate the realignment probability.
} 
based on our model with other investment strategies we investigate whether interest rate differentials reflect expected depreciations and/or increased risk predicted by our model ${ }^{10}$.

In table 3.6 the excess returns are given both for the estimation period and the forecasting period. The Irish punt is not included since there are no interest rates available for the Irish punt on the London Eurocurrency market. The Belgian franc and Danish krone start later for the same reason. We investigate five different investment rules.

The first strategy is to invest every period. For the estimation period, this strategy yields a significant positive return for the French franc, the Danish krone and the Italian lira. This might be due to a "Peso like" risk premium (Krasker, 1980). Investors are compensated for the small probability of a large devaluation. For the forecasting period, significant positive excess returns are no longer present. For the Italian lira the mean excess return is highly negative. The recent large depreciations of the lira associated with the devaluation and abandonment of the system were not compensated by comparably high interest differentials. The decline in excess returns for the other currencies is probably due to the increased credibility of the ERM.

The second strategy consists in investing whenever there is a positive interest differential. This rule is based on the idea that exchange rates behave like random walks. If the expected depreciation is zero, the interest differential determines your expected profit. For all currencies the mean excess return is higher, especially in the forecasting period. Within sample, the mean excess return for the Dutch guilder improves significantly. Within the theory of efficient markets these higher excess returns are only possible if the risk on this strategy is higher. Indeed, most of the standard deviations are slightly higher.

The third investment rule makes use of our model predictions. An investment is made if the expected excess return is positive. The mean excess returns on this investment rule are significantly higher than the returns on rule two for most currencies, both within and out-of-sample. Moreover, especially out-of-sample, the standard deviations are mostly smaller than for

\footnotetext{
${ }^{10}$ Ideally, expectations and risk measures, provided by the model, should be incorporated when evaluating the risk associated with an investment rule. However, as the expected returns and risk measures are not available for the strategies that do not make use of the model, we simply computed means and standard deviations over invesiment weeks, thcrcby implicitly assuming a constant expected return and risk in these weeks.
} 
rule two, although it should be noticed that the sample variance might not be the best measure of volatility in the presence of a peso-problem. This rule

Table 3.6: Excess returns of investment strategies

\begin{tabular}{||c|rcccc|rrrrr||}
\hline & \multicolumn{6}{|c|}{ Within Sample } & \multicolumn{5}{c||}{ Out-of-Sample } \\
\hline & BF & DG & FF & DK & IL & BF & DG & FF & DK & IL \\
\hline \multirow{4}{*}{1} & 1.24 & .16 & $1.97^{* *}$ & $2.62^{* *}$ & $3.59^{* *}$ & .15 & .08 & -.08 & .39 & -3.45 \\
& 25.63 & 12.83 & 23.54 & 16.47 & 30.19 & 17.48 & 4.21 & 10.40 & 13.18 & 42.98 \\
& 521 & 613 & 613 & 288 & 613 & 91 & 91 & 91 & 91 & 91 \\
\hline \multirow{4}{*}{2} & 1.27 & $1.11^{* *}$ & $2.09^{* *}$ & $2.62^{* *}$ & $3.67^{* *}$ & 2.77 & 1.29 & .37 & .58 & -3.45 \\
& 25.69 & 11.91 & 23.63 & 16.47 & 30.27 & 17.79 & 5.17 & 10.45 & 13.79 & 42.98 \\
& 518 & 453 & 603 & 288 & 609 & 26 & 24 & 79 & 77 & 91 \\
\hline \multirow{4}{*}{3} & $5.29^{* *}$ & $2.26^{* *}$ & $3.32^{* *}$ & $3.91^{* *}$ & $5.12^{* *}$ & $17.92^{* *}$ & $2.35^{* *}$ & .27 & $3.10^{* *}$ & -6.28 \\
& 18.60 & 13.39 & 24.80 & 16.49 & 29.40 & 14.70 & 4.60 & 9.27 & 11.49 & 55.89 \\
& 329 & 322 & 467 & 239 & 521 & 17 & 29 & 64 & 61 & 52 \\
\hline \multirow{4}{*}{4} & $6.10^{* * *}$ & $2.39^{* *}$ & $3.35^{* *}$ & $4.70^{* *}$ & $5.49^{* *}$ & $19.74^{* *}$ & $2.90^{* *}$ & .28 & $2.63^{*}$ & -11.18 \\
& 18.35 & 13.93 & 25.87 & 15.64 & 29.53 & 15.62 & 4.60 & 8.63 & 11.08 & 69.04 \\
& 292 & 278 & 405 & 214 & 461 & 14 & 20 & 45 & 52 & 33 \\
\hline \multirow{3}{*}{5} & $4.59^{* *}$ & $2.39^{* *}$ & $3.72^{* *}$ & $4.57^{* *}$ & $5.19^{* *}$ & $19.74^{* *}$ & $2.90^{* *}$ & .28 & 2.54 & 2.45 \\
& 15.63 & 13.93 & 20.72 & 16.20 & 28.87 & 15.62 & 4.60 & 8.63 & 11.38 & 12.80 \\
& 227 & 278 & 400 & 170 & 460 & 14 & 20 & 45 & 48 & 29 \\
\hline
\end{tabular}

- The sample period runs from April 1979 to Dorimber 1990 (613 weeks), and the forecast period from January 1991 to September 23, 1992 (91 weeks). For the Belgian franc interest rate data are only available from 1981 on, for the: Danish krone from July 1985 on.

- For each strategy three numbers are noted. The first is the excess return $\left(R_{t} \equiv\right.$ $i_{t-1}-i_{t-1}-\Delta s_{t}$ ), averaged over investment weeks (measured in percontage points on an annual basis). The second is the standard deviation of the returns. And the third is the number of weeks in which one is investing.

- For each currency the following five strategies are investigated:

1. invest in all periods,

2 . invest only when the interest rate differential is positive,

3 . invest when the expected return (interest differential-expected depreciation) is positive,

4. invest when the expected return divided by the conditional standard deviation $>5 \%$,

5 . invest when the expected return divided by the conditional standard deviation $>5 \%$ and the probability of a devaluation $<10 \%$.

- * $\left(^{* *}\right)$ indicates significance at the $10 \%(5 \%)$ level respectively. 
leads to significant excess returns for all currencies within sample and three currencies out-of-sample. The exception is the out-of-sample excess return for the Italian lira. For this currency, the depreciations in September 1992 were much larger than foreseen by the model (see figure 2.1).

The fourth strategy takes both the expectation and the conditional variance of our model into account. The returns on this strategy are even higher than for rule three for most currencies. Again, the out-of-sample result for the Italian lira is the great exception.

As depreciation risk is unbounded during realignments, the last investment rule explicitly penalizes for devaluation risk. Rule four is augmented by the condition that the probability of a devaluation, measured as the probability mass above the upper fluctuation margin, is less then $10 \%$. Most investment results are not so much altered by the condition, since it is rarely binding. The results improve for the currencies for which the timing of devaluations was rightly predicted (or enforced) by the market, e.g. the French franc within sample and the Italian lira out-of-sample, but worsen for those for which the timing of devaluations was not clearly foreseen, e.g. the Danish krone and the Belgian franc within sample.

The excess returns associated with the use of the above model are in line with but substantially higher than those obtained by Koedijk, Stork and De Vries (1993) and Koedijk and Kool (1993). In a study of model-based investment strategies for various subperiods of the EMS, they found that a strategy of borrowing in low interest currencies and investing in high interest currencies would have been profitable for the Belgian franc, the French franc and the Italian lira, especially since 1983. In these studies the investment decision was primarily based on devaluation risk.

Investment rule five points towards the existence of arbitrage opportunities in the foreign exchange market. Using a model that uses only information that is available to the market at the time of expectation formation, it is possible to extract weeks in which the mean return is higher and the variance lower. This means that the market is either not efficient or too risk averse to exploit expected opportunities for excess returns most of the time. Whatever the reasons were, just the mere existence of these opportunities would make the theoretical foundation for models based on the no arbitrage argument, e.g. the target zone and speculative attack models, highly questionable. 


\subsection{Conclusions}

In this chapter the MA(1)-GARCH(1,1)-jump models of chapter 2 are modified in two directions. First an error correction term, measuring the deviation of the spot rate from its central parity, is included to model the parity reversion. Second the jump probability is made time-varying.

Since the jumps in our models represent (anticipations for) realignments, the probability of a jump was made a function of economic fundamentals. It is shown that inflation differentials and trade deficits are significant determinants of exchange rates, if incorporated in this indirect manner. For most currencies the jump probability has decreased to less than one tenth of the values of the early eighties, in recent years.

The models are estinated using data from April 1979 to December 1990. The statistical properties of the data are very well reproduced by the models. For almost all currencies, the specification is not rejected when tested for serial correlation in mean and squared data, skewness, kurtosis or overall fit.

The models were also judged on their preclictive features. Using the parameter values obtained from the sample 1979 - 1990, we computed the one to four weeks ahead prodictions both for the sampling period and for a forecasting period running from January 1991 to September 23, 1992. Both within and out-of-sample all the models outperformed the random walk on all. horizons, in terms of mean squared forccast error. Apparently, the increased credibility of the ERM in recent years was sufficiently modeled by means of the decreased jump probability.

The increased credibility was also shown by the $95 \%$ forecast interval of the one week ahead predictions. The intervals are much smaller for the nineties then they were in the early eighties. Moreover, these graphs show that most realignments were preceded by a $95 \%$ forecast interval that was partly outside the target zone.

Finally, it was shown that large excess returns could be made in the foreign exchange market if predictions of the model were used, again both within and out-of-sample. Since our model uses only information that is available to the market, and since the higher returns were not accompanied by a higher variance, this means that either the foreign exchange market is not efficient, or that the market is too risk averse to exploit the large interest differentials. In the next chapter, we will explicitly model the excess returns, in order to find an explanation for their existence. 


\section{Chapter 4}

\section{Modeling weekly excess returns within the EMS}

\subsection{Introduction}

In the previous chapter, it was shown that substantial excess returns could have been made on an investment in the weak EMS currencies, thereby exploiting the interest differentials within the EMS. Most of the time, the interest differentials were larger than the realized depreciations. Moreover it was shown that the excess returns increased if predictions of our exchange rate model were used to select the weeks in which one should invest.

In the light of this evidence on the existence of excess returns, we decided to model the series on excess returns (deviations from the uncovered interest parity) themselves. Since it is possible that the interest rate differential compensates for some of the features of the exchange rate changes, modelling excess returns directly might give interesting additional insights in the mechanism of price formation and the efficiency of the foreign exchange market. From a macroeconomic point of view, these insights are important as the excess returns are often accompanied by high domestic interest rates compared to German ones. High rates, required for the stability of the exchange rate in the absence of capital controls, might very well result in a slowdown of economic activity.

As the excess returns incorporate the realized exchange rate changes, our model for the excess returns will resemble the one for the exchange rates, developed in chapter 3 . Under the assumption of rational expectations and 
market efficiency, the conditional expectation of the excess returns is equal to the risk premium. In order to investigate the linkage between expected risk and return, the model will be augmented by a volatility measure in the mean equation.

When modelling ex-post returns within a target zone, care has to be taken of the "peso problem" (Krasker, 1980). As long as a weak currency is not devalued, a high interest rate on this currency may suggest a large risk premium. These large returns might however be completely eroded, if that currency is devalued. In our model these effects are modeled separately. The positive effect of weakness (measured by the inflation differential with Germany) on the excess return (via the higher interest rate) is modeled by the volatility measure in the mean equation. The negative effects on excess returns of possibly large losses due to large depreciations are modeled by means of stochastic jumps, where the jump probability depends on the inflation differential. An increase in the inflation differential leads to an increased probability of a draw from the normal in a compound normal distribution with the lower mean (an expected loss) and the higher variance (more volatility).

Other features of the model are the inclusion of a moving average term and the position of the spot rate in the fluctuation band as explanatory variables of expected excess returns. Both variables result from the fact that market participants do not always correctly assess the probability of a devaluation. Finally, the persistence of volatility in the excess returns is modeled by a GARCH specification (Bollerslev, 1986).

The outline of this chapter is as follows. Section 4.2 gives some background on the modeling of risk premia. In section 4.3 , the data on excess returns are described. Section 4.4 provides the details of the model. Section 4.5 contains the empirical results and section 4.6 concludes.

\subsection{Modeling risk premia}

If investors are risk neutral and have rational expectations, the market's forecast of the future spot exchange rate is reflected in the interest differential. However, many researchers ${ }^{1}$ have found that the forward premium, which

\footnotetext{
${ }^{1}$ See for example the survey articles by Froot (1990) or MacDonald and Taylor (1992).
} 
under the assumption of covered interest parity is identical to the interest differential, is a biased predictor of the future exchange rate change. One way to rationalize this finding is to allow for risk aversion. If agents are risk averse, the interest differential does not only reflect the expected change in the exchange rate, but also a risk premium. Considerable effort has been spent on the modelling of risk premia, but the successes have been rare $^{2}$.

A major problem in the identification of risk premia is the two-sidedness of the foreign exchange market. Since agents in the two countries have objectives denominated in different currencies, it is no longer appropriate to use a model with just one type of "representative agent". In the literature, the representative agent model is usually restored by assuming absolute purchasing power parity (PPP) and by defining risk as the unexpected price change in one of two countries ${ }^{3}$. However, both absolute PPP and risk measures defined in terms of the number of goods one can buy are not of direct interest to the speculator in a foreign exchange market. A German investor might be searching for the highest return, denominated in D-marks, not measured for instance in terms of the number of American cars he can buy. At the same time an American investor is maximizing his dollar return. Since for both investors it is risky to invest in the other currency, it is not clear who is willing to pay for the premium, and whether this will be the same party all the time.

If investors are indeed risk averse, it is not at all clear that there should be a one to one relationship between expected depreciations and interest rates in the first place. The reason for this lose relationship is the possible existence of risk on both sides of the market. Expected returns will only be exploited if they outweigh the minimal required risk premium. As a consequence, a range of outcomes for the current spot rate is possible given the interest rate differential and the expected future spot rate, even if all market participants have the same expectations and risk profiles

$$
E_{t}\left(s_{t+1}\right)+i_{t}^{*}-i_{t}-r p_{t} \leq s_{t} \leq E_{t}\left(s_{t+1}\right)+i_{i}^{*}-i_{t}+r p_{i}^{*} .
$$

Here $s_{t}$ is the log exchange rate expressed in domestic currency per foreign currency, $i_{t}$ denotes the domestic one period interest rate, $r p_{t}$ is the risk

\footnotetext{
${ }^{2}$ See for instance Giavazzi and Giovannini (1989), Giovannini (1990) and the survey by Hodrick (1987).

${ }^{3}$ For an application of this framework on target zone exchange rates, see Svensson (1992b).
} 
premium one requires to invest in the foreign currency, and a * indicates a variable for the foreign country.

Within the European Monetary System this problem of two-sidedness is probably less severe since the risk of a devaluation within the EMS has been asymmetric most of the time. For practical purposes, the probability that the D-mark is devalued in terms of one of the other currencies can be considered zero. As a consequence, the depreciation risk for investments in the $\mathrm{D}$-mark is bounded by the exchange rate target zone. Under these circumstances even non-German investors might very well prefer D-marks to their domestic currency (so that $r p_{t}$ can be negative) since the risk of holding $\mathrm{D}$-marks is small and the gains that can be made if their currency is devalued can be substantial. Therefore, it seems reasonable to assume that the risk premium is given only to the investors who are willing to invest in the weak (non-German) currency. This premium is paid by those who have to lend in the weak currency, since in order to assure that the current spot rate stays within the fluctuation band, the interest rate on this currency will be higher than that on the D-mark.

\subsection{The data}

We investigate the excess returns on an investment in a weak EMS currency, relative to a risk-free investment in the $\mathrm{D}$-mark $\left(R_{t} \equiv i_{t-1}-i_{t-1}^{G e r}-\Delta s_{t}\right)$. Both interest rates and exchange rate series were taken from Datastream and are middle rate notations from the London Eurocurrency market.

Figure 4.1 shows the weekly excess returns and the devaluations (indicated by the diamonds) of the Belgian franc, the Dutch guilder, the French franc and the Italian lira for the period April 1979 to September 1992. The series for the Belgian franc start later since interest rates for the franc on the Eurocurrency market were not available before 1981. The Irish punt and Danish krone are not included at all for the same reason. Several interesting features emerge from these figures. First of all, realignments can lead to very large speculative losses, especially if these devaluations were not foreseen by the market. The most obvious examples are the February 1982 devaluation of the Belgian franc and the September 1992 devaluation of the Italian lira. However, when a devaluation was predicted by the market, its effect on the returns is much less dramatic. The returns might even be highly positive 
Figure 4.1: Excess returns and parity changes relative to the D-mark:
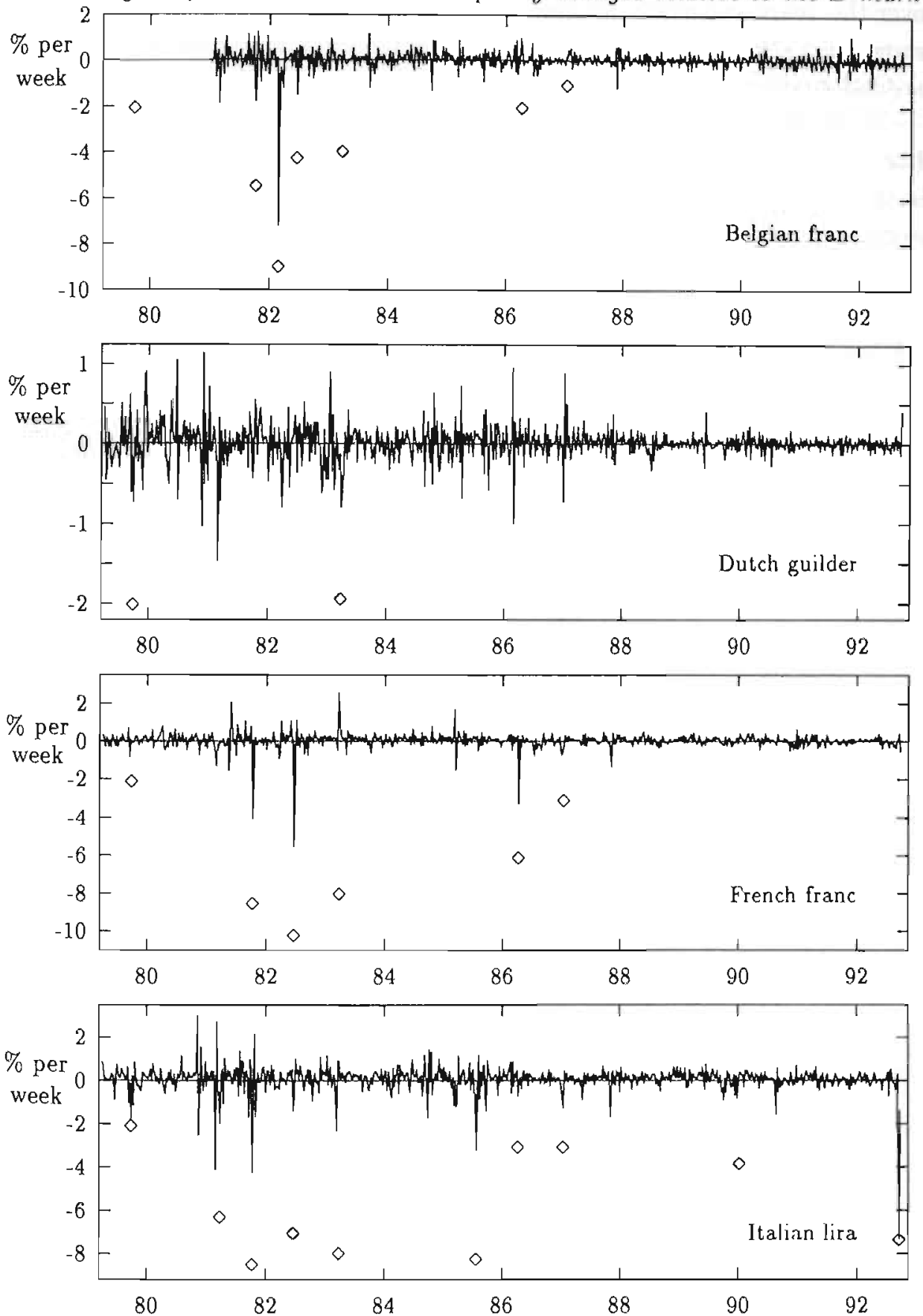
(the French franc in 1983). Second, the volatility of the series has declined over the years, especially for the Dutch guilder. Third, these graphs do not show clear arbitrage opportunities. On average small positive excess returns are followed by (large) negative returns and vice versa.

In table 4.1 some summary statistics are given for the excess returns. For all currencies the mean excess return is positive. This is in accordance with the existence of a positive risk premium for the weak currencies. The magnitude of the mean excess return for a particular currency is positively related to the number of devaluations experienced by that currency. As the low values of the first order autocorrelation show, there is no evidence for the existence of a unit root. Serial correlation in both the raw and the squared data is only significantly present for the Dutch guilder. However, these statistics are quite sensitive to the occurrence of large outliers. Large (negative) outliers also lead to very significant excess kurtosis and negative skewness.

Table 4.1: Summary statistics for weekly excess returns

\begin{tabular}{||l|cccc||}
\hline Statistic & BF & DG & FF & IL \\
\hline Mean $\left(\times 10^{4}\right)$ & 2.32 & 0.56 & 3.54 & 5.42 \\
St.dev $\left(\times 10^{4}\right)$ & 47.26 & 23.22 & 42.87 & 61.90 \\
$\rho_{e}(1)$ & $-0.11^{*}$ & $-0.16^{* *}$ & 0.00 & -0.08 \\
$L B_{e}^{A}(25)$ & $34.79^{*}$ & $41.84^{* *}$ & $36.22^{*}$ & 27.61 \\
$L B_{c^{2}}(25)$ & 7.26 & $176.20^{* * *}$ & 3.77 & 8.79 \\
Skewness & $-6.19^{* * *}$ & $-0.24^{* * *}$ & $-4.67^{* * *}$ & $-3.40^{* * *}$ \\
Excess kurtosis & $89.69^{* * *}$ & $6.32^{* * *}$ & $58.93^{* * *}$ & $37.43^{* * *}$ \\
\hline
\end{tabular}

- The data consist of 704 weekly observations from April 4, 1979 to September 2:3, 1992, except for the Belgian franc for which the starting date is January 7, 1981.

- $P_{e}(1)$ is the firsi order autocorrelation, $L B_{e}^{A}(25)$ is a Ljung-Box statistic, adjusted for ARCH-like heteroskedasticity, see Diebold (1987) and $L B_{e^{3}}(25)$ is a Ljung-Box statistic for the first 25 autocorrelations in the squared data.

- $\left.{ }^{* * *}{ }^{* * * *}\right]$ indicates significance at the $10 \%(5 \%)[1 \%]$ level respectively. 


\subsection{The model}

To motivate the model, assume that the objective of the monetary authorities is twofold, i.e. achieve a low inflation rate and a low unemployment level

$$
U^{\text {mon }}=f(\text { inflation; unemployment })
$$

where $U^{\text {mon }}$ is the objective or utility function of the monetary authorities, which is a decreasing function in its arguments. The most important instruments available to the monetary authorities are the parities and the level of the interest rates. A credible peg to the D-mark enables the monetary authorities to pursue an anti-inflationary policy, since this peg is only sustainable if domestic inflation rates converge to German levels. Such an external target might be more effective than an announced monetary target since the penalty for breaking this target (political loss of face) is higher than for breaking the monetary target (see Giavazzi and Pagano, 1988). As long as the inflation levels have not fully converged however, the exchange rate peg leads to a real appreciation relative to the D-mark. If this episode lasts for too long the loss of competitiveness might result in a slowdown in economic activity and, as a consequence, a rise of unemployment.

If the peg is not perceived to be fully credible yet, the slowdown of economic activity might even be worsened by the high interest rates the narket will demand for investments in the weak currency. Under these conditions a devaluation might seem appropriate, but it would seriously jeopardize the inflation objectives. On the one hand, a devaluation would lead to additional imported inflation and on the other hand it would reduce the market's belief in the announced targets. Moreover, in the long run a devaluation is likely to result in higher interest rates (which might lead to higher unemployment) due to the loss of credibility. It is not at all obvious what the optimal policy' in these circumstances is. Since the speculative loss can be considerable if a (large) devaluation is not foreseen by the market, the uncertainty of the market participants about future devaluations is very important. Uncertainty will be the driving force behind our model.

Since the political willingness to sustain the parities is not known, market participants are reluctant to invest in a weak currency. They are likely to withdraw their investment in this currency, by way of precaution, whenever 
a negative news item is announced concerning this currency ${ }^{4}$. These panic reactions result in sudden (possibly large) depreciations within the band.

In our model, the losses resulting from these depreciations are, together with the losses due to unforeseen devaluations, modeled by means of stochastic jumps. The statistical meaning of a jump is a draw from a normal distribution with a negative mean (an expected loss) and a high variance (much volatility). Since the jumps are related to parity realignments, we assume their intensity to be a function of fundamentals determining the realignment probability. In this chapter, only the inflation differential with Germany will be considered, thereby adapting specification (3.1) by imposing the restriction $\lambda_{t b}=0$.

$$
\lambda_{t}=1-\left(1+\exp \left(\lambda_{0}+\lambda_{\text {infd }} \text { infd }_{t-8}\right)\right)^{-1}
$$

with infd $d_{t-8}$ being the one year inflation differential with Germany.

It should be noticed, that $\lambda_{t}$ is not the same as the probability of a realignment at time $t$. Jumps might also occur in anticipation of realignments, speculative attacks or sudden panic due to some political or economical "news". Moreover, if the variance of the jump size is very high compared to its mean, the number of "jumps" exceeds the number of large depreciations (the jumps change the distribution, they can not be identified separately).

Each period market participants will assess the probability of a realignment in the upcoming week. The higher this perceived probability is, the higher will be the interest rate dernanded on that currency. As the market can not know the conditions under which the authorities will devalue, their expectations will be based among other things on the decisions taken by the monetary authorities. The authorities will therefore try to keep the exchange rate in well within the fluctuation band ${ }^{5}$, since a spot rate at the top of the band could be interpreted by the market as an indication for an upcoming

\footnotetext{
${ }^{4}$ Obst feld (1991) shows that the mere existence of the realignment possibility already destabilizes the exchange rate system, even if the authorities pledge they will only use this escape clause in extreme circumstances. This is primarily due to the fact that the contingents under which they will devalue are often not observable, or may change over time.

${ }^{5}$ Until the Basle-Nyborg agreement in September 1987, this was the official policy of the French monetary authorities.
} 
devaluation ${ }^{6}$. Only if the costs, in terms of high interest rates, of keeping the spot rate in the middle of the band are too high, the exchange rate will approach the weak margin.

Therefore, a high position of the spot exchange rate in the fluctuation band is likely to be accompanied by a high interest differential with Germany. This means that as long as no devaluation has been decided on, a high position in the fluctuation band leads to a large expected excess return. Moreover, again under the assumption of no devaluation, it is likely that returns are negatively autocorrelated. A speculative loss, that is an unforeseen depreciation (due to a rise in the expected realignment probal)ility for the upcoming week), is accompanied by a rise in the interst rate, whereas at the same time in the absence of a realignment the maximum depreciation is bounded by the fluctuation band. These effects might however be completely compensated by devaluations. If the timing of realignments would be always correctly foreseen by the market, it would not be clear whether the position in the band is informative about the future return.

Finally, risk averse investors require a higher risk premium, that is an increase of the expected excess return, in the presence of increased risk. This will be modeled by including the conditional standard deviation of the excess return in the mean equation of our model.

From these considerations the following equation for the mean excess return is put forward

$$
\begin{aligned}
R_{t} & \equiv\left(i_{t-1}-i_{t-1}^{G e r}-\Delta s_{t}\right) \\
& =\mu+\gamma S D_{t-1}+\phi(s-c)_{t-1}+\lambda_{t} \theta+\psi D_{t-1} \varepsilon_{t-1}+\varepsilon_{t},
\end{aligned}
$$

which is similar to the mean equation for $\Delta s_{t}$ in (3.2) and where $S D_{t-1}$ denotes the conditional standard deviation of $R_{t}$ given information up to period $t-1$ (see equation 4.6). The presence of this variable reflects the increase of excess returns due to that of uncertainty. The dummy variable $D_{t-1}$ takes the value zero after a devaluation and one otherwise. It is included since losses that result from parity changes are not expected to be compensated the next week. $\lambda_{t} \theta$ measures the contribution of the "jumps" to the expected return.

\footnotetext{
${ }^{6} \mathrm{Chen}$ and Giovannini (1993) found the realignment expectation to be positively related to the current position in the band
} 
Expression (4.2) can also be interpreted as a specification explaining the risk premium defined as $R_{t}^{*}=\dot{i}_{i-1}-i_{t-1}^{G e r}-E_{t-1} s_{t}+s_{t-1}$ with $E_{t-1} s_{t}$ denoting the expectation of $s_{t}$ conditional on the information available at period $t-1$. Therefore, we have $R_{t}^{*}=R_{t}-\varepsilon_{t}$. To the extent that the inflation differential reflects the degree of uncertainty in foreign exchange markets, it is expected to be a major determinant of the risk premia.

The distribution of the disturbance $\varepsilon_{t}$ is given by

$$
\varepsilon_{t} \sim\left(1-\lambda_{t}\right) N\left(-\lambda_{t} \theta, h_{t}^{2}\right)+\lambda_{t} N\left(\left(1-\lambda_{t}\right) \theta, h_{t}^{2}+\delta^{2}\right),
$$

where $\theta$ and $\partial^{2}$ are the expectation and variance respectively of the jump size. If the inflation differential rises, the probability of a draw from the normal distribution with lower mean (on average a loss) and higher variance (more volatility) rises. Finally, the persistence in volatility is modeled by means of a $\operatorname{GARCH}(1,1)$ specification (Bollerslev, 1986)

$$
h_{t}^{2}=\alpha_{0}+\alpha_{1} \varepsilon_{t-1}^{2}+\beta h_{t-1}^{2} .
$$

The differences with the model for the exchange rate changes given in chapter 3 are that $S D_{t-1}$ does not enter into the equation for the mean in (3.2) and that the trade balance surplus enters as an additional explanatory variable into the specification of the jump intensity of the form in (3.1). This variable has been deleted from (4.1) to avoid multicollinearity problems. Given that an MA(1)-GARCH(1,1)-Bernoulli-jump model has been found to perform quite well in explaining the exchange rate dynamics, we expect that the model in (4.1) to (4.4) will also be appropriate to explain excess returns.

Finally, the expected jump size $\theta$ could be made a function of fundamentals, such as the inflation differential, as well, but this extension did not yield a significant statistical result.

\subsection{Empirical results}

In table 4.2 the maximum likelihood results are shown. The effect of volatility $(\gamma)$, measured as the conditional standard deviation $\left(S D_{t-1}\right)$ is highly significant for three out of four currencies. As expected, volatility increases the mean excess return. Only for the Dutch guilder the coefficient is not 
Table 4.2: Empirical results for weekly excess returns

\begin{tabular}{||l|cccc||}
\hline & $\mathrm{BF}$ & $\mathrm{DG}$ & $\mathrm{FF}$ & $\mathrm{IL}$ \\
\hline & & & & \\
\hline$\mu\left(\times 10^{4}\right)$ & $-5.46^{*}$ & -0.53 & -2.65 & $-11.34^{*}$ \\
$\gamma$ & $(-1.72)$ & $(-0.47)$ & $(-0.57)$ & $(-1.68)$ \\
& $0.18^{* *}$ & 0.10 & $0.22^{* *}$ & $0.43^{* * *}$ \\
$\phi\left(\times 10^{2}\right)$ & $(2.38)$ & $(1.44)$ & $(1.91)$ & $(3.45)$ \\
& $3.83^{* * *}$ & 3.47 & 1.59 & 0.84 \\
$\psi$ & $(3.75)$ & $(1.57)$ & $(1.44)$ & $(1.55)$ \\
& $-0.30^{* * *}$ & $-0.27^{* * *}$ & $-0.10^{* * *}$ & $-0.12^{* * *}$ \\
$\lambda_{0}$ & $(-5.46)$ & $(-5.98)$ & $(-2.77)$ & $(-2.80)$ \\
& $-4.32^{* * *}$ & $-2.65^{* * *}$ & $-4.90^{* * *}$ & $-3.77^{* * *}$ \\
$\lambda_{\text {infd }}$ & $(-5.79)$ & $(-5.55)$ & $(-7.35)$ & $(-7.74)$ \\
$\theta\left(\times 10^{2}\right)$ & $36.80^{* * *}$ & 56.58 & $41.52^{* * *}$ & $14.65^{* * *}$ \\
& $(2.69)$ & $(1.46)$ & $(3.79)$ & $(3.98)$ \\
$\delta^{2}\left(\times 10^{4}\right)$ & -0.62 & $-0.14^{* *}$ & -0.49 & $-0.92^{* * *}$ \\
& $(-0.95)$ & $(-1.75)$ & $(-1.30)$ & $(-2.75)$ \\
$\alpha_{0}\left(\times 10^{6}\right)$ & 4.21 & $0.19^{* * *}$ & $2.60^{* *}$ & $2.79^{* *}$ \\
& $(1.01)$ & $(2.37)$ & $(1.77)$ & $(1.69)$ \\
$\alpha_{1}$ & $1.99^{* *}$ & $0.05^{*}$ & $3.70^{* * *}$ & $3.60^{* * *}$ \\
$\beta$ & $(2.17)$ & $(1.50)$ & $(7.20)$ & $(3.45)$ \\
$\beta$ & $0.21^{* *}$ & $0.18^{* * *}$ & $0.13^{* * *}$ & $0.15^{* * *}$ \\
& $(2.24)$ & $(2.68)$ & $(2.38)$ & $(2.10)$ \\
\hline Statistic & $0.51^{* * *}$ & $0.76^{* * *}$ & 0.06 & $0.40^{* * *}$ \\
\hline$\chi^{2}(29)$ & $(3.45)$ & $(8.72)$ & $(0.90)$ & $(3.27)$ \\
$L B_{e}(25)$ & & & & \\
$L B_{e^{2}}(25)$ & 36.04 & 37.39 & 33.64 & $50.94^{* * *}$ \\
Skewness & 24.23 & $35.01^{*}$ & 27.42 & $35.30^{*}$ \\
Excess kurtosis & 30.87 & 19.76 & 22.28 & 10.97 \\
$\bullet$ & 0.03 & 0.03 & -0.09 & -0.10 \\
& $0.39^{* *}$ & 0.15 & 0.17 & $0.35^{*}$ \\
\hline
\end{tabular}

- The data consist of 704 weekly observations from April 4, 1979 to September 23, 1992, except for the Belgian franc for which the starting date is January 7, 1981.

- $\chi^{2}(29)$ is an adjusted Pearson goodness-of-fit test performed on a classification in 30 cells. $L B_{e}(25), L B_{e}{ }^{2}(25)$, skewness and excess kurtosis are computed on normalized residuals, see appendix $A$.

- Heteroskedasticity-consistent $t$-values are in parenthesis.

- * $\left(^{* *}\right)[* * *]$ indicates significance at the $10 \%(5 \%)[1 \%]$ level respectively. 
significant. The reason for this result for the guilder is probably the small magnitude of the inflation differential, which is a major determinant of the conditional variance, during the whole sample period (see figure 3.1).

Inflation also has the expected effect ( $\lambda_{\text {infd }}$ is positive) for all currencies. Again, it is not significant for the Dutch guilder. For all currencies the probability of a jump increases with the inflation differential. Since the mean jump size $(\theta)$ is negative (although not always significant), this means that a relatively high inflation differential increases the probability of a big loss. The variance of the jump size $\left(\delta^{2}\right)$ however, is very big compared to its mean, so that the effect on volatility is also very important. As 1 he volatility increases with inflation, the risk of a big loss is at least partly compensated by an increase of the expected excess returns due to a rise in $S D$.

A position in the band above the central parity increases the expected return, as the estimates of $\phi$ are positive. This effect is only significant for the Belgian franc. One would expect a positive sign, if the devaluations were not all perfectly foreseen by the market. The significant negative moving average parameter $(\psi)$ is also in accordance with our expectations. Especially for the French franc this result is quite remarkable since the first order autocorrelation of the excess returns was positive. The positive correlation of $R_{t}$ is probably due to two successive negative outliers. By including jumps in the specification the model allows for the occurrence of outliers and the influence of these outliers is reduced, see chapter 2. The magnitude of the MA parameters is very much in line with those for the exchange rates themselves (see table 3.3). This means that the interest differentials do not compensate for the negative correlation in the exchange rate changes.

The $\operatorname{GARCH}(1,1)$ specification is appropriate in modelling the conditional heteroskedasticity, although an $\mathrm{ARCH}(1)$ specification would do just as well for the French franc. Again, these results are similar to those for the exchange rates in chapter 3 . Conditional heteroskedasticity is present in all series, although the $L B_{\varepsilon^{2}}$ statistic was only significant for the Dutch guilder (see table 4.2). The conditional heteroskedasticity would not be detected if jumps were not included.

Turning to the model diagnostics, we see that the models perform reasonably well. Using the adjusted Pearson chi-square goodness-of-fit test statistic $\left(\chi^{2}(29)\right.$, see appendix A), there is only evidence against the model for the It alian lira. The dependence in the data appears to be modeled appropriately 
using the MA(1)-GARCH(1,1) specification. Only for the Dutch guilder and the Italian lira, the Ljung-Box test based on the normalized residuals, see appendix $\mathrm{A}$, is significant (at the $10 \%$ level). When based on the squared residuals the Ljung-Box statistic is not significant at the conventional levels.

Finally, the resulting skewness and excess kurtosis in the normalized residuals are computed. Although both skewness and excess kurtosis are substantially reduced, there is still some excess kurtosis left for the Belgian franc and Italian lira. These results are completely due to the very large negative returns during the devaluations of February 1982 (for the Belgian franc) and September 1992 (the Italian lira), see figure 4.1.

Since it is not clear at first sight whether the effect of inflation on expected cxcess returns is dominated by volatility (via $\gamma S D$ ) or by the negative jumps (via $\lambda \theta$ ), we calculated the expected returns and variances, conditional on the inflation differential. For these calculations it was assumed that the spot rate was in the middle of the fluctuation band, and that the lagged error term was zero. The resulting expected return is

$$
E(R)=\mu+\gamma S D+\lambda \theta .
$$

The variance, conditional on the inflation differential, can be expressed in terms of the parameters of the model in the following way. From the distribution of the error term (equation 4.3) it follows that

$$
\begin{aligned}
E\left(\varepsilon_{t}^{2}\right) & =\left(1-\lambda_{t}\right)\left[\left(-\lambda_{t} \theta\right)^{2}+h_{t}^{2}\right]+\lambda_{t}\left[\left(\left(1-\lambda_{t}\right) \theta\right)^{2}+h_{t}^{2}+\delta^{2}\right] \\
& =h_{t}^{2}+\lambda_{t}\left(\delta^{2}+\left(1-\lambda_{t}\right) \theta^{2}\right) .
\end{aligned}
$$

The square root of expression (4.6) was used to compute $S D_{t-1}$ in (4.2). From the GARCH equation (4.4), one gets

$$
E\left(h^{2}\right)=\left(\alpha_{0}+\alpha_{1} E\left(\varepsilon^{2}\right)\right) /(1-\beta),
$$

which leads to the following variance specification, conditional on the inflation differential

$$
\begin{aligned}
E\left(\varepsilon^{2}\right) & =\left(\alpha_{0}+\alpha_{1} E\left(\varepsilon^{2}\right)\right) /(1-\beta)+\lambda\left(\delta^{2}+(1-\lambda) \theta^{2}\right) \\
& =\left(\alpha_{0}+(1-\beta) \lambda\left(\delta^{2}+(1-\lambda) \theta^{2}\right)\right) /\left(1-\alpha_{1}-\beta\right) .
\end{aligned}
$$

The square root of this expression is used to compute $S D$ in (4.5). 
Figure 4.2: Conditional expectation and variance of excess return
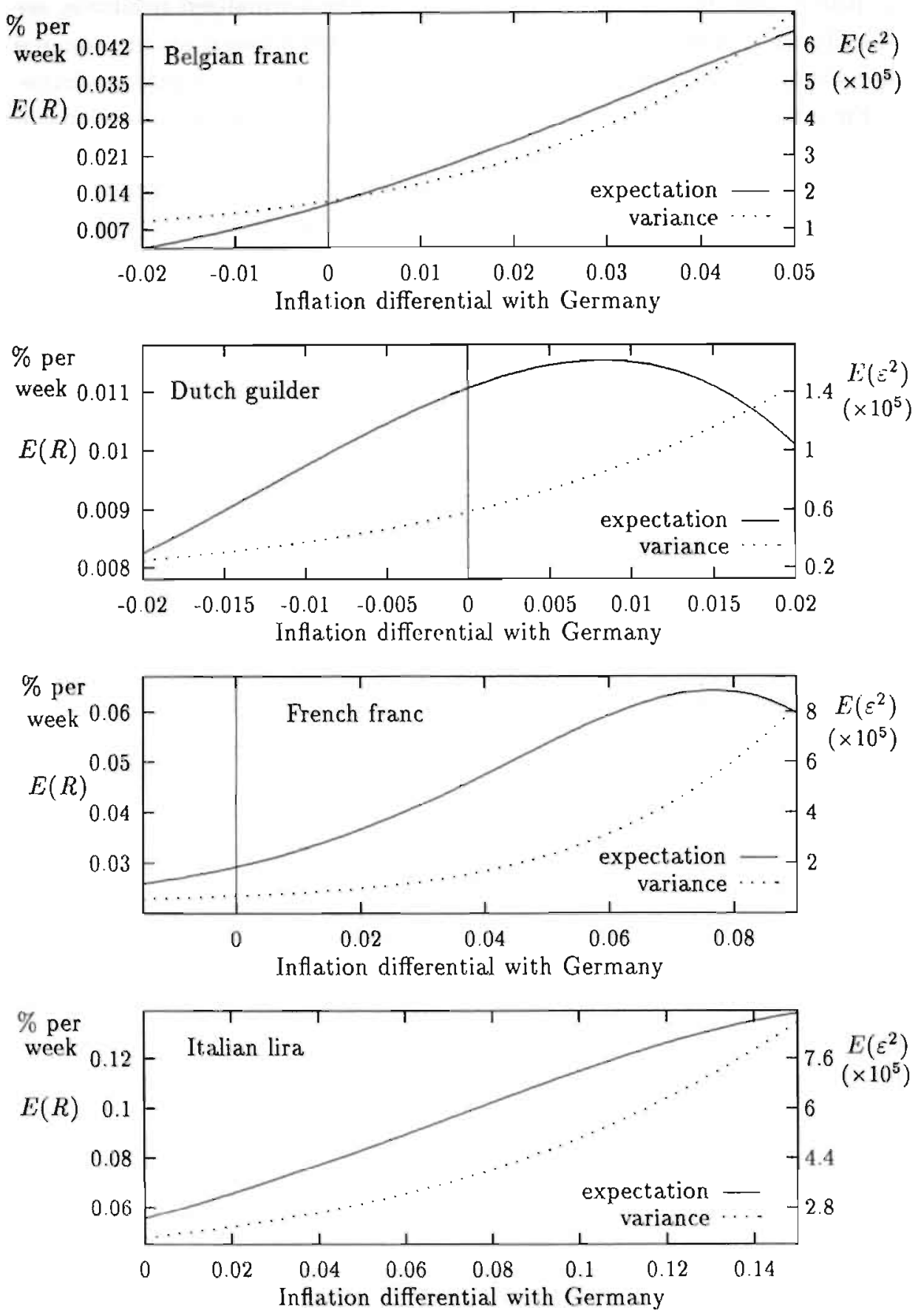
In figure 4.2 the expcctations (4.5) and variances (4.7) expressed as a function of the inflation differential are shown. On the horizontal axis, the inflation differential with Germany is shown. For each currency the range corresponds to the historical inflation differentials over the sample period (see figure 3.1).

For each currency the expected excess returns remain positive at zero and negative inflation differentials. This reflects the reputation of the D-mark as a strong currency. If the inflation differential is not too high, the inflation effect through the volatility measure $S D$ dominates the expected return. For higher inflation differentials however, the effect through $\lambda \theta$ becomes of more importance. For the French franc and the Dutch guilder, the highest expected return is reached at an inflation differential of about $8 \%$ and $1 \%$ respectively, after which the negative expected jump size dominates.

Under the assumptions of market efficiency and rational expectations, the expected return is equal to the ex-post risk premium. However, the determination of the premium strongly relies on the form of the specification of the model and the assumption that the true model has been known to the market. It is likely that in the early years of the EMS, market participants had to learn about its mechanisms. If, for example, they would have known the size of the devaluations in advance, they would probably not have invested in the French franc in 1981-1982, or they would have demanded a higher interest rate (as they did in 1983, see figure 4.1).

On the right hand scale the variance, conditional on the inflation differential, is depicted. The variance is influenced to a large extent by the inflation differential. For the French franc for instance, the conditional variance is about 16 times higher for a inflation differential of $9 \%$ than for a situation with a zero inflation differential. Although the differences for the other currencies are less severe, considerable differences are found for all of them.

The estimated risk premia $\hat{R}_{t}^{*}=R_{t}-\hat{\varepsilon}_{t}$ are given in the graphs of figure 4.3. The risk premia are highly volatile reflecting the volatility of the $\mathrm{x}$ change rates. They have been positive most of the time for the French franr. and the Italian lira. For these currencies, the magnitude of the premium his been in the order of several percentage points on an annual basis for sustained periods. On several occasions, the risk premium even reached a level of over $50 \%$ on an annual basis. These extremely high premia are due to the 
Figure 4.3: Expected weekly excess returns
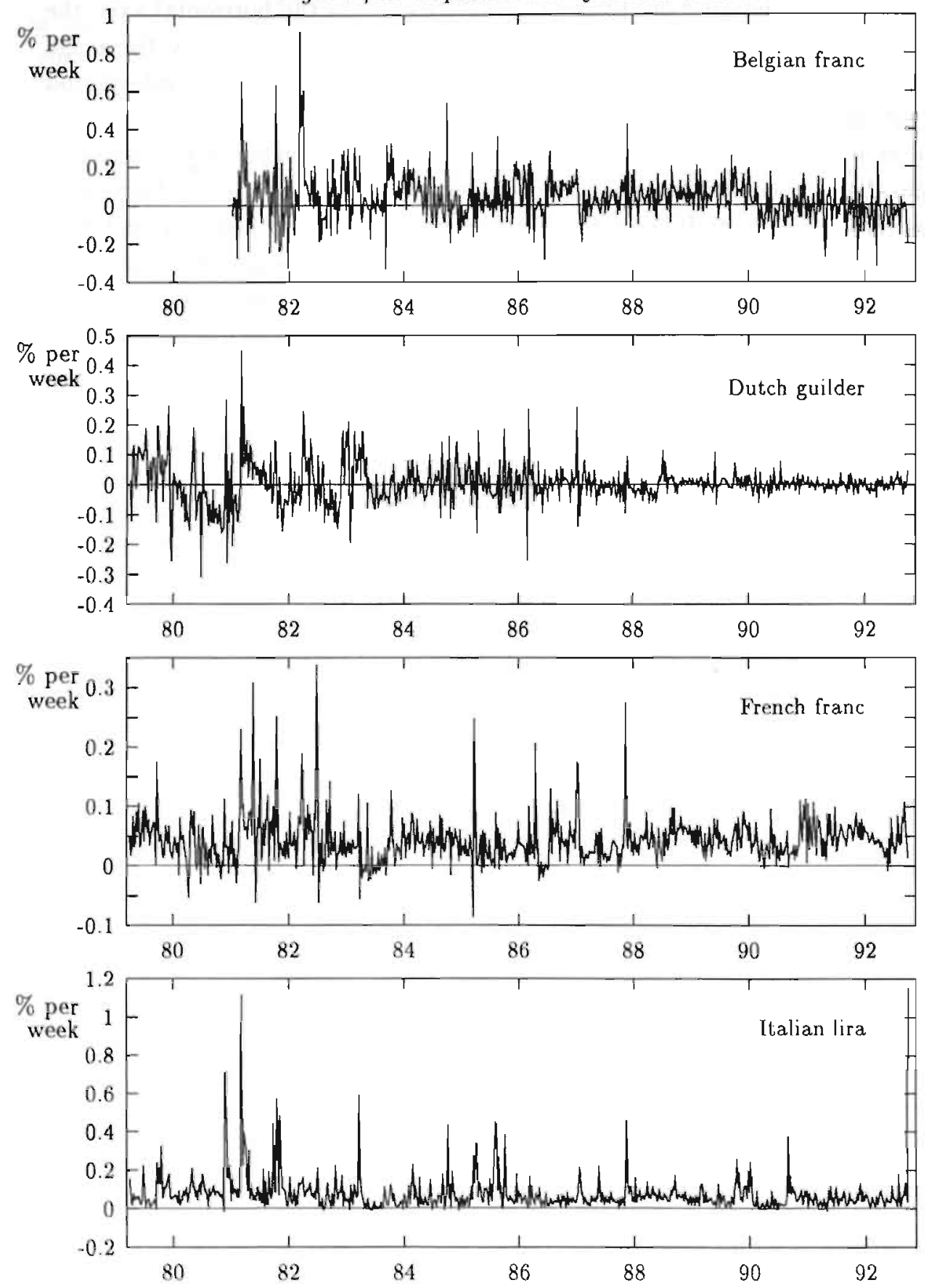
high conditional variance (due to the GARCH effect) after realignments.

Finally, we note that alternative variants of the model have been estimated too. The model in which the inflation differential is included in the mean equation (4.2) as well yielded less satisfactory results than the above model. Including the trade balance or the cumulative inflation differential since the last realignment in (4.1) did not lead to an improvement either. This is probably due to multicollinearity. A model in which the inflation differential enters into the mean equation (4.2) instead of the volatility measure $S D$ yielded satisfactory results but for theoretical reasons, the above model which links excess returns to volatility was preferred.

\subsection{Conclusions}

In this chapter a model for the weekly excess returns on four EMS exchange rates against the $\mathrm{D}$-mark was presented. The structure of the model is similar to that used in previous analyses of the behavior of the exchange rates themselves (see chapter 3). But the present model goes further as it explains excess returns through volatility. The model is a MA(1)-GARCH(1,1)Bernoulli-normal jump process with a mean that depends on the position of the currency in the fluctuation band of the EMS and on volatility, and with a jump intensity that depends on the inflation rate differential. This GARCH in mean-type model performs remarkably well compared to other GARCH in mean models used in finance.

Two major sources for the excess returns are found. The first is uncertainty, measured by the conditional standard deviation of the excess returns, which is influenced to a large extent by the inflation differential. The second source for excess returns is the continuously changing perceived realignment risk. These changes cause the excess returns to be negatively correlated and induce a positive relationship between the position of spot rate in the fluctuation band and the expected excess returns. However, this does not necessarily mean that the market is inefficient. It merely points towards the fact that the market does not always correctly predict the timing of devaluations, which is hardly surprising. Abnormal returns generally arose when the timing or size of a parity realignment was not correctly assessed by the market. 
The model describes the empirical regularities in excess returns remarkably well. It incorporates the linear relationship between expected returns and volatility and the nonlinear relationship between excess returns and the inflation differential, a major economic fundamental, in a very satisfactory manner. It performs remarkably well in explaining at least in part the observed excess returns in terms of increased volatility and increased inflation differentials, a finding which is very much in line with the efficient market hypothesis.

Estimates of the risk premium based on the model show that premia are substantial and highly volatile, reflecting the changing uncertainty present in the EMS. These findings are at variance with those of Svensson (1992b) and Beetsma (1992), who find that the foreign exchange risk premium for an imperfectly credible exchange rate band with devaluation risk is respectively of moderate or of small and constant size. From a macroeconomic point of view, understanding the dynamics of risk premia is important as the higl interest rates associated with large risk premia can lead to an economic slowdown.

Although risk premia are not completely explained by economic fundamentals, our results show that this can at least be partly achieved. Compared with earlier results for free-float currencies, this result is encouraging. The differences are probably due to the fact that EMS currencies always move in the direction of the fundamentals (if they move) whereas free-float currencies might be more frequently subject to speculative bubbles (see figure 2.1 ) which conceal the relationship between risk premia and economic fundamentals.

It should be realized however, that ex-post returns represent both risk premia and deviations between the expected and realized future spot rate. Our results for the MA term and the position in the band show that the market has not always correctly assessed the probability of a realignment. This might very well mean that the market expectation of the future spot rate was systematically biased. In the next chapter, we will use survey data on exchange rate expectations in order to be able to separate risk premia from systematic expectation errors. 


\section{Chapter 5}

\section{EMS credibility and risk premia using survey data}

\subsection{Introduction}

The driving force behind the models for the exchange rates and the excess returns discussed so far, is the market uncertainty about future realignments. In order to investigate whether this factor was indeed important, we will take a closer look at the behavior of market expectations over time. More specifically, we will examine the extent to which market expectations within the EMS were compatible with fixed parities. For this purpose, we will use survey data on EMS exchange ratc expectations between December 1985 and August 1991 for the Dutch guilder, Belgian franc, French franc, Italian lira, Spanish peseta and British pound, relative to the D-mark.

The survey data enable us to investigate the influence of the fluctuation band on expectations by replicating and extending the simplest test of target zone credibility (Svensson, 1991) as well as by testing the basic prediction of the target zone literature (bascd on credibility), that the spot position within the band and the expected change in the exchange rate will be inversely correlated.

Although there is some evidence that the EMS had become more credible between 1985 - 1991, interest differentials appeared to persist, indicating that the system was not fully credible. As already suggested in the previous chapter, the persistence of intra-EMS interest differentials probably reflected risk premia. The availability of the survey data now allows us to construct 
an ex-ante measure of the risk premium, which is not affected by possible expectation errors. We investigate the relationship between the ex-ante risk premium on the one hand, and the inflation differential relative to Germany and a measure of survey uncertainty on the other.

The plan of this chapter is as follows. In section 5.2 we describe actual EMS exchange rates and interest rates as well as the expected exchange rates according to the survey data which we use in our study. In section 5.3 we address the credibility issue. EMS risk premia are examined in section 5.4 and our conclusions are presented in section 5.5.

\subsection{Data-description}

Business International Corporation has been conducting a monthly survey of exchange rate expectations covering a number of currencies relative to the dollar and the D-mark since late 1985. The results of these surveys are published in its Cross Rates Bulletin. For publication purposes, survey participants are asked a few days prior to the end of the month to fax three, six and twelve month ahead expectations of a number of currencies with projections being made from the beginning of the following month.

The approximately thirty participants of the survey are treasurers of multinationals and private banks in four of the world's continents. Although not all participants will provide their views regarding a particular currency, the response rate is at worst 60 percent. The Cross Rates Bulletin reports the geometric mean forecast of the responses received, thus minimizing the effect of extreme forecasts. Unfortunately disaggregated respondent data is not available, although the standard deviation of the respondents' expectations and the spread between the highest and the lowest forecasts is reported. In table 5.1 we report the actual change, the expected change in the exchange rate and the interest differential relative to Germany for the European currencies.

Several interesting findings stand out from table 5.1. Although no formal statistical tests have been conducted, differences in the statistics for the expectations data and the interest differentials suggest, the presence of a contaminating factor, which is by definition the risk premium. Moreover, both the expected and the realized exchange rate changes exhibit nonnormality. Therefore robust testing procedures will be used throughout the chapter. 
Table 5.1: Actual and expected yearly changes in the D-mark rate and in yearly interest rate differentials, December 1985 to August 1991

\begin{tabular}{|c|c|c|c|c|c|c|}
\hline \multirow{6}{*}{$\begin{array}{l}\text { Mean } \\
\text { Variance } \\
\text { Skewness } \\
\text { Kurtosis }\end{array}$} & \multicolumn{6}{|c|}{ The actual change in the exchange rate } \\
\hline & DG & $\mathrm{BF}$ & $\mathrm{FF}$ & IL & SP & $\mathrm{BP}$ \\
\hline & -0.00041 & 0.00046 & $0.01254^{* *}$ & $0.01652^{* *}$ & $-0.01943^{* *}$ & $0.02078^{* *}$ \\
\hline & 0.00001 & 0.00011 & 0.00048 & 0.00053 & 0.00096 & 0.00692 \\
\hline & -0.06701 & 0.46038 & $1.74311^{* *}$ & -0.12623 & -0.21687 & $0.82011^{* *}$ \\
\hline & -0.16317 & -0.19530 & $3.12250^{\star *}$ & -0.41279 & -0.66124 & -0.19102 \\
\hline & \multicolumn{6}{|c|}{ The expected change in the exchange rate } \\
\hline & DG & $\mathrm{BF}$ & $\mathrm{FF}$ & IL & SP & $\mathrm{BP}$ \\
\hline Mean & $-0.00240^{* *}$ & $0.00605^{* *}$ & $0.01159^{* *}$ & $0.01635^{* *}$ & $0.02238^{* *}$ & $0.01705^{* *}$ \\
\hline Variance & 0.00006 & 0.00022 & 0.00021 & 0.00071 & 0.00041 & 0.00065 \\
\hline Skewness & $-0.54539^{*}$ & $0.61799^{* *}$ & 0.12769 & $-0.96965^{* *}$ & 0.19496 & -0.06554 \\
\hline \multirow[t]{3}{*}{ Kurtosis } & 0.33844 & 0.45612 & -0.15052 & $3.02775^{* *}$ & -0.50783 & -0.57811 \\
\hline & \multicolumn{6}{|c|}{ The interest differential } \\
\hline & DG & $\mathrm{BF}$ & $\mathrm{FF}$ & IL & SP & $\mathrm{BP}$ \\
\hline Mean & $0.00529^{* *}$ & $0.02078^{* *}$ & $0.02848^{* *}$ & $0.05292^{* *}$ & $0.06156^{* *}$ & $0.05338^{* *}$ \\
\hline Variance & 0.00002 & 0.00016 & 0.00032 & 0.00051 & 0.00036 & 0.00017 \\
\hline Skewness & 0.46396 & $0.59915^{* *}$ & $1.15419^{* *}$ & $0.76388^{* *}$ & 0.15977 & $-1.25359^{*}$ \\
\hline Kurtosis & -0.99238 & $1.21402^{*}$ & $2.58702^{* *}$ & $1.38838^{* *}$ & -0.16281 & $1.48900^{* *}$ \\
\hline
\end{tabular}

- Apart from the expectations, all data are taken from Datastream. Spot exchange rate quotations originate from Barclays bank. Interest differentials are computed from Eurodeposit rates with a twelve month maturity as reported in the Financial Times. Survey responses for the Spanish peseta began in November 1986

- * ${ }^{* *}$ ) indicates significance at the 10\% (5\%) level (assuming normality).

\subsection{EMS credibility}

Credibility or insufficient credibility has a profound effect on exchange rate expectations in Europe and is a key aspect of the functioning of the EMS target zone. Full credibility of a semi-fixed exchange rate regime like the EMS requires convergence of the economic fundamentals of the participating countries. As stressed in De Grauwe (1992), credibility is closely linked to the analysis of the costs and benefits of relinquishing the exchange rate as a policy instrument. If a country suffers from an external shock, the exchange rate might be the least-cost instrument to adjust the economy. If the government concerned has not yet build up a great reputation for keeping 
fixed parities, economic agents will anticipate a devaluation and adjust their inflation expectations, thereby further worsening the effects of the shock on the economy. Over the eighties the European Monetary System had witnessed a noticeable convergence of the economic fundamentals (see figure 3.1 ), as a result of which it is widely held in the literature that the EMS had gained credibility (e.g. Frankel and Phillips, 1991; Ungerer, Hauvonen, Lopez-Claros and Mayer, 1990; Weber, 1991). This was also reflected in the diminished jump probabilities in the exchange rate models of chapter 3 .

In this section we assess the credibility of the EMS by means of Svensson's (1991) simple test of target zone credibility. Using the 12 -month ${ }^{1}$ euro interest differential of the various EMS currencies relative to the D-mark, we compute the implied expected exchange rate one year ahead and investigate whether this exchange rate forecast lies within the EMS fluctuation band. If the EMS band is perceived by the market to be fully credible, the current actual exchange rate and the future expected exchange rates should both be within the EMS target zone boundaries. This is true even if there are risk premia, since the maximum risk in the absence of devaluations is bounded by the upper fluctuation margin so there is no reason not to exploit interest rate differentials that exceed the maximum depreciation within the band.

In addition to using interest differentials, we use the actual exchange rate prediction for one year ahead, taken from the survey data. These exchange rate predictions provide a direct and concise test for assessing EMS credibility.

In figures one to six we have plotted the actual EMS exchange rates relative to the $\mathrm{D}$-mark, the fluctuation bands, the exchange rate forecast implied by the interest differentials and the actual exchange rate prediction from the survey data set ${ }^{2}$.

In figure 5.1 the Belgian franc is plotted relative to the D-mark. Several points are noteworthy. First, the survey expectations are very volatile, reflecting the constantly changing perceived realignment probabilities. Second, it took until April 1990 for the Belgian franc to become credible within the EMS. In that month the German government agreed on the terms of monetary conversion and union with Eastern Germany, to be enacted July

\footnotetext{
${ }^{1}$ As stressed by Svensson (1991, 1993), tests of credibility should preferably use long term expectations.

${ }^{2}$ The expectations, shown at say January 1990, represent predictions for January 1991.
} 
Figure 5.1: Spot exchange rate and one year ahead forecasts: BF/DM

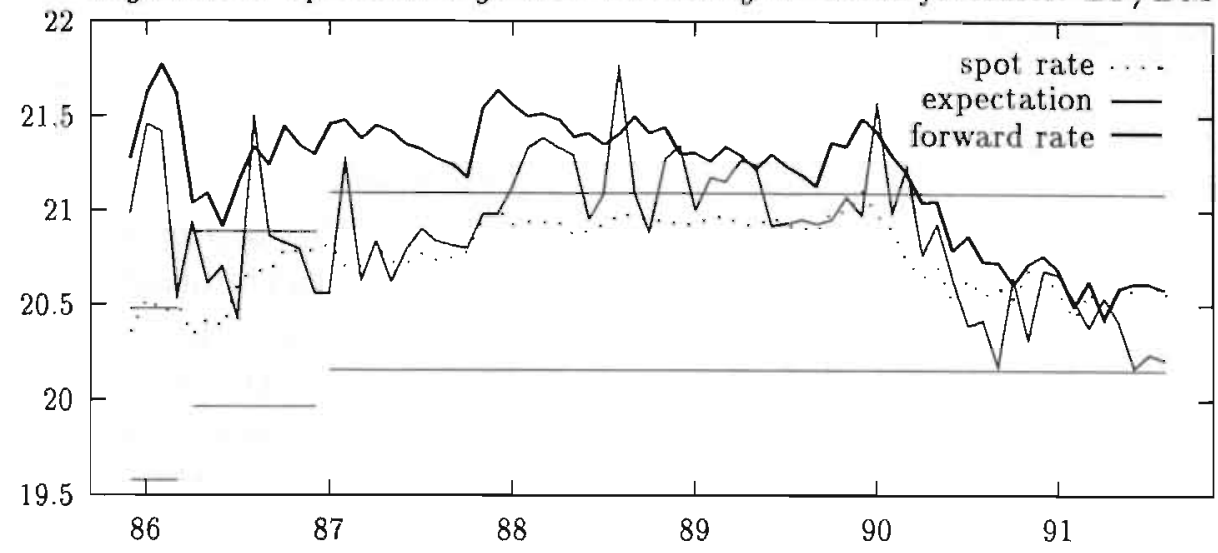

Figure 5.2: Spot exchange rate and one year ahead forecasts: FF/DM

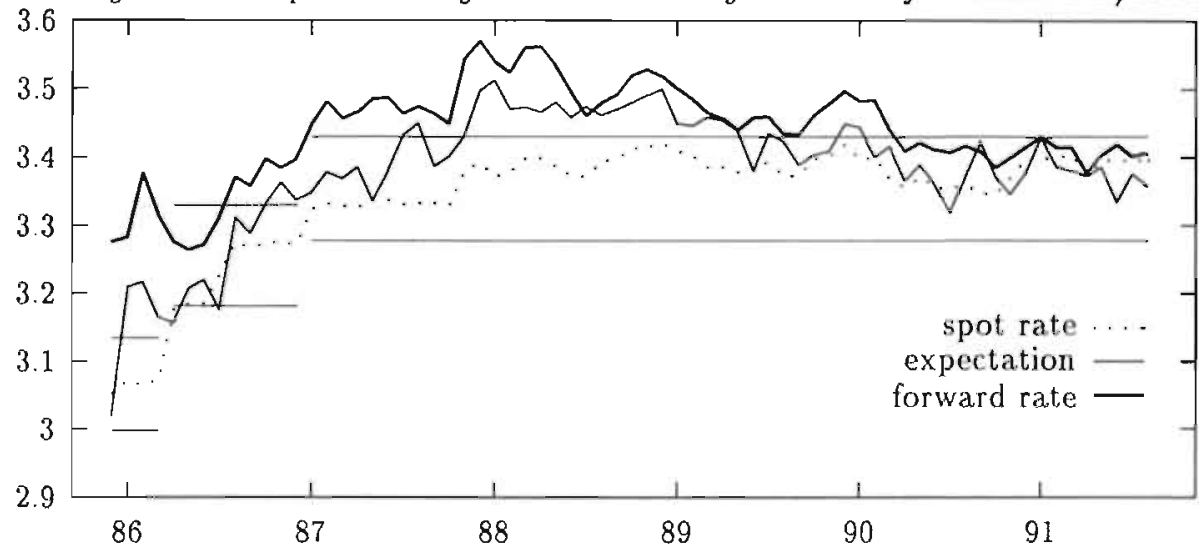

Figure 5.3: Spot exchange rate and one year ahead forecasts: IL/DM

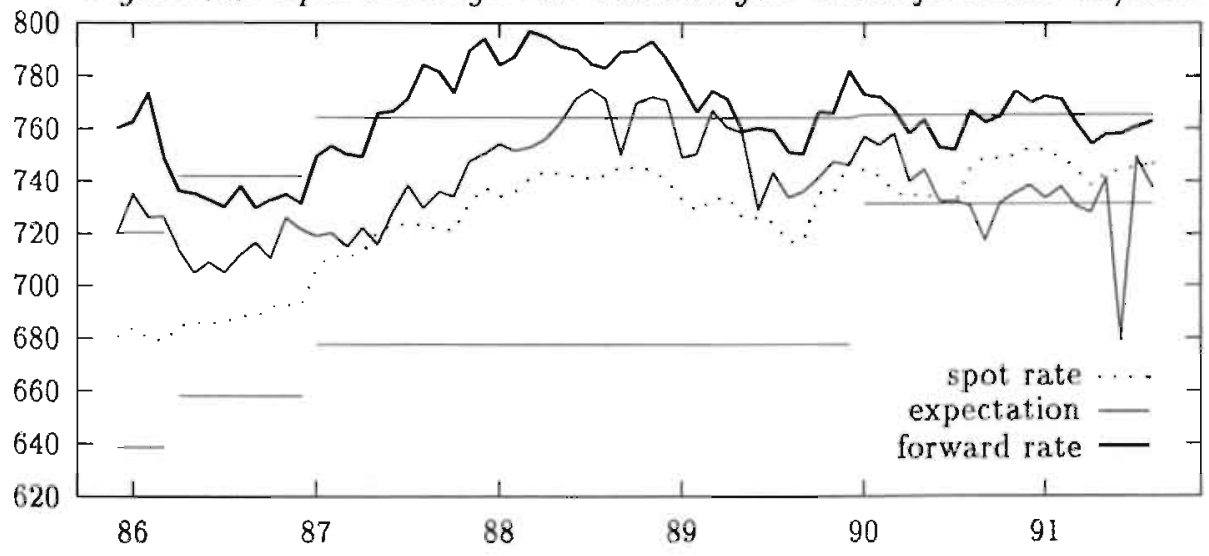


2, 1990. An important ingredient of this monetary union was the conversion rate at which the old East German mark was converted into D-mark. Prior to the unification one. East German mark traded at a rate of 6 East marks for 1 West mark in the black market. Nevertheless, the German authorities decided to use a 1:1 conversion rate for East German wages ${ }^{3}$. Apparently this rate and especially its consequences like a drastic deterioration in East German industries after the unification were viewed as highly problematic in the EMS foreign exchange rate market. Market participants therefore expected a strengthening of the Belgian franc relative to the D-mark. These first two points are visible for all the other currencies as well. Third, in June and July of 1990 the exchange rate forecasts based both on the interest differentials and on the survey data move further towards the center of the official fluctuation band of the Belgian franc. In addition to the effects of the German unification, this increase in credibility appcars to be at least partly the result of the declaration of the Belgian central bank in June 1990 that maintaining the Belgian franc - D-mark exchange rate would be its main policy target.

In figure 5.2 the French franc is shown relative to the D-mark. Although the last realignment of this currency was in early 1987, interest differentials and survey forecasts indicate that it took until April 1990 for the French franc to become credible. This increase in credibility probably reflects the French declaration in March 1990 never to devalue again.

In figure 5.3 the Italian experience is presented. As is apparent, the Italian lira's position in the EMS was not perceived to be credible at any time during the sample period. Both the expected exchange rate based on survey data and the expected exchange rate based on the interest differential lie outside the fluctuation bands. From this point of view it is not surprising that the lira had to devalue in September 1992. The surprising thing is that this devaluation did not occur any sooner.

In figure 5.4 we have plotted the Dutch experience. As is evident from the graph, the Dutch guilder has been credible during the whole sample period, according to expected exchange rates based both on interest differentials and on the survey data.

In figure 5.5 the Spanish experience is presented. This experience is relatively fresh since Spain only joined the exchange rate mechanism of the:

\footnotetext{
${ }^{3}$ For savings, above a certain limit, a conversion rate of $2: 1$ was used.
} 
Figure 5.4: Spot exchange rate and one year ahead forecasts: $D G / D M$

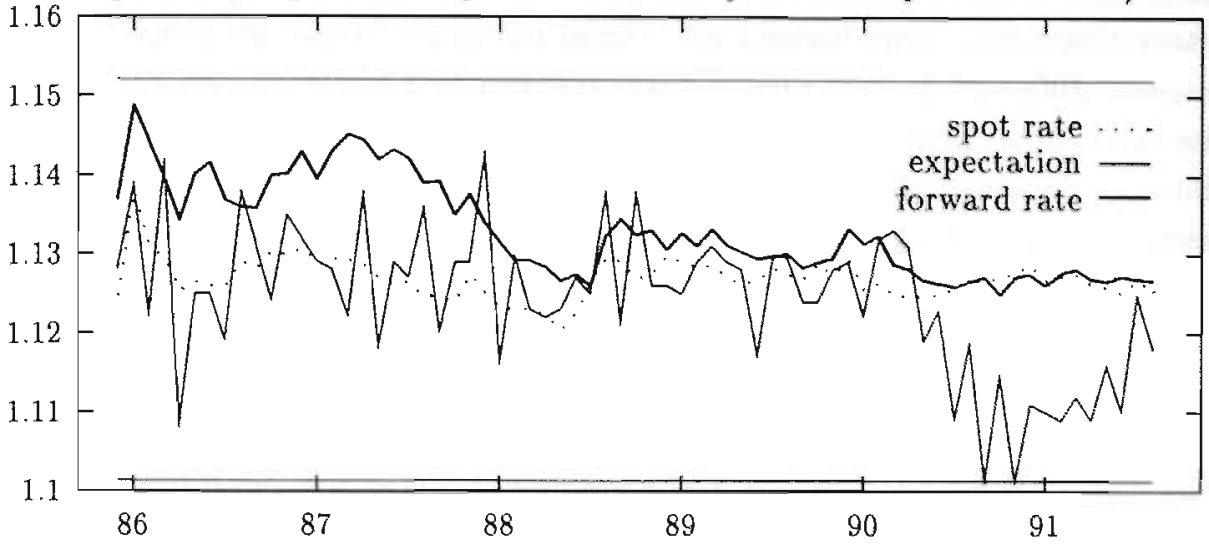

Figure 5.5: Spot exchange rate and one year ahead forecasts: SP/DM

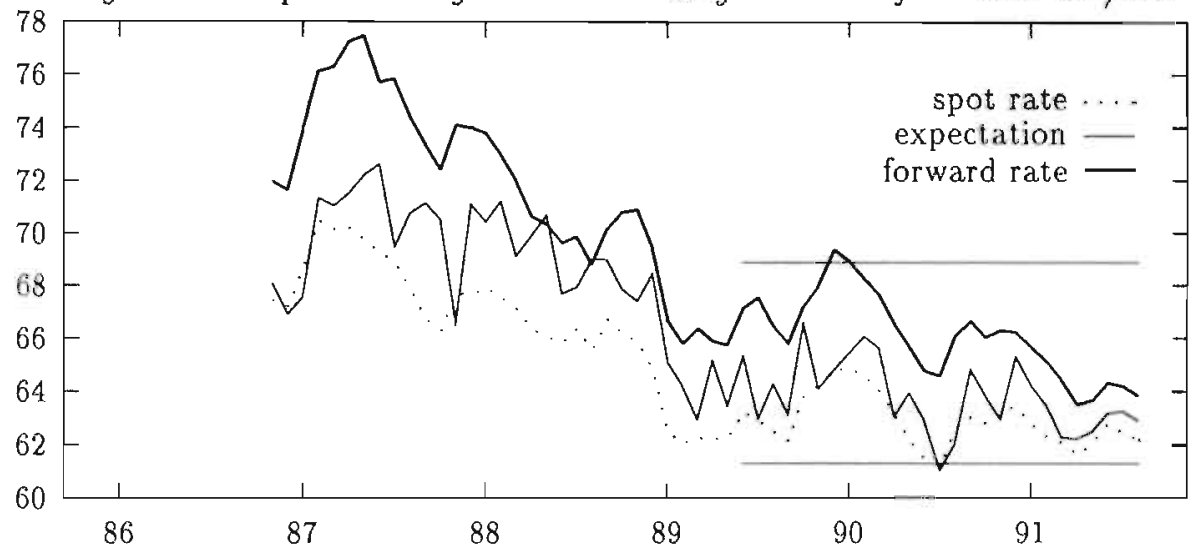

Figure 5.6: Spot exchange rate and one year ahead forecasts: BP/DM

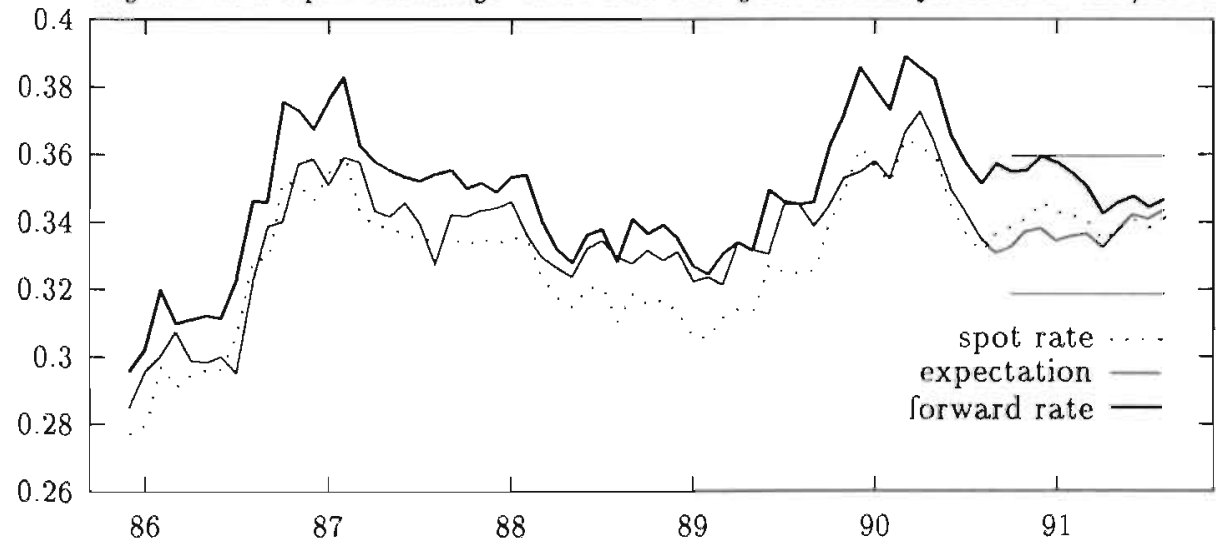


EMS on the 19th of June 1989. Despite this relatively short period, several interesting phenomena become clear from the graph. First, according to the interest differentials and survey data, the Peseta's band was credible from the start. The peseta probably benefitted from the reputation of the EMS that devaluations were no longer common practice. Second, more or less immediately after joining the exchange rate mechanism, the Spanish peseta moved to the lower part of the $6 \%$ fluctuation band, reflecting the strength of this currency ${ }^{4}$.

Finally, in figure 5.6, we present the results for the UK pound. The pound joined the exchange rate mechanism of the EMS on the 8th of October 1990. This had a noticeable effect on exchange rate expectations and interest rates. Moreover, it appears that the British pound had been credible since then according to the various measures.

In summary, we find that the Dutch guilder has been fully credible over the sample period December 1985 to August 1991. For the Belgian and French francs full credibility in the EMS setting dates only from April 1990, after which expectations for these currencies are consistently within the fluctuation band. The Italian lira appeared not to be credible at any time during the sample period: both the forecasts based on interest differentials and the forecasts of the survey data appeared to be frequently above or below the fluctuation band. The two newcomers in our sample, the Spanish peseta and the British pound, appeared to be credible from the start. One reason why these newcomers were perceived to be credible might be the known political resistance to realignments. Both the number, and the average magnitude of the realignments had decreased over the years. Although the main reason for this reduction had been the economic convergence of the economies, it was also quite clear that this convergence was far from complete, especially for the Italian lira. With the Danish rejection of the Maastricht treaty in June 1992, the optimism on the functioning of the EMS started eroding. Tensions continued to build up and reached a climax before the French referendum in September 1992. Italy and the UK experienced severe speculative attacks on their currencies, which led to the suspension of their membership from the system. These events clearly showed that a devaluation can be forced

\footnotetext{
${ }^{4}$ The strength of the peseta was probably due to the very high Spanish interest rates. According to economic indicators such as inflation or trade deficits, the peseta should have been a weak currency.
} 
upon politicians, if the market believes this to be necessary. The intriguing lesson from these recent developments is that credibility, built up in many years, can easily vanish if the underlying fundamentals in the participating countries are not converging and/or if the authorities are not clear on the priority given to exchange rate stability.

In addition to the simplest target zone credibility test, we also test whether EMS exchange rate behavior conformed with the basic predictions of the standard target zone models based on credibility, as developed by Krugman (1991). The target zone literature starts from the observation that due to the forward looking nature of rational agents the presence of an $\mathrm{ex}$ change rate band exerts an influence on the current movements of exchange rates. By adopting a continuous-time framework, assuming normal innovations and a band from which the exchange rate cannot escape, Krugman (1991) showed that the relationship between economic fundamentals and the exchange rate should be S-shaped. The presence of the band and possible intervention by the monetary authorities drives the exchange rate away from the edges towards the center of the fluctuation band. Hence in a fully credible target zone one would expect to find a negative correlation between the spot position of the exchange rate in the band and the expected change in the exchange rate ${ }^{5}$.

While the target zone literature provides an intuitive account of the influence of the band, the empirical validity of these models has not been undisputed. Meese and Rose (1990) test both parametrically and nonparametrically for the presence of the nonlinear terms introduced by the regulated Brownian motion but fail to turn up evidence in favor of these terms. Attempts by other researchers to detect the S-shape have not been successful either.

We use survey data to directly test for the negative correlation. In table 5.2 we present the correlation between the spot position and the expected change for the periods December 1985 to August 1991 and April 1990 to August 1991. We used interest differentials as well as the survey data to make forecasts of the exchange rate changes.

As the table shows, we failed to find evidence for a negative relationship between the spot position and the expected change in the exchange rate for the period December 1985 to August 1991. For the sub-period April

\footnotetext{
${ }^{5}$ For an extensive overview of the target zone literature, see Svensson (1992a).
} 
1990 to August 1991, however, we do find significant evidence of a negative correlation. Using the survey expectations, we find a negative correlation for all currencies, except the Spanish peseta. The results for the interest rate data are less convincing. Here we find a significant negative correlation for the Dutch guilder and the French franc, whereas the negative sign for the Italian lira is not quite significant at the $10 \%$ level. However, all the correlations over the latter period are smaller than over the whole sample period, indicating an increasing credibility. In summary, we find evidence suggesting that exchange rate behavior within the EMS has conformed more closely to the predictions of target zone models since April 1990 and that exchange rate expectations within the EMS are influenced by the band.

Table 5.2: Correlation coefficients between position in band and expected change in the exchange rate

\begin{tabular}{||c|cc|cc||}
\hline \multirow{2}{*}{} & December & 1985 - August 1991 & \multicolumn{2}{|c||}{ April 1990 - August 1991 } \\
\cline { 2 - 5 } & Survey & Interest diff. & Survey & Interest diff. \\
\hline DG & -0.04 & 0.08 & $-0.64^{* *}$ & $-0.79^{* *}$ \\
BF & $0.34^{* *}$ & $0.55^{* *}$ & -0.27 & 0.33 \\
FF & 0.00 & $-0.27^{* *}$ & $-0.52^{* *}$ & $-0.82^{* *}$ \\
IL & 0.14 & 0.19 & $-0.42^{*}$ & -0.37 \\
SP & 0.08 & $0.44^{* *}$ & 0.09 & 0.11 \\
UK & & & -0.46 & 0.36 \\
\hline
\end{tabular}

- Correlations for the Spanish peseta and the British pound are computed with data from June 1989 and October 1990 onwards respectively.

- * $\left(^{* *}\right)$ indicates significance at the $10 \%(5 \%)$ level (assuming normality).

The results reported in table 5.2 are somewhat stronger than the ones obtained by Frankel and Phillips (1991). They computed the same correlations, using survey data on the US dollar over the period February 1988 to July 1991. They found only meager evidence of a negative correlation. The differences might be caused by the use of cross-rates in their study and/or by differences in the sample period.

Although the figures and results in table 5.2 seem to suggest that the EMS had gained credibility between 1985 and 1991, considerable EMS interest differentials persisted. In a fully credible fixed exchange rate regime one 
would expect interest differentials to disappear over time. To deal with this issue, we compare interest differentials with exchange rate expectations, the difference of which is by definition equal to the risk premium.

\subsection{EMS risk premia}

Starting point in our analysis of EMS risk premia is the definition of covered interest parity, which equates the interest differential to the forward discount. Defining $s_{t}$ as the natural log of the spot exchange rate (domestic currency per unit of forcign currency) at time $t$, and $f_{t, t+k}$ as natural $\log$ of forward rate at time $t$ for delivery at time $t+k, i_{t, t+k}$ as the interest rate on a eurodeposit in domestic currency at time $t$ and maturing at time $t+k$, and $i_{t, t+k}^{*}$ as the equivalent interest rate on the foreign currency, then the covered interest parity relation may be stated as

$$
f_{t, t+k}-s_{t}=i_{t, t+k}-i_{t, t+k}^{*}
$$

Assuming market efficiency and rational expectations (and asymmetric risk, see the discussion in section 4.2), the forward exchange rate is equal to the expected future spot rate plus a risk premium, $r p_{t, i+k}$ (see Hodrick and Srivastava, 1984). Equation (5.1), may therefore be restated as follows

$$
E_{t}\left(s_{t+k}\right)+r p_{t, t+k}-s_{t}=i_{t, t+k}-i_{t, t+k}^{*}
$$

As is evident from equation (5.2), the risk premium is by definition equal to the difference between the interest differential and the expected change in the exchange rate. As already described in the previous chapter (see also Dornbusch, 1991), the nature of this risk premium is primarily of the "pesotype" (Krasker, 1980). The argument goes as follows. When some weak EMJ members in the past decided to start following the macroeconomic policies required to converge to Germany, the anchor country, it took some time to convince financial markets of the country's true commitment to the announced policy. Simultaneously, monetary authorities were constrained by their own policies, because devaluations to account for the current inflation differentials would jeopardize the adjustment itself. As a consequence, stable exchange rates - as an indicator of actual policy - were still accompanied by relatively high interest differentials, reflecting the possibility of a policy 
turn-around and an associated devaluation of the weak EMS currency ${ }^{6}$. In order to investigate the relevance of this argument, the relationship between the risk premium and economic fundamentals that influence the devaluation prolrability will be examined.

Apart from the results in the previous chapter, empirical evidence on risk premia in forcign exchange markets, documenting conomic explanations, is extremely scarce. Giovannini (1990), for instance, finds that his measures of the risk premium can explain little, if any, of the interest differential. One major drawback of most previous studies on the risk premium was that these relied on ex post measures of the premium. These results are only valid if the realized future spot rate is an unbiased measure of the expected future spot rate. Especially in the presence of a peso problem, the consequences of this assumption might be severe. The available survey data now allows us to construct an ex-ante measure.

In table 5.3 we present the results of fitting a regression of the risk premia on its lagged values and the lagged inflation differential. As the inflation differential was shown to be a significant variable for the ex-post risk premium in the previous chapter, it is also expected to be of influence for the exante measure. The inclusion of lagged premia follows Wolff (1987) who finds evidence that premia denominated in US dollars are correlated. The past year inflation differential is lagged by two months since consumer price statistics are released with a six to eight week delay.

The $F$ test statistic indicates the existence of fourth order autocorrelation for the Spanish peseta and the British pound. This does not make the results inconsistent however, although robust standart errors have to be used. Therefore, the $t$-values were computed using the Newey-West (1987) procedure.

In accordance with our findings on the ex-post EMS risk premium in chapter 4 , we find significant results for the effect of the inflation differential on the risk premium for the Belgian franc, the French franc and the Spanish peseta $^{7}$. We fail to find evidence for the Italian lira. Another interesting feature, reported in table 5.3 is the significantly positive intercept for sev-

\footnotetext{
${ }^{6}$ This argument suggests that the system is not fully credible.

The finding of a significant inflation effect is also in accordance with the findings of Rose and Svensson (1993), who found the inflation differential to be the only fundamental determining the market expectation of a realignment.
} 
Table 5.3: EMS risk premia and inflation differentials

\begin{tabular}{|c|c|c|c|c|c|c|}
\hline \multicolumn{7}{|c|}{$r p_{t, t+12}=\alpha_{0}+\alpha_{1} r p_{t-1, t+11}+\alpha_{2} r p_{t-2, t+10}+\alpha_{3} i n f d_{t-2}$} \\
\hline & DG & $B F$ & $\mathrm{FF}$ & IL & SP & $\mathrm{BP}$ \\
\hline$\alpha_{0}\left(\times 10^{2}\right)$ & $\begin{array}{c}0.57 \\
(3.18)\end{array}$ & $\begin{array}{c}0.89 \\
(5.09)\end{array}$ & $\begin{array}{c}0.53 \\
(2.54)\end{array}$ & $\begin{array}{c}1.08 \\
(1.19)\end{array}$ & $\begin{array}{c}0.30 \\
(0.36)\end{array}$ & $\begin{array}{c}1.24 \\
(0.97)\end{array}$ \\
\hline$\alpha_{1}$ & $\begin{array}{c}0.04 \\
(0.37)\end{array}$ & - & $\begin{array}{c}0.32 \\
(3.97)\end{array}$ & $\begin{array}{c}0.16 \\
(1.24)\end{array}$ & - & $\begin{array}{c}0.35 \\
(3.62)\end{array}$ \\
\hline$\alpha_{2}$ & $\begin{array}{c}0.29 \\
(3.09)\end{array}$ & - & - & $\begin{array}{c}0.32 \\
(5.11)\end{array}$ & - & - \\
\hline$\alpha_{3}$ & $\begin{array}{c}0.17 \\
(1.52)\end{array}$ & $\begin{array}{c}0.86 \\
(3.78)\end{array}$ & $\begin{array}{c}0.36 \\
(9.93)\end{array}$ & $\begin{array}{c}0.20 \\
(0.98)\end{array}$ & $\begin{array}{c}0.87 \\
(4.98)\end{array}$ & $\begin{array}{c}0.26 \\
(1.08)\end{array}$ \\
\hline$R^{2}$ & 0.27 & 0.18 & 0.32 & 0.17 & 0.31 & 0.15 \\
\hline D.W. & 1.93 & 2.08 & 1.79 & 2.01 & 1.89 & 2.06 \\
\hline$F$ & $\begin{array}{c}0.48 \\
{[0.75]}\end{array}$ & $\begin{array}{c}0.56 \\
{[0.70]}\end{array}$ & $\begin{array}{c}1.80 \\
{[0.14]}\end{array}$ & $\begin{array}{c}0.84 \\
{[0.50]}\end{array}$ & $\begin{array}{c}3.02 \\
{[0.03]}\end{array}$ & $\begin{array}{c}3.04 \\
{[0.02]}\end{array}$ \\
\hline
\end{tabular}

- The sample consists of 67 monthly observations from February 1986 to August 1991, except for the Spanish peseta for which the starting date is Novernber 1986.

- $P$-values and heteroskedasticity and fourth order autocorrelation consistent $t$-values are between brackets and parentheses respectively.

- The $F$ test statistic is a heteroskedasticity consistent test for fourth order autocorrelation (see Wooldridge, 1990).

eral currencies. This probably reflects the German anti-inflation reputation. Even in the absence of actual inflation differentials, the D-mark is preferred to the other currencies.

Inspired by the significant influence of the trade balance in the exchange rates models of chapter 3 , the trade deficit was added as an explanatory variable, but it was found to be statistically insignificant. Another candidate for the premium might be a dummy variable measuring a structural change since April 1990. As we expect the risk premium to be related to devaluation risk, one might expect a structural change in the premium after the EMS had gained credibility in this month. However, no significant change was found for any of the currencies. A possible explanation for this lack of significance might be the multicollinearity with the inflation differential. The entrance to the ERM did not seem to have a significant effect either, both for the British pound and for the Spanish peseta. 
Table 5.4: EMS risk premia: inflation differentials and survey uncertainty

\begin{tabular}{||l|cccccc||}
\hline \multicolumn{6}{||c}{$r p_{t, t+12}=\alpha_{0}+\alpha_{1} r p_{t-1, t+11}$} & \multicolumn{4}{c||}{$\alpha_{2} r p_{t-2, t+10}+\alpha_{3}$ infd $_{t-2}+\alpha_{4}$ spread $_{t}$} \\
\hline \multirow{2}{*}{$\alpha_{0}\left(\times 10^{2}\right)$} & DG & BF & FF & IL & SP & BP \\
\hline \multirow{3}{*}{$\alpha_{1}$} & 0.38 & 0.51 & 0.45 & 0.82 & 0.01 & -1.26 \\
& $(1.82)$ & $(2.34)$ & $(1.71)$ & $(1.02)$ & $(0.01)$ & $(-1.29)$ \\
$\alpha_{2}$ & 0.05 & - & 0.32 & 0.16 & - & 0.24 \\
& $(0.48)$ & & $(4.05)$ & $(1.21)$ & & $(1.91)$ \\
$\alpha_{3}$ & 0.27 & - & - & 0.32 & - & - \\
& $(2.72)$ & & & $(5.69)$ & & \\
$\alpha_{4}$ & 0.14 & 0.75 & 0.36 & 0.18 & 0.89 & 0.43 \\
& $(1.21)$ & $(3.24)$ & $(11.41)$ & $(0.91)$ & $(5.5 .1)$ & $(3.06)$ \\
$R^{2}$ & 0.03 & 0.05 & 0.01 & 0.03 & 0.03 & 0.14 \\
$D . W$ & $(1.46)$ & $(2.37)$ & $(0.58)$ & $(1.23)$ & $(0.36)$ & $(2.15)$ \\
$F$ & 0.31 & 0.24 & 0.32 & 0.18 & 0.32 & 0.24 \\
& 1.93 & 2.13 & 1.79 & 2.01 & 1.91 & 2.08 \\
& 1.96 & 0.35 & 1.62 & 0.96 & 2.85 & 3.07 \\
& {$[0.11]$} & {$[0.84]$} & {$[0.18]$} & {$[0.44]$} & {$[0.03]$} & {$[0.02]$} \\
\hline
\end{tabular}

- For notes, see table 5.3.

In table 5.4, the effects of heterogeneous expectations in the survey are also taken into account. In Frankel and Froot (1990) it is shown that dispersion in expectations, measured by the percentage standard deviation, Granger-causes market volume and volatility. If survey dispersion and market volatility are really positively related, one should expect this dispersion to influence the risk premia as well. Since the survey standard deviation was no longer reported from mid 1990 on, we used the spread between the highest and lowest value as a measure of survey uncertainty. The results are somewhat mixed. Although all the coefficients on survey uncertainty have the expected positive sign, only two out of six are signiticantly different from zero (at the $5 \%$ level) ${ }^{8}$. The results for the inflation differentials in the equation for the risk premia improve significantly for the British pound, so that a highly significant inflation effect on the risk premium is now found for four out of six currencies.

\footnotetext{
${ }^{8}$ The limited significance of the survey spiread could be due to changes in the response rate, which introduces differencesi in the survey uncertainty measure, unrelated to market uncertainty.
} 


\subsection{Conclusion}

In this chapter, survey data on EMS exchange rates between December 1985 and August 199\ were used to investigate EMS credibility and risk premia for the Dutch guilder, the Belgian franc, the French franc, the Italian lira, the Spanish peseta and the UK pound. It was found that, except for the Italian lira, the hypothesis of the simplest test of target zone credibility can not be rejected for the period since early 1990. The results for the Belgian and French francs are especially interesting. For both currencies it appears that, despite the fact that the last realignment was in early 1987, it took until April 1990 for their position in the EMS to become credible. The observed increase in credibility in this month is probably partly due to the expected weakening of the D-mark as a result of the announcement on the terms of monetary conversion and union with East Germany.

As an additional test of EMS credibility, it was investigated whether exchange rate behavior within the EMS was in line with the basic prediction of the target zone literature, that the expected depreciation of a currency will be inversely correlated to its position in the band. This was shown to hold for the Dutch guilder, the French franc and the Italian lira since early 1990.

Although the system had become more credible over the sample period, interest differentials within the EMS persistcd. This probably reflected the presence of risk premia. We explicitly investigated EMS risk premia and found for four out of six currencies statistically significarit relationships between the ex-ante risk premium and the inflation differential relative to Germany. These results are very much in line with the findings for the ex-post risk premium in the previous chapter. Using totally different data (monthly instead of weekly; survey expectations instead of realizations; y'arly premia instead of weekly) and techniques, the inflation differential is shown to be a significant determinant of the risk premium in both specifirations.

Although our sample period was characterized by growing r redibility, the developments following the Danish and French referenda on the Maastricht treaty have clearly shown that this credibility was not lasting. In the next chapter, this sudden loss of credibility will be the subject of investigation. 


\section{Chapter 6}

\section{German interest rates and the European Monetary System}

\subsection{Introduction}

In August 1993 the European Monetary System all but collapsed due to speculative attacks on almost all participating currencies. The relatively small fluctuation margins of $\pm 2.25 \%$ for the bilateral rates were (at least temporarily) enlarged to $\pm 15 \%$, except for the Dutch guilder D-mark rate.

The liberalization of capital flows had made the system extremely vulnerable for speculation. In September 1992 this had already led to successful speculative attacks on the Italian lira and the British pound, which led to the abandonment of these currencies from the systom. There is however an important difference between these currencies and the ones that were under pressure in the summer of 1993. Both the Italian lira and the British pound were probably overvalued. For the lira this was duc to sustained higher inflation rates than Germany, which had led to a real appreriation of the liri against the D-mark of almost $40 \%$ since 1979. For the British pound, the overvaluation was probably due to the very high rate under which the pound joined the exchange rate mechanism. This rate was generally seen as too high. The speculative attacks on the Spanish peseta and the Portuguese escudo might also be explained from overvaluation due to sustained inflation differentials. However, the pressure on the Belgian and French francs, the Danish krone and the Irish punt can not be explained from overvaluation. For several years, the inflation rate for these currencies was lower than the 
German one (see figure 3.1). Moreover, trade balances were historically high (figure 3.2), so there was no clear sign of lack of competitiveness.

If lack of competitiveness was not the reason for the attacks, what than. The removal of capital controls surely made the system vulnerable for speculation, but for it to be successful there has to be agreement among speculators on the target. In the financial press, the high German interest rates are viewed as the main reason for the pressure in the EMS. The argument goes as follows. As the expected depreciation of the D-mark is limited by the fluctuation band ${ }^{1}$, interest rates of the countries participating in the $\mathrm{cx}$ change rate mechanism can hardly be lower than German ones, due to the uncovered interest parity. As long as the German inflation rates were lower than the ones in the other ERM countries, this was not much of a problem since real interest rates could still be relatively low. Now Grrman inflation rates have risen above the ERM level however, the uncovered interest parity condition leads to very high real interest rates in the other countries. These high rates are especially problematic since the economic conditions in most European countries are not very good. GNP growth rates are zero or even negative, and unemployment rates are rising. That this was seen as a major problem can be deduced from especially French attempts to lower domestic interest rates, among others by official statements that the German interest rates had to be lowered as well.

If the high German interest rates are indeed a major cause for the increased tensions, the consequences for the EMS might be severe. The German unification meant large inflationary pressures, primarily in Germany. At the same time, it increased the opportunities for especially the German industry. Although the EMS is not yet a monetary union, the consequences of this asymmetric shock are very similar. The German unification resulted in such asymmetric developments within Europe, that the different countries would prefer different monetary policies. The European community became even less an "optimal currency area" 2 . A change in the parities would not be of help in this situation, since it would not change domestic interest rates. An enlargement of the fluctuation band might have been inevitable in this

${ }^{1}$ Due to the reputation of the Bundesbank, the probability of a devaluation of the D-mark can be considered zero.

${ }^{2}$ For the assessment of the European Community as an optimal currency area see Bayoumi and Eichengreen (1993), Eichengreen (1992) and De Grauwe and Vanhaverbeke (1991). 
case. Furthermore, the desirability of the European Monetary Union might come into question.

In order to investigate this possibility we need a good measure of the interest rate, the ERM countries would have preferred if they should not have been constrained by the German interest rate. However, in practice, we do not observe these domestically preferred interest rates since interest rates are almost entirely based on the uncovered interest parity condition with the D-mark. In this chapter, the observed German interest rates will be used to assess an optimal interest rate policy. A reaction function for the German call money rate will be estimated, accounting only for the response to the domestic German situation, and this reaction function will then be used to determine the "optimal" interest rate in the other ERM countries. Thereby, it will be implicitly assumed that the Bundesbank is both able and willing to determine its own interest rates, regardless of the rest of the world. Furthermore, it will be assumed that the central banks in the other ERM countries would have reacted according to the same reaction function if they could have followed a fully independent monetary policy themselves.

First it will be investigated whether German interest rates were indeed historically high since the German unification, given the domestic German situation. Second, the same reaction function will be used to simulate the "optimal" interest rates in the other ERM countries, based on their domestic situation. Third, the difference between this simulated rate and the expected German call money rate, which can be interpreted as an indicator of the costs of losing monetary independence due to the membership of the ERM, will be used as an extra explanatory variable determining the jump probability in the model for weekly exchange rate changes, developed in chapter 3. 


\subsection{A reaction function for German interest rates}

\subsubsection{Relevant variables in the reaction function}

Before formulating a rcaction function for the German monetary policy, it is important to realize the purposes of this function for our investigations. 'These purposes are twofold. First, we want to investigate whether the German monetary policy changed, due to the German unification. Second, we want to compare the (ierman interest rate with the interest rate the other European countries would prefer, given their domestic situation. Especially this second purpose constrains the possible candidates for this reaction function since only variables reflecting domestic circumstances are to be included. Moreover, these variables should be easily comparable between countries.

The main goal of monetary policy of the Deutsche Bundesbank is to ensure the stability of the price level ${ }^{3}$. Furthermore, the Bundesbank has to support the economic goals of the Federal Government as long as this does not conflict with its primary task. These goals comprise among others balance of payments equilibrium, a high level of employment and a reasonable economic growth rate. In order to achieve thesn tasks, the Bundesbank has several instruments at its disposal in the form of discount policy, lombard policy, open market policy and the minimum reserve policy.

In this chapter the German call money rate will be modeled. The main reason for choosing the call money rate is the importance of this rate for the other ERM countries. Market rates are of direct interest for the other countries, whereas for instance the German discount rate is only important through its effect on the market rates. Moreover market rates are easily comparable between countries, whereas for instance discount rates are not since the importance of discount rates depends on the conditions under which banks can make use of these rates. The call money rate is the most appropriate market rate to model in a reaction function since it is more directly influenced by the central bank than longer term rates.

As price stability is the main objective, the inflation rate will be an important factor in the reaction function. Price stability can also be controlled in the long run by means of the money supply. Since 1985 the Bundesbank

\footnotetext{
${ }^{3}$ Paragraph 3 of the 'Gesetz über die Deutsche Bundesbank, 1957'
} 
publishes official targets for broad money (M3). However, the money supply is only an intermediate objective and in practice, policy has concentrated more on the final target, that is the inflation rate, than on the money supply (see Schächter and Stokman, 1992). Moreover, since our objective is to translate the German reaction function to other ERM countries, the money supply might not be very suitable, since the velocity of money might be different for different countries.

The macro variables unemployment and GDP growth rate are difficult to interpret. It is most likely that what is considered "reasonable" changes through time. Moreover, not only the present state matters, but also, or even more, the expected development of these variables in the near future. In our model, these variables will be represented by a business cycle indicator. This indicator also incorporates expected future developments and might be less sensitive for the changing perceptions of reasonable growth and unemployment. A relationship between the business cycle and interest rates does not necessarily mean that the Bundesbank neglects inflation during a recession. It is very likely that expected inflation is lower during a recession so that interest rates can be lowered ceterus paribus, without endangering inflation targets.

As to the target of balance of payments equilibrium, we decided to use the current account surplus as a percentage of GDP. A current account deficit is expected to result in higher interest rates, in order to decrease demand and as such imports. Previous studies (see among others Schächter and Stokman, 1992), found this variable to be of more importance than the basic balance. However, for our purpose there might be a problem with this variable as the interpretation of a current account deficit might be different for different countries.

Balance of payments deficits (or surpluses) might also be due to structural deviations from purchasing power parity. 'These deviations might for instance be due to sustained higher interest rates in Germany than abroad. If this is really the case, current account deficits might better be responded to by means of a decline in interest rates. In several studies this possibility is circumvented by including the US dollar interest. rate as an extra explanatory variable. However, as our main objective is to determine a "desired" interest rate, based only on domestic circumstances, we will not include this variable. In order to validate this decision, we have to assume that the German Bun- 
desbank is both able and willing to determine its own interest rate policy, regardless of the rest of the world. In the literature, there is some evidence of this German dominance hypothesis. Henry and Weidmann (1993) found that since the German unification, German interest rates are no longer influenced by interest rates in both France and the US. Before the unification however, there was both a long run (cointegration) and a Granger causal relationship from the US interest rates to the German interest rates, and vice versa. This study does not include variables other than interest rates, so it might be the case that the causal relationships are the result of a third factor affecting both interest rates in a similar fashion (for instance oil price changes).

Finally, German interest rates might also be influenced by the other countries in the European Monetary System. Again, these reactions are assumed to be absent. This is valid under the asymmetry assumption. Several studies have confirmed this asymmetry within the ERM, meaning that German interest rates cause interest rates in other ERM countries, but not the other way around. Biltoft and Boersch (1992), find support for this assumption, especially since 1987, using Granger causality tests on daily data. Bruneau, Dauphin, Jondeau and Nicolai (1992) use the concept of neutrality (tests for zero terms in the long-run impulse response function) to assess the asymmetry in German and French interest rates. They also find evidence in support of asymmetry. Henry and Weidmann (1993) also confirm asymmetry using both Granger causality tests, neutrality tests and long-run (cointegration) test on daily data.

To conclude, we specify the reaction function as a relationship between the German call money rate on the one hand and the inflation rate, a business cycle indicator and the current account on the other.

\subsubsection{Econometric issues}

In order to find a proper functional form for the above specification, we first take a look at the data. Table 6.1 contains augmented Dickey.Fuller statistics for the German call money rate $\left(r_{t}\right)$, the inflation rate $\left(\right.$ inf $\left.f_{t}\right)$, the business cycle indicator $\left(b u s_{t}\right)$ and the current account as a percentage of GDP $($ cur $)$. The sample consists of 135 monthly observations from April 1979 (the start of the ERM) to June 1990. The end date is chosen this way since in July 1990 the German monetary union with its conversion rate of one 
East-mark for one D-mark was enacted ${ }^{4}$. This conversion rate, which was decided on against the advise of the Bundesbank, was generally seen as highly problematic since it was not in line with East German productivity levels. This unification might very well have led to a change in the German interest rate policy as East-German (consumptive) demand became an important extra source for inflation.

Table 6.1: Augmented Dickey-Fuller test statistics
\begin{tabular}{||c|cccc|}
\hline & $r_{t}$ & inf $_{t}$ & bus $_{t}$ & cur $_{t}$ \\
\hline$\hat{\tau}_{\tau}$ & -1.62 & -1.82 & -3.14 & -1.80 \\
\hline
\end{tabular}

- The sample consists of 135 monthly observations from April 1979 to June 1990.

- The test was performed with a constant, a trend and three lags of the differenced series.

- The $10 \%$ critical value is -3.15 .

As shown in table 6.1, all series investigated contain a unit root, meaning they are difference-stalionary. If there exists a linear combination of these variables that is stationary, these variables are said to cointegrate. This combination then determines a long-run "equilibrium" since actual developments can only deviate from this relationship in the short run but not in the long run (otherwise the combination would not be stationary).

Since the introduction of cointegration (Engle and Granger, 1987) it has been one of the most important research areas in both theoretical and applied econometrics. On the theoretical side many different approaches have been advocated for the efficient estimation and testing of cointegrating relationships. In an overview, Phillips and Loretan (1991) investigate the different approaches from the viewpoint of efficiency, both asymptotically and in finite samples. Campbell and Perron $(1991,1992)$ provide rules the applied researcher should follow when modeling cointegrating relationships. Despite these (and other) overviews several questions remain unanswered. Among these is the question whether we should start with a full system based on an unrestricted vector autoregression (VAR) or with a partial or single equation framework (see Urbain, 1993 for an example). The unrestricted VAR

\footnotetext{
${ }^{4}$ Using data up to October 1989 (before the fall of the Berlin wall) or March 1990 (announcement of the terms of the unification) only did not significantly change the results.
} 
approach, proposed by Johansen $(1988,1991)$ and Johansen and Juselius (1990) has the advantage of being asymptotically efficient and that restrictions are easily checked. Partial systems however are easier to handle since they are of a lower dimension. Moreover, if the number of cointegrating relations is correctly assessed and weak exogeneity conditions are satisfied, it can be shown that partial systems have similar optimal properties (Johansen, 1992; Boswijk, 1992). Incorrect exogeneity assumptions however, invalidate any subsequent inference.

For our analysis, we are only interested in a reaction function for German interest rates, and not so much in a model for inflation. So preferably we use the single equation framework. In order to statistically validate this approach, we first have to check whether there is only one cointegrating relation between these variables, and whether the weak exogeneity assumptions hold. Moreover, we will use our model for the German interest rates to predict interest rates in both Germany and the other ERM countries by means of dynamic simulations, conditional on the observed inflation rate, business cycle indicator and current account. This conditioning is only meaningful if interest rates do not Granger cause the conditioning variables. This means that the conditioning variables have to be strongly exogenous for the interest rate (see Engle, Hendry and Richard, 1983). Therefore, we will start our analysis from the unrestricted VAR. First it will be checked whether the number of cointegrating relations is indeed one, then the strong exogeneity assumptions will be tested by means of the Mosconi-Giannini (1992) procedure. If these assumptions are not clearly rejected, we will proceed with a single equation error-correction model.

\subsubsection{Empirical results}

The starting point of the system approach, advocated by Johansen, is the unrestricted Gaussian VAR of the $k$-dimensional vector time series $x_{t}$, written in error correction form

$$
\Delta x_{t}=\mu+\Pi x_{t-1}+\sum_{i=1}^{p-1} \Gamma_{i} \Delta x_{t-i}+\varepsilon_{t}
$$

where $\varepsilon_{t}$ denotes a $k$-dimensional normal variate with mean zero and covariance matrix $\Sigma$. The number of cointegrating relationships is given by the rank of the $\Pi$ matrix. This rank can be estimated by computing the empirical canonical variates of $x_{t-1}$ with respect to $\Delta x_{t}$, corrected for short term 
dynamics and deterministic components. The number of significant canonical correlations can be determined by means of a sequence of likelihood-ratio $(L R)$ statistics whose limiting distribution is a function of vector Brownian motions (see Johansen, 1988, 1991). Table 6.2 shows the $L R$ statistics 'trace test' and 'maximum eigenvalue' for our data. The difference between the two tests is the alternative hypothesis against which is tested. The trace test has the full $\operatorname{rank}(k)$ as its alternative whereas max. eigenvalue tests $\operatorname{rank}(\Pi) \leq j$ against $\operatorname{rank}(\Pi)=j+1$. The order of the VAR system was determined at three, based both on likelihood ratio tests and the Akaike information criterion. Seasonal dummies and a linear trend were found to be insignificant, so they were excluded. The maximum eigenvalue tests indicates the presence of one cointegrating relationship between these four variables (at the $10 \%$ level), whereas the significance level for one cointegrating vector for the trace test is just above the $10 \%$. These low significance levels might be due to the clear ARCH effects in the call money rate, which badly affects the power of the tests (Gardeazabal and Regúlez, 1992, p.102).

Table 6.2: Cointegration rank tests

\begin{tabular}{||ccc||}
\hline Trace Test & $H_{0}$ & Max. Eigenvalue \\
\hline 1.799 & $\mathrm{r} \leq 3$ & 1.799 \\
5.681 & $\mathrm{r} \leq 2$ & 3.881 \\
22.006 & $\mathrm{r} \leq 1$ & 16.325 \\
49.705 & $\mathrm{r}=0$ & $27.699^{*}$ \\
\hline
\end{tabular}

- The tests were performed with a VAR order of 3 , a restricted constant and no seasonal dummies.

- * $\left({ }^{* *}\right)$ indicates significance at a $10 \%(5 \%)$ level.

The finding of just one cointegrating relationship is the first condition for a single equation analysis to be appropriate. Next, the exogeneity properties are examined. Given the rank of the $\Pi$ matrix $(r)$, $\Pi$ can be written $\Pi=\alpha \beta^{\prime}$, where both $\alpha$ and $\beta$ are $(r \times k)$ matrices of full column rank. The rows of $\beta^{\prime}$ are the cointegrating vectors while columns of $\alpha$ contain the factor loadings, i.e. the weights of the cointegrating vectors in the different equations. A variable is said to be weakly exogenous for a particular cointegrating relationship if the corresponding element of $\alpha$ is zero for this variable. If the right number of cointegrating relationships has been determined, restrictions on $\alpha$ or $\beta$ can be tested by means of $\chi^{2}$ distributed likelihood ratio statistics. Since for our analysis, absence of Granger causality is also required, 
we will test simultaneously for restrictions on $\alpha$ and the short term dynamics. This can be done by means of the Mosconi-Giannini (1992) procedure, which explicitly takes account of the cointegration rank both under the null and the alternative hypothesis. The appropriate test statistic for this case, which is $\chi^{2}(10)$ distributed, is 19.914 , so the strong exogeneity assumption is rejected at the $3 \%$ level. This rejection is probably due to the current account which does not seem to be weakly exogenous for the cointegrating relationship. However, the importance of the current account in the system can be questioned since null restrictions on the concerned elements of the $\beta$ and/or $\Gamma$ matrices are not rejected at the $5 \%$ level. We will proceed with a single equation error correction model to test for the significance of the current account for the interest rate. Weak exogeneity and (Yranger causality will be tested for (see Boswijk, 1992, Chapter 5).

Table 6.3 contains results for three different singlc equation error correction models. The first is the unrestricted intercst rate cquation of the system approach, conditional on the weak exogeneity of the other variables.

$$
\Delta r_{t}=\alpha\left(r_{t-1}-\beta_{0}-\beta^{\prime} z_{t-1}\right)+\gamma_{0} \Delta z_{t}+\sum_{i=1}^{2} \gamma_{i} \Delta x_{t-i}+\nu_{t}
$$

where $z_{t}^{\prime}=\left\{\text { inf } f_{t}, b u s_{t}, \text { cur }_{t}\right\}^{\prime}, x_{t}^{\prime}=\left\{r_{t}, z_{t}\right\}^{\prime}$ and where $\gamma_{i}$ is a rowvector of the appropriate order. The weak exogeneity hypothesis is clearly rejected, using both the Lagrange Multiplier ( $L M$-weak, see Boswijk, 1992, chapter 5) or $F$-form of the Wald statistic ( $F$-weak, see Johansen, 1992). The hypothesis of no Granger causality is not rejected. These results are in accordance with the results from the multivariate analysis. As the data clearly exhibits ARCH-like heteroskedasticity and non-normality, heteroskedasticityconsistent covariance matrices were used. The VAR order of three seems to be appropriate to model the short term dynamics, as the $F$-test for residual autocorrelation is not significant. The assumed change in policy after the German unification is not detected by the Chow test.

As to the coefficients of the model, we see that none of the short term dynamic variables is significant individually. $F$-tests for joint significance of sub-sets of these variables were also found to be insignificant. That is why we re-estimated the model without the differenced variables. The models for the conditioning variables were not changed. The results are shown as the second model. The results are very similar. The weak exogeneity assumption is even more strongly rejected. This rejection is primarily due to the current account 
Table 6.3: Single equation models for the German call money rate

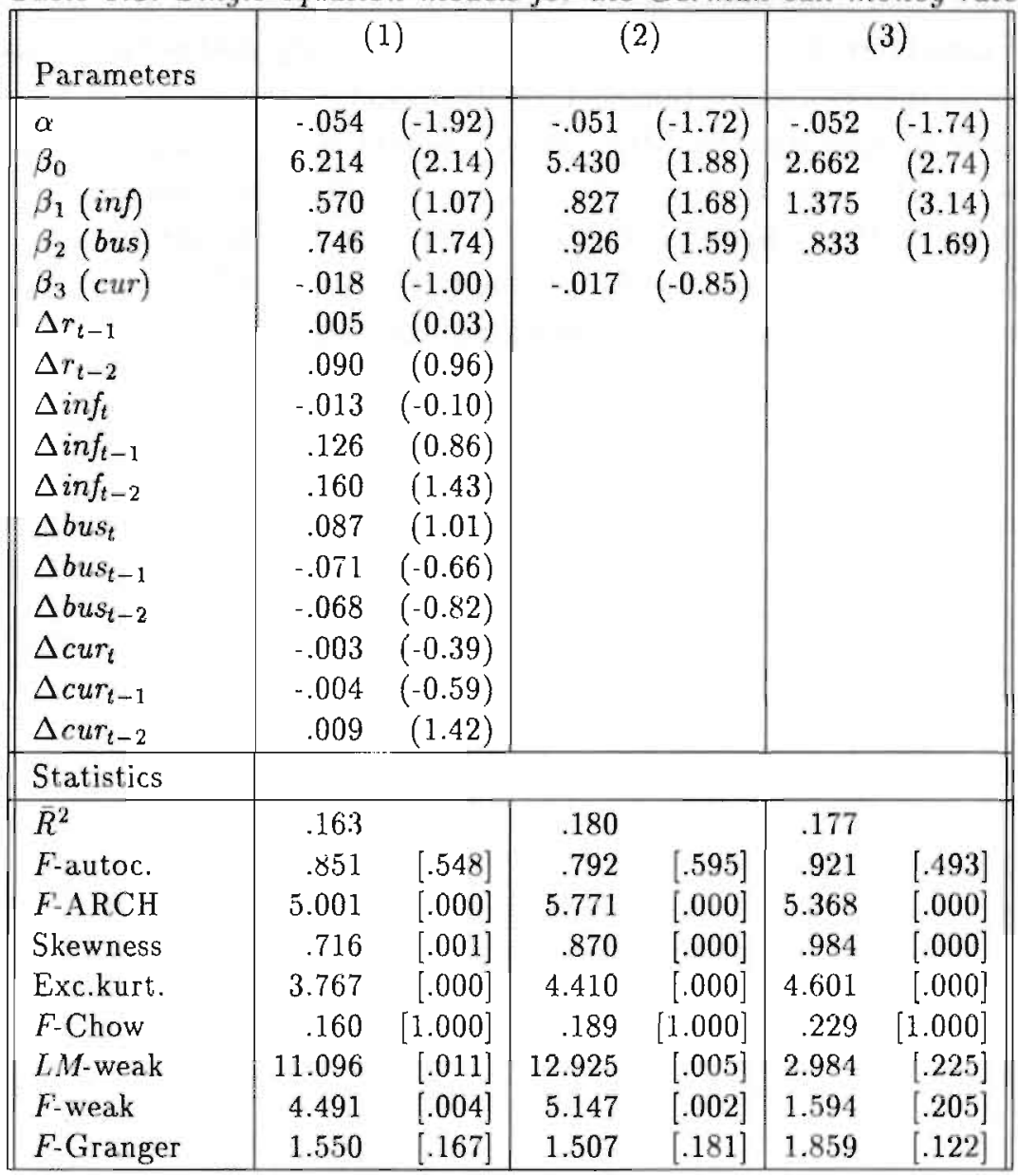

- The sample consists of 135 monthly observations from April 1979 to June 1990.

- $P$-values and heteroskedasticity-consistent $t$-values are in square brack ets and parentheses respectively.

- Fautoc. and $F$-ARCH are $F$-tests for seventh order autocorrelation and ARCH effects respectively.

- F-Chow tests for predictive failure for the sample 90:7-93:6.

- $L M$-weak and $F$-weak are the $L M$ and the $F$-form of the Wald statistic. for weak exogeneity (Boswijk, 1992, Chap.5). They are computed with heteroskedasticity-consistent covariance matrices.

- F-Granger is a heteroskedasticity-consistent test for the joint significance of $\Delta r_{t-1}$ and $\Delta r_{t-2}$ in the marginal models of the conditioning variables. 
equation. The influence of the current account on the interest rate can be questioned however. The absence of weak exogeneity makes traditional inference on the error-correction coefficients invalid, so the $t$-value of -0.85 is as such only an indication that the current account is not a significant variable for the interest rate. However, also after a correction for endogeneity of curt (see Boswijk, 1992, chapter 6.3.2) ${ }^{5}$, the coefficient remains insignificant. The lack of significance might be due to the fact that there has been a current account surplus for most of our sample, whereas earlier research (see among others Schächter and Stokman, 1992) indicates much stronger results for a deficit than for a surplus. Moreover, as the influence of the current account on the desired interest rate policy might very well be different for different countries, we decide to drop the current account as an explanatory variable.

That brings us to our final model, indicated (3). For this model the weak-exogeneity hypotheses are no longer rejected. (iranger causality is no problem either, so we can use the model for dynamic simulations. There are strong indications for ARCH-effects and non-normality however. This makes the estimators less efficient, but not inconsistent, although robust standard errors have to be used. The deletion of the differenced variables has not led to significant correlation in the residuals.

As to the coefficients, both the inflation rate and the business cycle indicator significantly influence the interest rate. The magnitude of the inflation parameter (1.38), which can be interpreted as the long-term semi-elasticity of inflation, is very much in line with earlier studies on the German discount rate. Black (1983) found a long-term semi-elasticity of 1.21 , using data for 1963 to 1979 and Willms (1983) of 1.31 for data from 1973 to 1982. The speed of adjustment of the interest rate to its "long-run equilibrium" is only $5.2 \%$ a month. This means that it takes more than a year before only half of an adjustment is realized.

The overall fit of this reaction function is shown in figure 6.1, which compares the actual call money rate with a dynamic simulation. This simulation is based on the actual values for inflation and business cycle and the predicted value for the interest rate. The reaction function seems to explain the actual developments rather well. The sudden increase in the interest rate in 1981 was not predicted. This increase was due to a sharp rise in the interest

${ }^{5}$ This updating formula for the long term parameters is only available for homoskedastic normal standard errors, which makes the results difficult to interpret for our case. 
rates in the United States, due to a change in monetary policy after Reagan had been elected for president.

Figure 6.1: Realized and simulated German call money rate

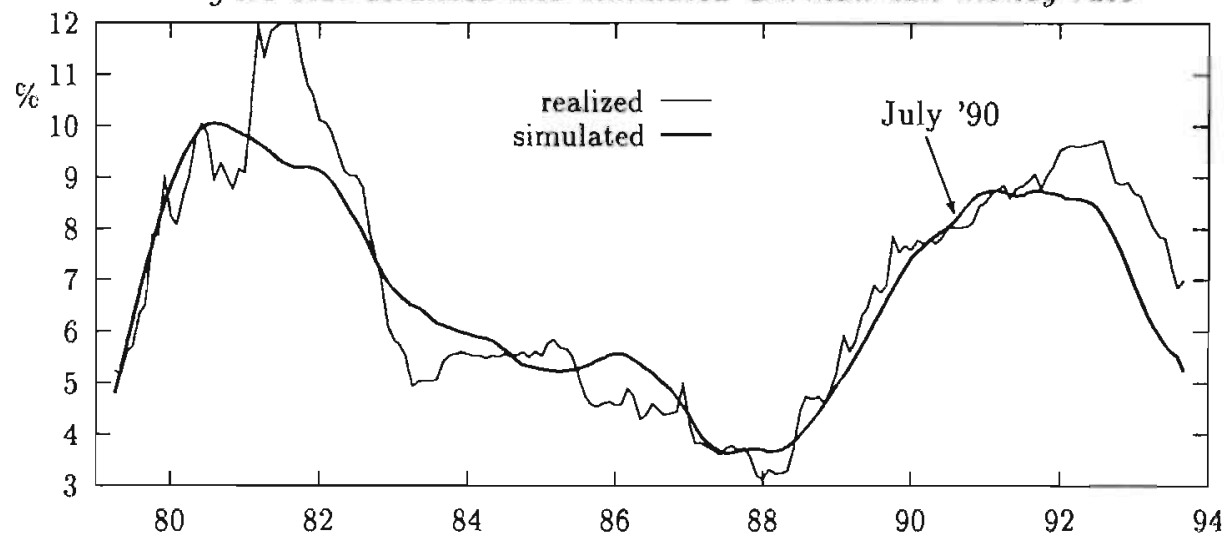

The German unification has not immediately led to a change in the interest rate policy. Only at the end of 1991, the call money rate starts rising above the predicled value. Since then, the actual rate has been 1.5 to $2 \%$ higher than predicted from the reaction function over 1979 to June 1990. This does not necessarily mean that the Bundesbank has been over anxious for inflation lately. The German unification, with its very large capital transfers to Eastern Germany, became a very important extra source of inflation. The German inflation rate has indeed risen to relatively high figures of over $4 \%$. So, a change in the interest rate policy might very well have been appropriate from a domestic point of view. One might even say that the Bundesbank was rather late in its response.

This extra source of inflation is of course only important for Germany and not for the other ERM countries. However, within the exchange rate mechanism of the EMS higher German interest rates have to result in higher interest rates in the other countries as well, due to the uncovered interest parity. In the next section, the consequences for the EMS of this asymmetric shock will be investigated. 


\subsection{Implications for other EMS countries}

\subsubsection{The desired interest rate from a domestic perspective}

In this section, the reaction function of the Bundesbank will be used to determine the preferred interest rate, solely based on domestic circumstances, for the other European countries. This domestically preferred rate will then be compared with the German interest rate. The membership of the exchange rate mechanism restricts the European countries in their monetary policy. The importance of this loss of monetary independence depends among other things on the extent to which the preferred monetary policy from a domestic point of view conflicts with the policy induced by the system.

The extent to which a German reaction function can be used to determine the optimal policy for other European countries might be questionable for a number of reasons, so the results should be interpreted carefully. Given the low inflation reputation of the Bundesbank, it is very well possible that other central banks would prefer a lower interest rate than the Bundesbank in similar circumstances. Furthermore, different preferences may also be due to differences in the effectiveness of the monetary policy. Also, it should be realized that Germany inflation was at most $7 \%$, so the functional form of the reaction function might be different for high inflation levels.

Notwithstanding these pitfalls, it is still interesting to compute the resulting interest rates for the other countries, if it is only to show that French complaints on the German interest rate do have some ground. Furthermore, if the European Monetary Union is to be created, there can only be one interest rate for all the participating countries. Therefore, it is important to know whether the preferred interest rate is similar across countries.

In figure 6.2 , the simulated call money rates for the different ERM countries are shown, together with the corresponding actual rates and the German rate. Several things are striking in these charts. First of all, the fit of the simulated rate is remarkably good for several currencies, although the very wild short term fluctuations are not mimicked. This indicates that most of the time, the "optimal" interest rate from a domestic point of view did not conflict with the restrictions imposed by the exchange rate system.

Second, for most countries the actual call money rate was slightly lower than the simulated rate. This might reflect the anti-inflation reputation of the 
Figure 6.2: Realized and simulated call money rates
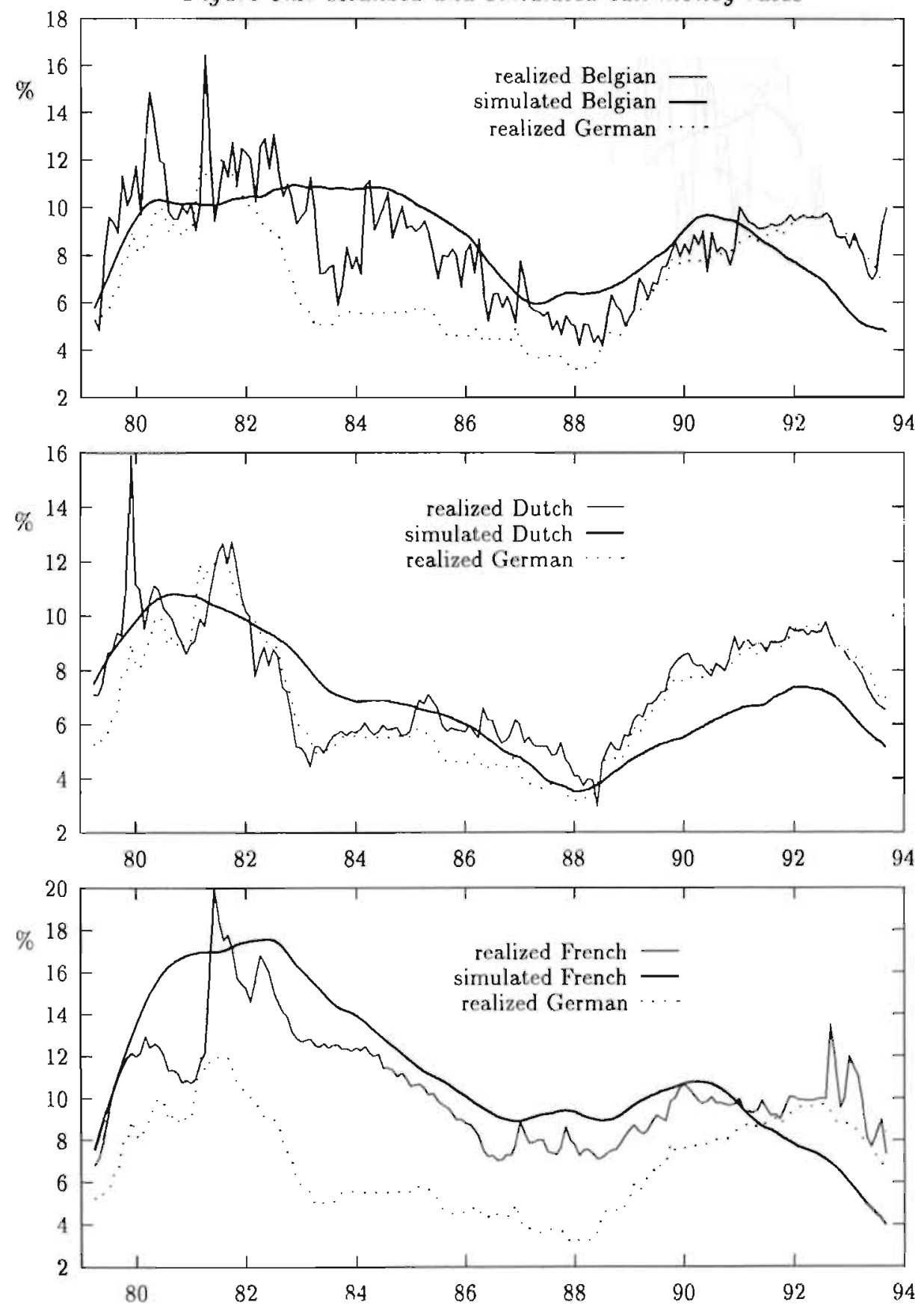
Figure 6.2 continued: Realized and simulated call money rates
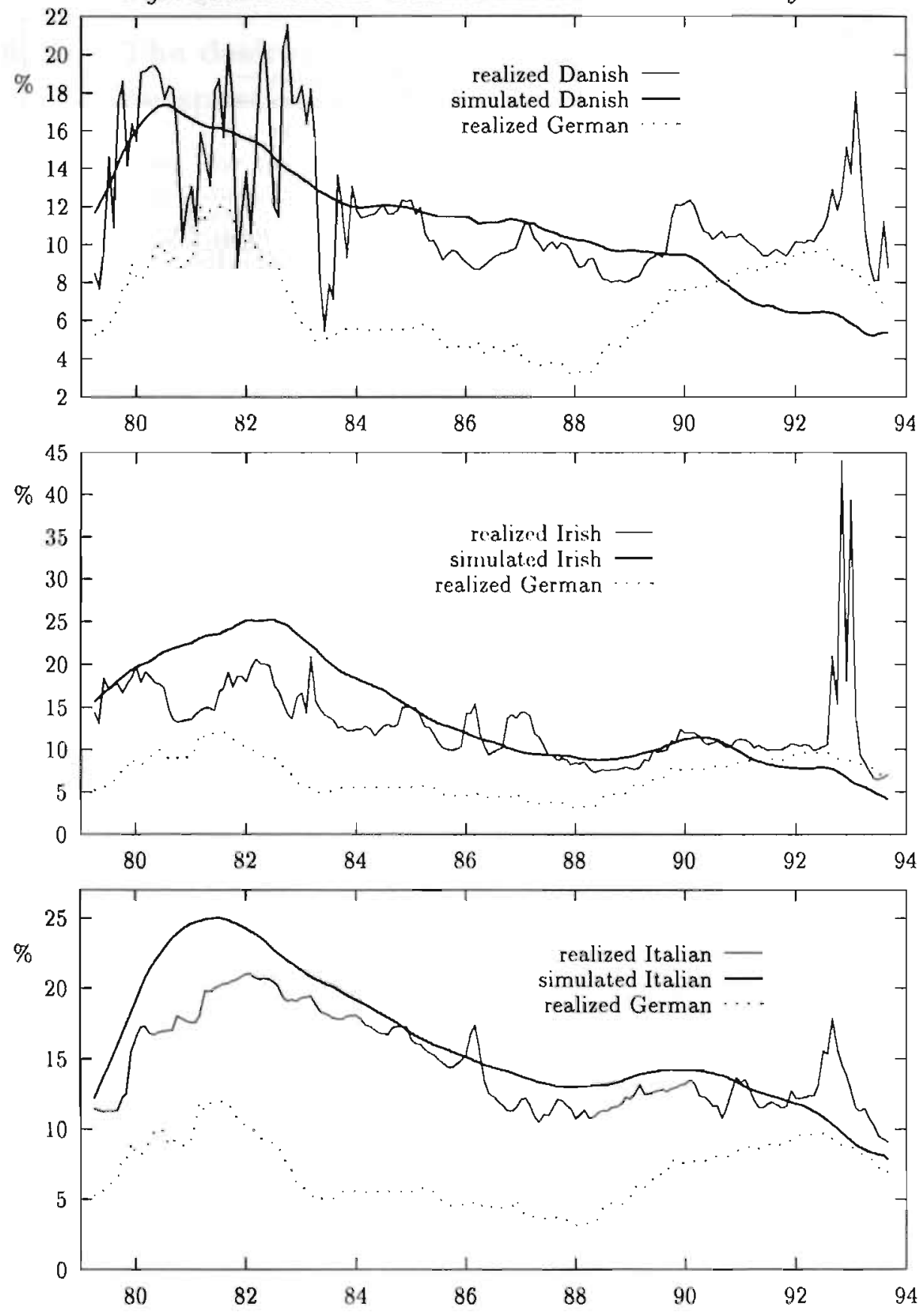
Figure 6.2 continued: Realized and simulated call money rates
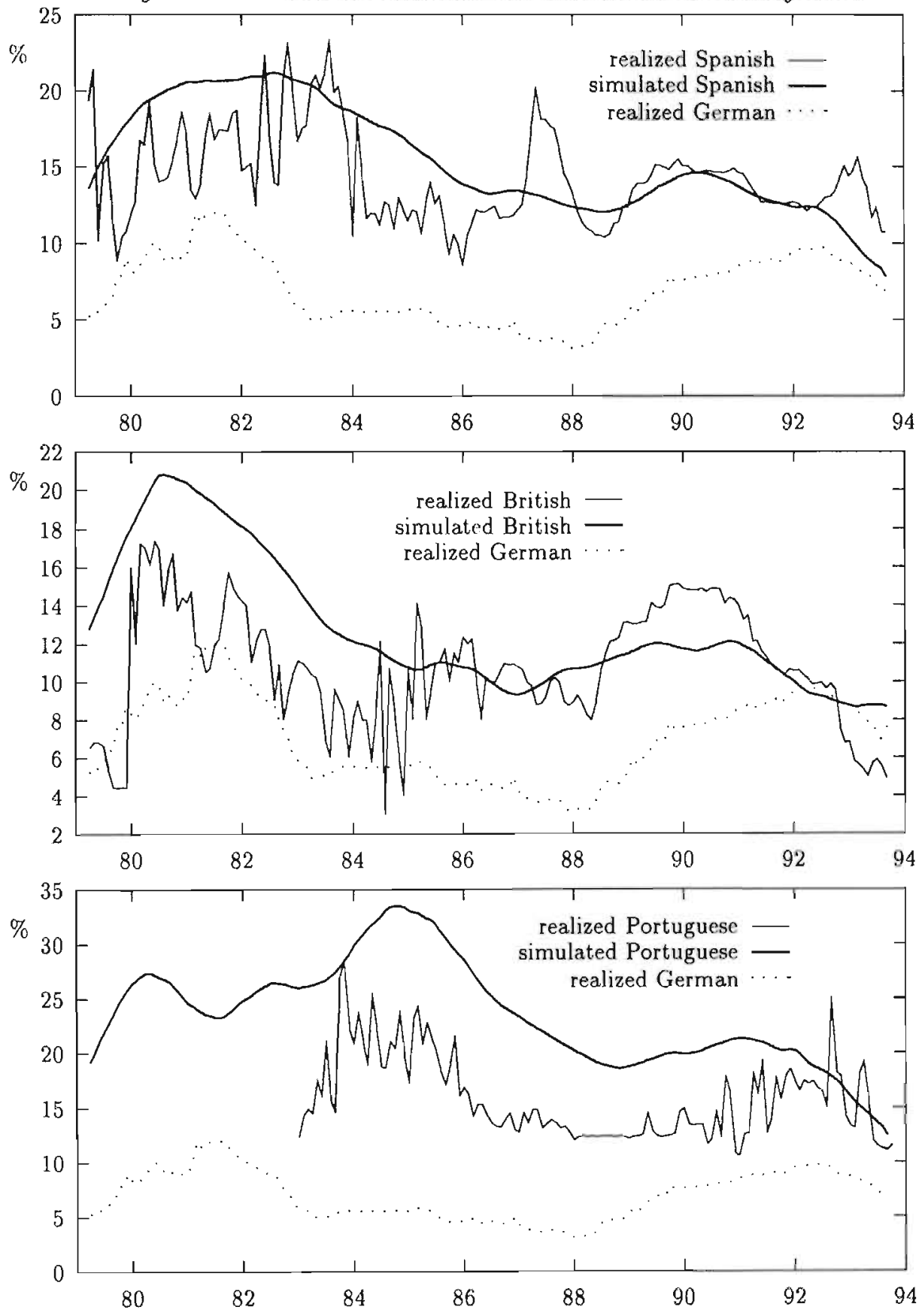
Bundesbank. By joining the ERM, the European countries could "borrow" this reputation, thereby lowering the cost of a disinflationary policy. This was generally seen as one of the main benefits for the European countries of joining the ERM (see Giavazzi and Pagano, 1988). In October 1990 this was also one of the main arguments for the UK to participate in the system.

Third, the good fit stops somewhere in the nineties after which the simulated interest rate is lower than the actual rate, and even lower than the German call money rate for most countries. The difference between the simulated and German rate generally increased to sometimes more than $3 \%$. Since the reputation of the Bundesbank is such that the probability of a devaluation of the D-mark can be considered zero, interest rates of ERM countries can hardly be lower than German ones, due to the uncovered interest parity. In the nineties, this restriction was indeed binding for several ERM countries. So, there are indications that the German interest rates were problematically high for the other ERM countries. For several countries this might very well have been one of the reasons for the speculative attacks on their currencies, resulting in even higher domestic interest rates. This is very clear for the Irish punt but also for other currencies.

The extent to which these high interest rates were perceived by the market to be problematic depends also on the benefits of the ERM. As inflation levels in most European countries had already been reduced to German levels or even more, the argument of borrowed reputation from the Bundeshank had lost its importance. Stable exchange rates are of course beneficial in themselves, but this is primarily so for small open economies with their main trading partners in the ERM area, i.e. Belgium and the Netherlands.

The decision to devalue or to suspend membership of the ERM is above all a political one. This implies that not only economic circumstances determine the probability of a speculative attack, but also the more or less subjective political interpretations of this reality. Tensions in the ERM only began to rise after the rejection of the Maastricht treaty in the Danish referendum of June 1992. They reached a climax just before the French referendum, which predicted outcome was also close to rejection. By that time French and British authorities were openly complaining about the interest rate policy of the Bundesbank, thereby stressing the costs of their membership. The Netherlands on the other hand, always followed the Bundesbank without complaints. Being a small open economy, there seem to be no doubts at all 
about the benefits of a credible peg with the D-mark, although this policy resulted in relatively high interest rates since 1988 . For a long time, there seemed to be agreement on this subject in Belgium as well. In August 1993 however, this episode ended with the "Leuven coup". Economists from the Leuven University started a public debate on the desirability of the Belgium membership of the ERM ${ }^{6}$. Although the authorities firmly rejected the possibility of suspending membership, this debate at least temporarily destroyed the credibility of the Belgian franc.

\subsubsection{An econometric model for the exchange rate}

In order to assess the impact of these high German interest rates on the ERM, the difference between the expected German rate and the simulated rate will be included in the exchange rate model developed in chapter 3 . There it was shown that weekly exchange rate changes of the currencies participating in the ERM could be modeled by means of an MA(1)- $\mathrm{CARCH}(1,1)$ errorcorrection jump specification. Since the jumps represent (anticipations for) realignments, the probability of a jump was made a function of economic fundamentals that influence the devaluation probability, i.e. the inflation differential with Germany and the trade balance surplus. These two fundamentals have both to do with the competitiveness of a country and as such were very successful in explaining most of the tensions within the ERM until 1992. The recent tensions however, can not be explained from external weakness. In order to investigate whether the level of the German interest rate was causing the problems, the difference (if positive) between the expected German call money rate (using one month ahead predictions based on the estimated reaction function) and the simulated European currency rate will be included as an extra explanatory variable, determining the jump probability. This difference can be interpreted as an indicator of the costs of losing monetary independence due to the membership of the ERM.

The resulting probability of a jump $\left(\lambda_{t}\right)$ reads as

$$
\lambda_{t}=1-\left(1+\exp \left(\lambda_{0}+\lambda_{\text {infd }} i n f d_{t-8}+\lambda_{t b} t b_{t-8}+\lambda_{r d} r d_{t-1}\right)\right)^{-1},
$$

\footnotetext{
${ }^{6}$ The costs of high interest rates are probably more important for Belgium than for other ERM countries due to the very high public debt.
} 
where inf $d_{t-8}$ denotes the inflation differential between the concerned country and Germany, $t b_{t-8}$ the trade balance surplus of this country and $r d_{t-1}$ the difference between the expected German interest rate and the simulated interest rate for the European country, if this difference was positive: $r d=\max \left(0, E\left(r^{G e r}\right)-r_{s i m}^{E u r}\right)$. All these variables were only available on a monthly basis. In order to get weekly data, a linear interpolation was used. A time lag was used since information on these variables does not become immediately available.

One might also consider the difference between the simulated interest rate and the actual call money rate for a particular currency as explanatory variable. The level of the domestic interest rate is what matters, so it might be a more direct measure than the German call money rate. There are however several reasons why the domestic call money rate might not be suitable for our purpose. First of all, as can be seen from figure 6.2 , the call money rate shows much volatility for several countries. The large peaks in the call money rate are probably due to speculative attacks against a currency, and as such might be a leading indicator for an upcoming devaluation. However, jumps are not only caused by devaluations, but also by large movements within the band. Since rises in the interest rate and depreciations occur simultaneously if the market panics, the interest rate can not be a leading indicator for these jumps. Second, the influence of the call money rate on the jump probability will be completely dominated by the extreme values, especially for the Irish punt. Third, a high domestic interest rate does not indicate the reason, that is an expected devaluation or a high German interest rate.

The other equations of the model are identical to the ones in chapter 3 . They will be repeated here for clarity. The resulting model for the logarithm of the exchange rate $\left(s_{t}\right)$ is given by

$$
\Delta s_{t}=\mu+\phi(s-c)_{t-1}+\lambda_{t} \theta+\psi D_{t-1} \varepsilon_{t-1}+\varepsilon_{t},
$$

where $\mu$ is the intercept, $c_{t-1}$ is the logarithm of the central parity, $D_{t-1}$ is a dummy variable that takes the value 0 if the currency was devalued in period $t-1$, and 1 otherwise. $\lambda_{l} \theta$ denotes the contribution of the jumps to the exchange rate change. $\theta$ is the mean jump size, and $\lambda_{t}$ is the probability of a jump, as shown in (6.1).

The disturbance $\varepsilon_{t}$ is distributed as

$$
\varepsilon_{t} \sim\left(1-\lambda_{t}\right) N\left(-\lambda_{t} \theta, h_{t}^{2}\right)+\lambda_{t} N\left(\left(1-\lambda_{t}\right) \theta, h_{t}^{2}+\delta^{2}\right) .
$$


Conditional on no jump, which has probability $1-\lambda_{t}, \varepsilon_{t}$ is normally distributed with expectation $-\lambda_{t} \theta$ and variance $h_{t}^{2}$, otherwise the expectation is $\theta$ higher (the mean jump size) and the variance $\delta^{2}$ higher (the variance of the jump size). To model the time-varying volatility $h_{t}^{2}$ is given a $\operatorname{GARCH}(1,1)$ specification (see Bollerslev, 1986)

$$
h_{t}^{2}=\alpha_{0}+\alpha_{1} \varepsilon_{t-1}^{2}+\beta h_{t-1}^{2} .
$$

This model, combining equation (6.1) to (6.4) can be estimated by maximum likelihood. The results of this are shown in the next section.

\subsubsection{Empirical results}

In table 6.4 the empirical results are shown for the Belgian and French francs, the Danish krone and the Irish punt. Only these currencies were considered since these currencies have been under pressure lately (unlike the Dutch guilder), their simulated interest rate was considerably lower than the German one, and they have participated in the system long nough to br able to identify the parameters (for instance for the parity reversion term). Positivity of the variance parameters was enforced hy cstimating the square root of these parameters.

For all currencies there is a significant parity reversion tendency $(\phi<0)$, which is in the order of $1.8 \%$ to $2.9 \%$ a week. This is probably due to the long episode without realignments between 1987 and 1992. Also very striking is the strong significance of the negative moving average term $(\psi)$. This can be explained from the existence of the fluctuation band in combination with the difficulty to rightly assess the timing of a devaluation. If the market expects a currency to devalue in the upcoming week, this currency will strongly depreciate this week to the top of the band. If this currency is not devalued the next week, it can not depreciate further. Very likely, the assumed probability of a devaluation will decline again, and the currency will appreciate, thereby partly offsetting the depreciation of the week before. The MA term sufficiently models the correlations in the mean since the Ljung-Box statistic $\left(L B_{e}(27)\right)$ for 27 th order autocorrelation, computed on normalized residuals (see appendix A), is not significant for any of the models.

As to the coefficients determining the jump probability, not all the parameters are significantly different from zero. This lack of significance has 
primarily to do with multicollinearity, especially between the inflation differential and the trade balance. For the Danish krone, this even resulted in an inflation coefficient of the wrong sign (although not significant), which was remedied by restricting it to zero. The joint significance of the inflation differential and trade balance coefficients can be deduced from the Wald and $L R$ statistics for the hypothesis $\lambda_{i n f d}=\lambda_{t b}=0$. This hypothesis is always rejected for both statistics.

Table 6.4: Maximum likelihood results for the exchange rate models

\begin{tabular}{|c|c|c|c|c|c|c|c|c|}
\hline $\begin{array}{l}\text { Parameters } \\
\mu\left(\times 10^{4}\right)\end{array}$ & \multicolumn{2}{|c|}{ Belgian franc } & \multicolumn{2}{|c|}{ French franc } & \multicolumn{2}{|c|}{ Danish krone } & \multicolumn{2}{|c|}{ Irish punt } \\
\hline $\begin{array}{l}\mu\left(\times 10^{4}\right) \\
\phi \\
\psi \\
\lambda_{\overline{0}} \\
\lambda_{\text {infd }} \\
\lambda_{t b} \\
\lambda_{r d} \\
\theta\left(\times 10^{2}\right) \\
\delta^{2}\left(\times 10^{4}\right) \\
\alpha_{0}\left(\times 10^{6}\right) \\
\alpha_{1} \\
\beta\end{array}$ & $\begin{array}{r}1.403 \\
-.019 \\
-.386 \\
-5.198 \\
10.166 \\
-22.101 \\
.070 \\
.877 \\
2.740 \\
1.192 \\
.178 \\
.660\end{array}$ & $\begin{array}{r}(1.59) \\
(-2.46) \\
(-8.64) \\
(-3.98) \\
(0.39) \\
(-2.46) \\
(0.13) \\
(1.23) \\
(1.07) \\
(2.08) \\
(2.87) \\
(5.85)\end{array}$ & $\begin{array}{r}0.982 \\
-.018 \\
-.129 \\
-6.464 \\
47.873 \\
-10.466 \\
1.702 \\
.923 \\
3.051 \\
3.585 \\
.198 \\
.031\end{array}$ & $\begin{array}{r}(1.28) \\
(-2.43) \\
(-3.32) \\
(-5.12) \\
(2.70) \\
(-1.48) \\
(2.44) \\
(1.68) \\
(2.24) \\
(8.95) \\
(3.22) \\
(0.83)\end{array}$ & $\begin{array}{r}-5.905 \\
.374 \\
.729 \\
1.291 \\
6.577 \\
.149\end{array}$ & $\begin{array}{r}(1.35) \\
(-3.98) \\
(-4.06) \\
(-8.83) \\
\\
(-2.69) \\
(1.58) \\
(2.93) \\
(2.78) \\
(12.25) \\
(2.93)\end{array}$ & $\begin{array}{r}0.708 \\
-023 \\
-.264 \\
-4.449 \\
9.832 \\
-3.074 \\
.846 \\
1.193 \\
5.827 \\
4.647 \\
.381 \\
.086\end{array}$ & $\begin{array}{r}(0.89) \\
(-2.73) \\
(-6.97) \\
(-8.22) \\
(0.88) \\
(-1.84) \\
(2.47) \\
(2.23) \\
(1.67) \\
(6.98) \\
(3.00) \\
(1.69)\end{array}$ \\
\hline \multicolumn{9}{|l|}{ Statistics } \\
\hline $\begin{array}{l}\text { Wald } \\
L R \\
L B_{e}(27) \\
L B_{e^{a}}(27) \\
\text { Skewness } \\
\text { Exc.kurt. } \\
\chi^{2}(29)\end{array}$ & $\begin{array}{r}6.521 \\
10.606 \\
31.519 \\
20.686 \\
-.009 \\
.383 \\
23.830\end{array}$ & $\begin{array}{l}{[.038]} \\
{[.005]} \\
{[.250]} \\
{[.801]} \\
{[.916]} \\
{[.032]} \\
{[.737]}\end{array}$ & $\begin{array}{r}10.955 \\
21.631 \\
16.310 \\
30.028 \\
.145 \\
.344 \\
36.167\end{array}$ & $\begin{array}{l}{[.004]} \\
{[.000]} \\
{[.947]} \\
{[.313]} \\
{[.105]} \\
{[.054]} \\
{[.169]}\end{array}$ & $\begin{array}{r}7.236 \\
5.243 \\
24.475 \\
34.539 \\
.079 \\
.140 \\
33.844\end{array}$ & $\begin{array}{l}{[.027]} \\
{[.073]} \\
{[.604]} \\
{[.151]} \\
{[.379]} \\
{[.434]} \\
{[.245]}\end{array}$ & $\begin{array}{r}9.906 \\
8.688 \\
31.388 \\
54.607 \\
.116 \\
.470 \\
48.984\end{array}$ & $\begin{array}{l}{[.007} \\
{[.013} \\
{[.256} \\
{[.001} \\
{[.193} \\
{[.008} \\
{[.012} \\
{[}\end{array}$ \\
\hline
\end{tabular}

- The sample consists of 749 weekly Wednesday observations from April 4, 1979 to August 4, 1993.

- $P$-values and heteroskedasticity-consistent $t$-values are in square brackets and parentheses respectively.

- Wald and $L R$ are Wald and likelihood-ratio statistics for the hypothesis: $\lambda_{\text {injd }}=$ $\lambda_{t 0}=0$,

- The Ljung-Box statistics $L B_{e}$ and $L B_{z^{2}}$, Skewness and Excess kurtosis are computed on normalized residuals (see appendix A)

- $\chi^{2}(29)$ is an adjusted Pearsan-type goodness-of-fit test, computed on a classification in 30 cells (see appendix A). 
An expected German interest rate above the simulated European country rate leads to an increase in the jump probability for all currencies. For the Belgian franc, the coefficient $\left(\lambda_{r d}\right)$ is not significant. The reason for this lack of significance is probably the timing of the speculative attacks on the Belgian franc. It took until August 1993 before the Belgian franc came under pressure, so only in the last week of our sample. The rest of the $1991-1993$ period under which the expected German interest rate was higher than the simulated Belgian rate, the Belgian franc was one of the strongest currencies of the system. For the Danish krone, the coefficient is just not significantly different from zero. The limited significance for this currency is probably due to the fact that the highest differential between the simulated Danish and the expected German interest rate was realized in the first half of 1992 (see figure 6.2 ), whereas the speculative attacks came later (after the referendum).

Figure 6.3: Jump probabilities
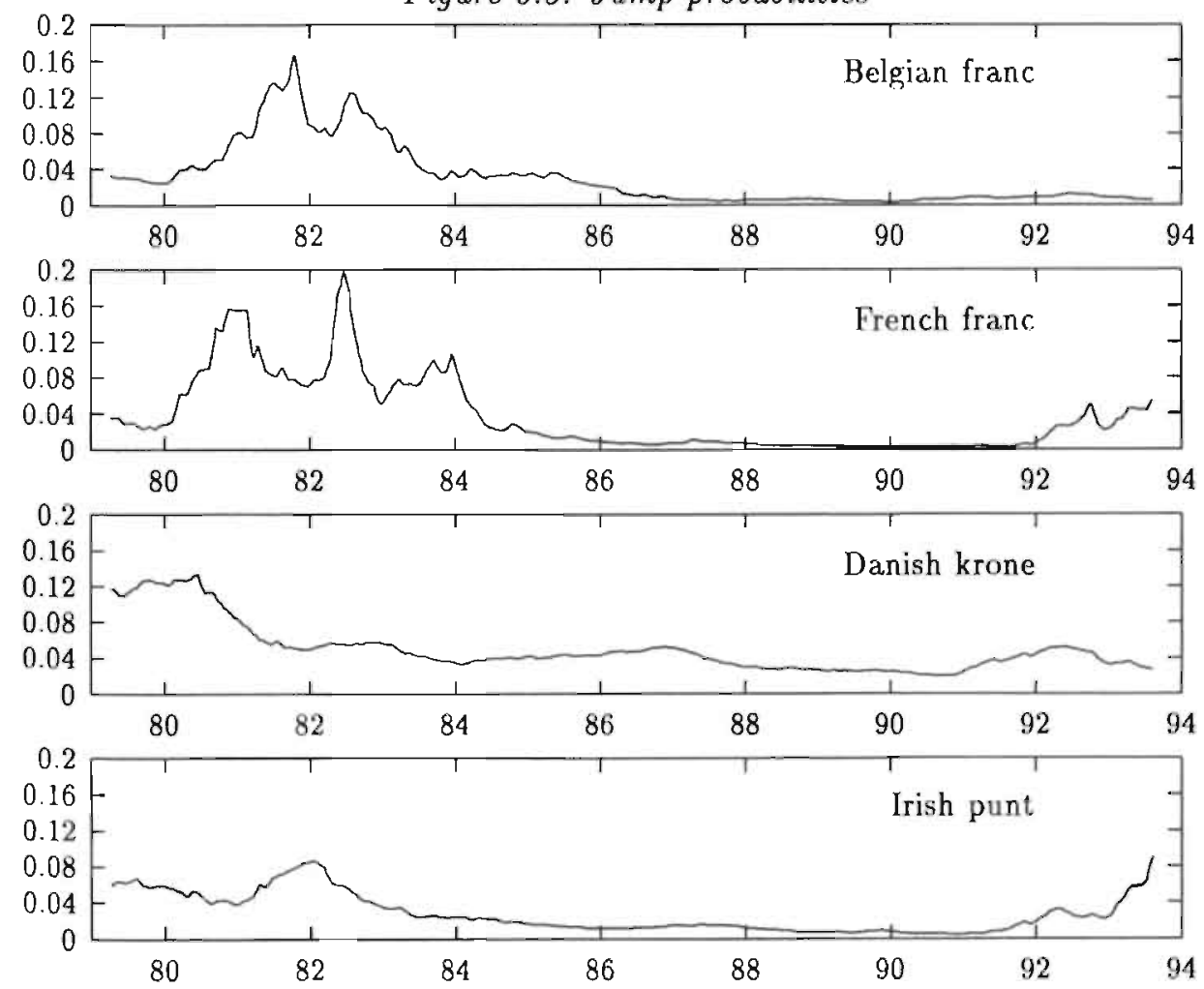
In figure 6.3 the resulting jump probabilities are shown. For all currencies the jump probability was high in the early eighties, due to large trade deficits and high inflation rates relative to Germany. These high probabilities generally reduced during the eighties, due to improving trade balances and the increased economic convergence between the countries. In $1991-1992$ the probabilities start rising again, except for the Belgian franc, due to the high German interest rates.

The mean jump size $(\theta)$ is positive for all currencies, which is in accordance with the positive skewness found in the data (see appendix $B$ ). This positive skewness is appropriately modeled since there seems to be no skewness left in the normalized residuals. If a jump occurs, the mean depreciation is about $1 \%$ larger than otherwise. The variance of the jump size $\left(\delta^{2}\right)$ however, is very high compared to its mean, so that jumps should not only be associated with large depreciations, but also with large appreciations. The influence of the jumps on the volatility of the exchange rate is most important.

The $\operatorname{GARCH}(1,1)$ specification is quite successful, although an $\operatorname{ARCH}(1)$ specification would do just as well for the French franc and the Danish krone. For the Danish krone, the $\beta$ parameter was deleted since the positivity restriction created problems with the convergence and with the estimation of the numerical hessian matrix. For the Irish punt, the $\operatorname{GARCH}(1,1)$ specification is probably not appropriate since there are significant autocorrelations left. in the squared normalized residuals (see $L B_{e^{2}}(27)$ ).

The overall fit of the models is quite reasonable. The $\chi^{2}(29)$ statistic is the adjusted Pearson chi-square goodness-of-fit test (appendix A). Only for the Irish punt there is evidence against the model. From the computed excess kurtosis statistics it can be seen that there is still some excess kurtosis left for the Belgian franc and the Irish punt. 


\subsection{Conclusions}

The main purpose of this chapter was to investigate what went wrong with the European Monetary System in the summer of 1993. Was the abolishment of capital controls in itself enough to destabilize the system, or were there economic reasons for the collapse of the system. Since many observers held the Bundesbank at least partly responsible, the investigation was concentrated at the German interest rates. Two sub-questions were asked. First, were the German interest rates indeed high, both from a domestic and a European point of view. Second, is there any statistical evidence that these high interest rates destabilized the EMS. Both questions were affirmed.

In order to investigate the reasonability of the German interest rales, a reaction function for the Bundesbank was specified determining the German call money rate over the period April 1979 to June 1990. Using the single equation error correction framework, a significant relation was found between the call money rate on the on hand and the inflation rate and a business cycle indicator on the other. With this model, a dynamic simulation was performed using actual inflation and business cycle data, and the predicted call money rate. From the end of 1991 on, the German call money rate was $1.5 \%$ to $2 \%$ higher than predicted from the above reaction function. This might have been the result of the extra inflationary pressures resulting from the German unification.

When the above reaction function was applied to data for the other ERM countries, the simulated interest rate, which can be interpreted as the desired interest rate based only on domestic circumstances, was already lower than the actual German call money rate since 1991 for most countries. The difference between the two generally increased to sometimes more than $3 \%$. Since the uncovered interest parity condition with the D-mark makes it impossible for ERM countries to lower their interest rate far below the German one, the high German interest. rates were indeed problematic for the other ERM countries.

The significance of this problem was investigated by including, the difference (if positive) between the predicted actual German call money rate and the simulated ERM country rate as an explanatory variable in the model for weekly ERM exchange rate changes developed in chapter 3 . For three out of four currencies investigated, the difference increases the probability of a jump. Here, by a jump is meant an extra draw from a normal distribution, 
with a positive mean (on average a depreciation) and a high variance (an increase in volatility), which can be interpreted as results from panic reactions due to devaluation expectations, or as realignments themselves.

So, our main conclusion is that the Grerman unification destabilized the European Monetary System. This major asymmetric shock resulted in a different preferred monetary policy for Germany than for the other ERM countries. Since Germany is the center country of the system, the system came under severe pressure. What this means for the future working of the system and for the creation of the European monetary union remains to be seen. The current recession in Germany also reduces the optimal interest rate in Germany, thereby tightening the gap in optimal interest rates. In the longer run however, the growth capacity of Eastern Germany will presumably lead to relatively high economic growth rates and (demand) inflation in Germany compared to the other countries. Europe does not seem to be an optimal currency area any more (if it ever was). 


\section{Chapter 7}

\section{Summary and conclusions}

In this thesis, the working of the exchange rate mechanism of the EMS has been described. For this purpose, five empirical studies have been conducted to study the behavior of exchange rates and risk premia in the ERM. Within the ERM, the exchange rates are restricted to stay between relatively small fluctuation margins. The theoretical literature, as discussed in chapter 1, mainly focusses on the stabilizing effects of these bands. Instead of intervening, it is also possible to adjust the central parities however, so that the bands are moved, provided that all ERM members agree. In this thesis, it is argued and shown that this possibility of a realignment affects the exchange rate movements even if no realignment occurs.

As the size of the parity adjustments can be very large, especially if a currency is clearly overvalued, and since the timing of a devaluation is extremely difficult to predict, market participants are reluctant to invest in a weak currency. Therefore, the interest rate on this currency has to be relatively high. Moreover, the announcement of negative news items concerning this currency can easily lead to panic reactions, resulting in sudden large depreciations within the band and even higher interest rate differentials. As the costs of keeping the spot rate within the band, in terms of loss of reserves and high interest rates, can be very high, a sudden depreciation can also be initiated by the market, to enforce a realignment. The presence of an official exchange rate band introduces large arbitrage opportunities as the exchange rate can not smoothly adjust beyond the boundary of this band. Speculators can anticipate a discrete jump in the exchange rate, if the parities are realigned, which may lead to enormous speculative gains. These speculative 
attacks were eminently present in recent years, and led to the enlargement of the fluctuation margins in August 1993.

In chapter 2 , it was shown that these volatile movements within the band can, together with the depreciations resulting from the large devaluations, be modeled by means of stochastic jumps. The jump size was assumed to be normally distributed, with a positive mean (on average a depreciation) and a high variance (much volatility). For the intensity, the Bernoulli and Poisson specifications were compared. The differences between the two were found to be negligible. Other aspects of the model are an MA specification to take account of the stabilizing effects of the intervention policy and a GARCH specification to model the persistence in volatility. Using weekly data on six ERM currencies in terms of the D-mark, it was shown that these jumps are very important in explaining the fat, tails and the skewness of the distribution of exchange rates. If the jumps were not included, the negative MA term was not always detected and the GARCH specification became explosively nonstationary for several currencies.

As the jumps in our models are related to realignment risk, the probability of a jump was made a function of economic fundamentals in chapter 3 . Both an inflation differential with Germany and a trade balance deficit were found to significantly influence the exchange rate, in incorporated in this indirect way. The models were also modified to include an error-correction term, measuring the deviation of the spot rate from its central parity. The success of the models was demonstrated by comparing the mean squared forecast error of the model, for one to four weeks ahead predictions, with that of the random walk. Both within and out of sample, all models outperformed the random walk. Also, the $95 \%$ forecast intervals were given. They were much smaller in the nineties than they were in the early eighties, reflecting the growing convergence. Finally, the model was used to select weeks in which it was profitable to invest in the weak ERM currencies. It was shown that significant excess returns could be made in the foreign exchange market, and that the result significantly improved if our model predictions were used.

In order to find an explanation for the existence of the excess returns (deviations from uncovered interest parity), they were modeled themselves in chapter 4. Using a model specification quite similar to the one for the exchange rates, two sources for excess returns were found, namely uncertainty and changes in the perceived realignment probability. The uncertainty was 
measured by the conditional standard deviation, which was influenced to a large extent by the inflation differential. This risk-return tradeoff is very much in line with the assumption of market efficiency and rational agents. The changes in the perceived devaluation risk caused the excess returns to be negatively correlated and resulted in a positive relationship between the position of the spot rate in the band and the expected excess return. As realignments can result in large speculative losses, these finding do not necessarily conflict with efficient markets either. The expected excess returns, which under the assumption of market efficiency and rational agents represent risk premia, were shown to be highly volatile and substantial, reflecting the changing uncertainty present in the EMS.

The interpretation of excess returns as risk premia is only valid under the assumption of no systematic forecast errors of the market participants. In order to disentangle risk premia from forecast errors, survey data on exchange rate expectations were used in chapter 5. First it was shown that, at least until April 1990, most central parities were not perceived to be credible by the market. Moreover, the survey expectations showed very volatile behavior, which is in accordance with our assumption of positive and constantly changing perceived realignment risk. Then, the differences between the interest differentials with Germany and the survey expectations, which by definition are equal to the ex-ante risk premia, were regressed on, among other things, the inflation differential with Germany. Although the data and the techniques were completely different from the ones in chapter 4, a significant inflation effect on the risk premium was again found.

In chapter 6 the near collapse of the system in August 1993 was investigated. Almost all participating countries experienced speculative attacks against their currencies, whereas only some of them were clearly overvalued. In the financial press, the high German interest rates were viewed as the main cause. Due to the inflationary pressures resulting from the German unification, the Bundesbank had raised the official interest rates. The ERM countries had no choice but to follow the Bundesbank, due to the uncovered interest parity, although their domestic situation called for a low interest rate. In order to investigate whether German interest rates were indeed high, a reaction function for the German call money rate over the period April 1979 to June 1990, based only on the domestic German situation, was estimated. By means of a dynamic simulation, it was shown that the German 
call money rate was indeed $\pm 1.5 \%$ higher than predicted from the end of 1991 on. When this reaction function was applied to the other ERM countries, the simulated call money rate, which can be interpreted as the preferred interest rate based only on domestic circumstances, turned out to be substantially lower than the German rate since 1990 - 1991. The difference generally increased to sometimes more than $3 \%$. The influence on the exchange rate mechanism was examined by including the difference between the expected German interest rate and the simulated European country rate, as an extra explanatory variable for the jump probability in the models of chapter 3 . For two out of four currencies investigated, the difference significantly increased the probability of a jump.

So, what do we learn from these exercises. From a purely technical point of view, the necessity to align an econometric model with reality is once again demonstrated. In chapter 2 , it was shown that a model without stochastic jumps could not appropriately model the MA-GARCH specification and in chapters 3,4 and 6 a significant effect of economic fundamentals on the exchange rate was only found because these effects were modeled by means of the unprecedented method of endogenous jumps.

From an economic viewpoint, the most important lesson of this thesis is that official exchange rate bands do not necessarily stabilize the exchange rate (as suggested by the theoretical target zone literature), as they also introduce realignment risk. Bearing this in mind, it is interesting to recapitulate recent developments. In August 1993, the fluctuation margins were enlarged to $\pm 15 \%$. As stressed in chapter 6 , the market anticipated that the European countries were not prepared to bare the high interest rates resulting from a speculative attack, as they were already complaining about the level of the German interest rates. The widening of the band was generally explained as the total collapse of the system. After an initial period of large depreciations, things do not look so bad after all, however. Most currencies currently fluctuate again within the relatively small margins of $2.25 \%$. By enlarging the bands, the countries had regained their monetary independence. By not using this independence to lower the interest rate, but to stabilize the exchange rate instead, they have largely regained their credibility. This increased credibility and the fact that the exchange rates are no longer officially bounded by small bands, substantially reduced the probability of a future speculative attack. 
This recent success of wide margins should not be interpreted as a general solution to the insufficient credibility problem within a target zone, however. One of the benefits of joining the ERM was to lower the costs of a disinflationary policy, since an exchange rate peg with the D-mark provided the monetary policy with a more credible target. With very wide margins, the presence of this external target might not be very useful, since substantial monetary independence remains. Moreover, the political signal of stable exchange rates now, is not sufficient to remain credible forever as long as economies have not converged, since current inflation differentials worsen the state. The speculative attacks against the Italian lira in September 1992 clearly illustrated this point. Capital controls (and timely devaluations) might be more suitable to alleviate the speculative pressures in these circumstances.

As to the implications of this thesis for the future developments within the EMS, one can say the following. The dynamic simulations for the interest rates (see figure 6.2) showed a clear divergence between the German (and possibly the Dutch) preferred interest rate from a domestic perspective, and those for the other European countries. From this, one may conclude that the European union became less an optimal currency area lately. The preferred interest rate is only one aspect however. Recent developments have shown that most countries still preferred stable exchange rates within Europe above a lower interest rate. Within the current system, most of these countries still have to pay a slight risk premium, due to the possibility of a policy turnaround, whereas in the European monetary union (EMU) the interest rate could be lowered to the German level. Therefore, these countries might, very well prefer the creation of the EMU in the short term, from an economic perspective. For Germany however, the creation of the EMU would mean a loss of monetary independence since the monetary policy of the system would no longer be determined by the Bundesbank but by the European central bank. Following the asymmetric developments in Europe due to the German unification, this loss of sovereignty might be too high a price, especially if the "weaker" EMS countries are also to participate.

Remains the question whether there is a need for official small fluctuation margins before the transition to the EMU takes place. The main advantage of official small fluctuation margins is that the exchange rate peg provides the monetary policy with a more credible target since high inflation rates will sooner lead to a devaluation, which is generally seen as politically undesir- 
able. Now European inflation levels have reduced to German levels (and even more) however, this credibility device is no longer needed. In these circumstances, small fluctuations within wide official margins might be preferred since official small bands increase the probability of speculative attacks. On the one hand, small official bands introduce the possibility of predictable discrete jumps in the exchange rate, if a speculative attack is successful. On the other hand, the priority given to stable exchange rates is less clear than in a situation of stable rates within wide official margins. 


\section{Appendix A}

\section{Simple diagnostic tests for likelihood functions}

\section{A.1 Problem setting}

Typical stylized facts of high frequency financial data series are fat tails and conditional heteroskedasticity. That is why non-normal distributions, with or without a GARCH specification (Bollerslev, 1986) have been widely applied in the analysis of financial data. Candidate fat-tailed distributions are among others the Student- $t$, a normal-Poisson mixture, a discrete mixture of normals, a generalized error distribution, a normal-lognormal mixture or a stable Paretian distribution. Since the normal distribution is nested in these distributions, one can easily test for normality. However, as the other distributions are not nested, one can not use the standard tests to discriminate between them (although tests for non-nested hypotheses could be used, of course).

The selection of an appropriate distribution is particularly difficult since most diagnostic tests are based on the normal distribution. Although the asymptotic properties under other distributions are sometirnes known for these diagnostics, their behavior in finite samples is mostly unknown. One can of course simulate the small sample properties, as has for instance been done for the skewness and kurtosis parameters for the Student- $t$ distribution by De Ceuster and Trappers (1992), but especially for discrete mixture distributions it is simply impossible to tabulate confidence intervals since there are too many parameters determining the distribution. 
Most studies use the value of the log-likelihood function to discriminate between candidate distributions. However, a high value of the loglikelihood function does not necessarily mean that the shape of the proposed distribution resembles the distribution of the data. Although the parameter estimates might be consistent under a wider class of distributions, see Gouriéroux, Monfort and Trognon (1984), the conditions under which pseudo maximum likelihood methods are applicable are not always easily checked. Moreover, as several important applications of these models, for instance option pricing (Ball and Torous, 1985) or forecast intervals, rely on the whole distribution, and not just on the first (and second) moment, a Pearson chisquare goodness-of-fit test might be preferred. This test statistic however, can not be easily computed for mixture distributions with a time-varying variance since the statistic requires independent and identically distributed observations.

In this appendix a simple transformation is proposed to overcome the problems related to testing models with non-normal distributions.

\section{A.2 Test statistics}

A Pearson goodness-of-fit test compares the empirical distribution of the (standardized) residuals with the theoretical distribution assumed to hold under the null hypothesis ${ }^{1}$. This is usually done by classifying the residuals in cells according to their magnitude. From the theoretical distribution function the borders of the groups are computed in such a way that the expected number in each group is the same (although this is not required). The selection of the number of groups is not evident, but it should increase with the number of observations at a speed $T^{0.4}$ (Kendall and Stuart, 1967, chapter 30). For independent identically distributed observations it can be shown that

$$
\sum_{i=1}^{g} \frac{\left(n_{i}-E n_{i}\right)^{2}}{E n_{i}} \sim \chi^{2}(g-1)
$$

where $g$ is the number of groups, and $n_{i}$ is the number of observations in group $i$.

\footnotetext{
${ }^{1}$ The same null hypothesis can be tested by means of several other test statistics. For an overview of the literature on the applicability of these tests in the case of the estimated parameter, see Heckman (1984).
} 
A problem with this test statistic for models with a changing variance over time is that the residuals of these models are neither identically nor independently distributed. For the normal or Student- $t$ distribution, this problem can be overcome by standardizing the residuals. For the discrete mixture distributions however, such a standardization will not be of help since the standardized residuals of these models still have time dependent third and fourth moments which depend on the conditional variance.

This problem can be solved by redefining the classifying mechanism of the residuals. Instead of classifying according to their value, we calculate for each residual the probability of observing a smaller value. This procedure implies checking whether the empirical cumulative distribution function is uniformly distributed:

$$
H_{0}: \quad G\left(\text { res }_{t}, \Phi\right) \sim U[0: 1]
$$

where $G\left(\right.$ res $\left._{t}, \Phi\right)$ is the value of the cumulative distribution function for residual $t$, given the proposed distribution under $H_{0}(G)$, evaluated at the true parameters $(\Phi)$. In practice, we do not know the true parameters however, so we replace them by the maximum likelihood estimates $(\hat{\Phi})$, the consequences of which are discussed in the next section. The sorting mechanism for this test statistic is:

$n_{i}=\sum_{t=1}^{T} I_{i t}$, where $I_{i t}=\left\{\begin{array}{ll}1 & \text { if }(i-1) / g<G\left(\text { res }_{t}, \hat{\Phi}\right) \leq i / g \\ 0 & \text { otherwise }\end{array} \quad \forall 1 \leq i \leq g\right.$

For the normal or Student-t distribution, the results of this classifying mechanism are exactly the same as the ones obtained by grouping standardized residuals according to value. Instead of using the inverse of the cumulative distribution function to compute the borders of the groups given previously set probabilities, this mechanism classifies probabilities computed by means of the cumulative distribution function.

The goodness-of-fit test requires independent observations. This means that a rejection of the null hypothesis of this test might be due to dependence in the data, which might be remedied by a modification in the ARMAGARCH specification. If the data should be normally distributed, absence of serial correlation (which is necessary for independence) could be checked by means of a Ljung-Box or Box-Pierce statistic. Given the fact that there 
is a one to one relationship between the value of a standard normal residual and the value of its cumulative distribution function, we can compute "normalized" residuals in the following manner:

$$
\operatorname{res}_{t}^{n} \equiv F^{-1}\left(G\left(\operatorname{res}_{t}, \hat{\Phi}\right)\right)
$$

where $l^{\prime-1}($.$) is the inverse of the standard normal cumulative distribution$ function ${ }^{2}$. If for instance, for a particular residual, the probability of observing a smaller value is $2.5 \%$, the corresponding standard normal residual is -1.96 . Under the assumption of a corrertly specified model, res $t_{t}^{n}$ is approximately standard normally distributed, and all the usual diagnostic tests can be applied to check this.

Since a tcsting procedure based on this transformation fully utilizes the distribution under the null, it will most likely be more powerful than a robust testing procedure based on standardized residuals (residuals divided by their conditional standard deviation). These robust tests have to be valid under a wide range of alternative distributions, whereas the normalized residuals are known to be normally distributed under the null.

\section{A.3 The estimated parameters issue}

A practical problem with the chi-square test (A.1) is that the statistic does not have a $\chi^{2}$ distribution in general if some of the parameters are estimated. The sampling distribution of the test statistic is influenced by possible parameter estimation error. Only if the estimation is conducted on grouped data, where the groups correspond with the cells used to perform the test, it can be shown that the statistic is exactly $\chi^{2}$ distributed, where the degrees of freedom is reduced by the number $(k)$ of estimated parameters. In this case there is a direct link from the estimation procedure to the outcome of the test statistic. Chernoff and Lehmann (1954) derived the asymptotic distribution for the test statistic if the parameters are estimated by maximum likelihood

\footnotetext{
${ }^{2}$ The same transformation was previously proposed by Smith (1985). The use of cumulative distribution functions to transform data from one distribution to another was already proposed by Pearson (1933).
} 
based on ungrouped data ${ }^{3}$ :

$$
\sum_{i=1}^{g} \frac{\left(n_{i}-\hat{E} n_{i}\right)^{2}}{\hat{E} n_{i}} \sim \chi^{2}(g-k-1)+\sum_{j=1}^{k} \xi, Z_{j}^{2}
$$

where $\hat{E} n_{i}$ is the expected number of observations, based on the estimated ML estimators. The $Z_{j}^{2} \mathrm{~s}$ are independent chi-squared random variables with one degree of freedom and each $\xi_{j}$ is an unknown constant in $[0,1]$. 'l'he size of these constants probably reflects the robustness of the test statistic: to small changes in the parameters and the link between the test outcome and the estimation procedure. In the estimation procedure based on grouped data, the test statistic is exactly minimized at the estimated parameters and therefore all $\xi_{j}$ s are equal to zero. For the ML estimates however, the link between the estimation procedure and the outcome of the test is far less clear, so the $\xi_{j}$ s might very well be close to one. In a particular sample, it might even be the case that the ML estimates differ slightly from the true parameters, but that the test statistic is higher for the estimates than for the true values. Asymptotically, the magnitude of the $\hat{\xi}_{j} s$ will become unimportant as the number of cells will go to infinity, if increased with the number of observations at a speed $T^{04}$.

In order to investigate the order of magnitude of the $\xi_{j} s$, the test statistic was also computed for other parameter values. Heuristically speaking, it is only advisable to reduce the degrees of freedom if the outcome of the test is systematically lower for the ML estimators than for other possible parameter outcomes. More formally, if:

$$
g(X, \hat{\theta})<\int_{\Theta} g(X, u) f(u) d u
$$

where $g(X, \hat{\theta})$ is the test statistic, evaluated at the maximum likelihood estimators, and $f(u)$ is the asymptotic density function of the maximum likelihood estimator. By integrating out the uncertainty about the parameter estimators (by means of simulation), the test statistic might be more closely related to the test statistic for the true parameters.

For most models under investigation in this study, the differences between the two test statistics of equation (A.4) were small. For some models, the

\footnotetext{
${ }^{3}$ Therefore, the statistic is sometimes called the Chornoff-Lehmann statistic
} 
the sign of the bias in small samples, it is not clear that the test statistic is systematically lower when evaluated at the estimated parameters than for other possible parameter values, so no degrees of freedom adjustment seems needed. Asymptotically, the number of cells goes to infinity, so the bias becomes unimportant. 


\section{Appendix B}

\section{Moments of the mixture distributions}

The distribution of the error term of the Bernoulli jump model with $N\left(\theta, \delta^{2}\right)$ distributed jump sizes and heteroskedastic normal innovations can be expressed in the following way

$$
\varepsilon_{t}^{B e r n} \sim(1-\lambda) N\left(-\lambda \theta, h_{t}^{2}\right)+\lambda N\left((1-\lambda) \theta, h_{t}^{2}+\delta^{2}\right) .
$$

From this distribution we compute the first four unconditional moments, $\mu_{1}^{B}$ to $\mu_{4}^{B}$ as linear combinations of non-central moments of normal distributions.

$$
E\left(\varepsilon_{t}^{B e r n}\right)=E[(1-\lambda)(-\lambda \theta)+\lambda(1-\lambda) \theta]=0=\mu_{1}^{B} .
$$

The second moment can be computed from

$$
E\left(\varepsilon_{t}^{\text {Bern }}\right)^{2}=E\left[(1-\lambda)\left\{(-\lambda \theta)^{2}+h_{t}^{2}\right\}+\lambda\left\{(1-\lambda)^{2} \theta^{2}+h_{t}^{2}+\delta^{2}\right\}\right],
$$

so that

$$
\mu_{2}^{B}=\left(\lambda-\lambda^{2}\right) \theta^{2}+E h^{2}+\lambda \delta^{2},
$$

where $E h^{2}$ is the unconditional expectation of $h_{t}^{2}$, which can be estimated by its sample mean. For the $\operatorname{GARCH}(p, q)$ specification it is possible to eliminate $E h^{2}$ and express $\mu_{2}^{B}$ only in terms of the parameters in the model. This is not done here to keep the result applicable to other variance specifications as well. 
For the third moment one gets:

$$
\begin{aligned}
E\left(\varepsilon_{t}^{B e r n}\right)^{3}=E\left[(1-\lambda)\left\{(-\lambda \theta)^{3}-3 \lambda \theta h_{\ell}^{2}\right\}+\right. \\
\left.\lambda\left\{(1-\lambda)^{3} \theta^{3}+3(1-\lambda) \theta\left(h_{\imath}^{2}+\delta^{2}\right)\right\}\right],
\end{aligned}
$$

and

$$
\mu_{3}^{B}=\left(\lambda-\lambda^{2}\right) \theta\left\{(1-2 \lambda) \theta^{2}+3 \delta^{2}\right\} .
$$

So that the skewness $(M 3)$ is equal to:

$$
M 3^{B} \equiv \frac{\mu_{3}^{B}}{\left(\mu_{2}^{B}\right)^{3 / 2}}=\frac{\left(\lambda-\lambda^{2}\right) \theta\left\{(1-2 \lambda) \theta^{2}+3 \delta^{2}\right\}}{\left(\left(\lambda-\lambda^{2}\right) \theta^{2}+E h^{2}+\lambda \delta^{2}\right)^{3 / 2}} .
$$

Finally, the fourth moment can be deduced from:

$$
\begin{aligned}
E\left(\varepsilon_{t}^{B e r n}\right)^{4}= & E\left[(1-\lambda)\left\{(-\lambda \theta)^{4}+6(-\lambda \theta)^{2} h_{t}^{2}+3 h_{t}^{4}\right\}+\right. \\
& \left.\lambda\left\{(1-\lambda)^{4} \theta^{4}+6(1-\lambda)^{2} \theta^{2}\left(h_{t}^{2}+\delta^{2}\right)+3\left(h_{t}^{2}+\delta^{2}\right)^{2}\right\}\right],
\end{aligned}
$$

so that

$$
\begin{aligned}
\mu_{4}^{B}=\left(\lambda-\lambda^{2}\right) \theta^{2}\left\{\left(1-3 \lambda+3 \lambda^{2}\right) \theta^{2}\right. \\
\left.+6 E h^{2}+6(1-\lambda) \delta^{2}\right\}+3 E h^{4}+6 \lambda \delta^{2} E h^{2}+3 \lambda \delta^{4}
\end{aligned}
$$

and

$$
\begin{aligned}
M 4^{B} & \equiv \frac{\mu_{4}^{B}}{\left(\mu_{2}^{B}\right)^{2}}-3 \\
& =\frac{3 V\left(h^{2}\right)+\left(\lambda-\lambda^{2}\right)\left\{3 \delta^{4}+(6-12 \lambda) \theta^{2} \delta^{2}+\left(1-6 \lambda+6 \lambda^{2}\right) \theta^{4}\right\}}{\left(\left(\lambda-\lambda^{2}\right) \theta^{2}+E h^{2}+\lambda \delta^{2}\right)^{2}} .
\end{aligned}
$$

where $V\left(h^{2}\right)$ is the unconditional variance of $h_{t}^{2}$, which can be estimated by its sample analog. 
The distribution of the error term of the Poisson-normal mixture has the following form

$$
\varepsilon_{t}^{P_{o i s}} \sim e^{-\lambda} \sum_{j=0}^{\infty} \frac{\lambda^{j}}{j !} N\left((j-\lambda) \theta, h_{t}^{2}+j \delta^{2}\right) .
$$

From this distribution, the first four unconditional moments, $\mu_{1}^{P}$ to $\mu_{4}^{P}$ can be computed as linear combinations of non-central moments of normal distributions.

$$
\begin{aligned}
& E\left(\varepsilon_{t}^{\text {Pois }}\right)=E\left[e^{-\lambda} \sum_{j=0}^{\infty} \frac{\lambda^{j}}{j !}(j-\lambda) \theta\right]=e^{-\lambda} e^{\lambda}(\lambda-\lambda) \theta=0 \\
& \mu_{1}^{P}=0 .
\end{aligned}
$$

The second moment can be derived from

$$
E\left(\varepsilon_{t}^{P o i s}\right)^{2}=E\left[e^{-\lambda} \sum_{j=0}^{\infty} \frac{\lambda^{j}}{j !}\left((j-\lambda)^{2} \theta^{2}+h_{t}^{2}+j \delta^{2}\right)\right]
$$

so that

$$
\mu_{2}^{P}=\lambda \theta^{2}+E h^{2}+\lambda \delta^{2}
$$

For the third moment one gets:

$$
E\left(\varepsilon_{t}^{P_{\text {ois }}}\right)^{3}=E\left[e^{-\lambda} \sum_{j=0}^{\infty} \frac{\lambda^{j}}{j !}\left((j-\lambda)^{3} \theta^{3}+3(j-\lambda) \theta\left(h_{t}^{2}+j \delta^{2}\right)\right)\right]
$$

and

$$
\mu_{3}^{P}=\lambda \theta^{3}+3 \lambda \theta \delta^{2}
$$

So

$$
M 3^{P} \equiv \frac{\mu_{3}^{P}}{\left(\mu_{2}^{P}\right)^{3 / 2}}=\frac{\lambda \theta^{3}+3 \lambda \theta \delta^{2}}{\left(\lambda \theta^{2}+E h^{2}+\lambda \delta^{2}\right)^{3 / 2}}
$$


Finally, the fourth moment can be deduced from:

$$
\begin{array}{r}
E\left(\varepsilon_{t}^{\text {Pois }}\right)^{4}=E\left[e ^ { - \lambda } \sum _ { j = 0 } ^ { \infty } \frac { \lambda ^ { j } } { j ! } \left((j-\lambda)^{4} \theta^{4}+6(j-\lambda)^{2} \theta^{2}\left(h_{t}^{2}+j \delta^{2}\right)+\right.\right. \\
\left.\left.3\left(h_{t}^{2}+j \delta^{2}\right)^{2}\right)\right]
\end{array}
$$

so that

$$
\begin{array}{r}
\mu_{4}^{P}=\left(3 \lambda^{2}+\lambda\right) \theta^{4}+6 \lambda \theta^{2} E h^{2}+3\left(\lambda^{2}+\lambda\right) \delta^{2}\left(2 \theta^{2}+\delta^{2}\right)+ \\
3 E h^{4}+6 \lambda \delta^{2} E h^{2}
\end{array}
$$

and

$$
M 4^{P} \equiv \frac{\mu_{4}^{P}}{\left(\mu_{2}^{P}\right)^{2}}-3=\frac{3 V\left(h^{2}\right)+\lambda \theta^{4}+6 \lambda \theta^{2} \delta^{2}+3 \lambda \delta^{4}}{\left(\lambda \theta^{2}+E h^{2}+\lambda \delta^{2}\right)^{2}}
$$




\section{Appendix C}

\section{Data sources}

- Central parities: Ungerer et al. (1990), table 4, appended by the author.

- Survey exchange rates: Business International Corporation, Cross Rates Bulletin.

All the other variables are taken from Datastream:

- Wrokly Wednesday exchange rates: London Eurocurrency market (middle rates). All currencies were measured in the British pound. D-mark rates were computed assuming perfect arbitrage.

- Weekly Wednesday interest rates: London Eurocurrency market. For table 3.6 the one week D-mark interest rates used are offer rates, for the other currencies bid rates were used. In chapter four, middle rates were used.

- Monthly consumer prices: International Financial Statistics (line 64).

- Monthly producer prices (for the Irish exchange rate model): International Financial Statistics (line 63).

- Monthly trade balance figures: OECD, Main Economic Indicators, imports and exports in US dollar terms.

- Monthly exchange rates (chapter 5): middle rate dollar quotations from Barclays bank. D-mark rates were computed assuming perfect arbitrage. 
- Monthly call money rates: International Financial Statistics (line 60B).

- Business cycle indicator: OECD, composite leading indicator (trend restored), detrended by a quadratic trend over 1979:4 - 1993:6.

- Monthly current account: Monthly Report of the Deutsche Bundesbank.

- Quarterly GDP: Monthly Report of the Deutsche Bundesbank. To get monthly data, a linear interpolation was used. 


\section{References}

[1] Akgiray, V. and G.G. Booth (1988), "Mixed Diffusion-Jump Process Modeling of Exchange Rate Movements," The Review of Economics and Statistics 70, 631-637.

[2] Andrews, D.W.K. (1988), "Chi-Square Diagnostic Tests for Econometric Models: Theory," Econometrica 56, 1419-1453.

[3] Baillie, R.T. and T. Bollerslev (1989), "The Message in Daily Exchange Rates: A Conditional-Variance Tale," Journal of Business \& Economic Statistics 7, 297-305.

[4] Ball, C.A. and A. Roma (1993), "A Jump Diffusion Model for the Euro. pean Monetary System," Journal of International Money and Finance $12,475-492$.

[5] Ball, C.A. and W. Torous (1983), "A Simplified Jump Process for Common Stock Returns," Journal of Financial and Quantitative Analysis 18, 53-65.

[6] Ball, C.A. and W. Torous (1985), "On Jumps in Stock Prices and Their Impact on Call Option Pricing," Journal of Finance 40, 155-173.

[7] Bayoumi, T. and B. Eichengreen (1993), "Shocking Aspects of European Monetary Unification," in: Torres, R. and F. Giavazzi (eds.) Adjustment and Growth in the European Monetary Union, Cambridge: Cambridge University Press, forthcoming.

[8] Beetsma, R.M.W.J. (1992), "Imperfect Credibility of the Band and Risk Premia in the European Monetary System," CentER Discussion Paper 9254, Tilburg University.

[9] Beetsma, R.M.W.J. (1993), "Bands and Statistical Properties of EMS Exchange Rates: A Monte Carlo Investigation of Three Target Zone Models," Journal of International Money and Finance, forthcoming. 
[10] Bera, A.K. and M.L. Higgins (1993), "ARCH Models: Properties, Estimation and Testing," Journal of Economic Surveys 7, 305-366.

[11] Bertola, G. (1993), "Continuous-Time Models of Exchange Rates and Intervention," in: F. van der Ploeg (ed.), Handbook of International Macroeconomics, London: Basil Blackwell.

[1'] Bertola, G. and R.J. Caballero (1992), "Targct Zones and Realignments," American Economic Review 82, 520-536.

[13] Bertola, G. and L.E.O. Svensson (1993), "Stochastic Devaluation Risk and the Empirical fit of Target Zone Models," Review of Econornic Studies 60, 689-712.

[14] Biltoft, K. and C. Boersch (1992), "Interest Rate Causality and Asymmetry in the EMS," Open Economies Review 3, 297-306.

[15] Black, S.W. (1983), "The Use of Monetary Policy for Internal and External Balance in Ten Industrial Countries," in: J.A. Frenkel (ed.), Exchange Rates and International Macroeconomics, The University of Chicago Press.

[16] Blackburn, K. and M. Sola. (1993), "Speculative Currency Attacks and Balance of Payments Crises," Journal of Economic Surveys 7, 119-144.

[17] Bollerslev, T. (1986), "Generalized Autoregressive Conditional Heteroskedasticity," Journal of Econometrics 31, 307-327.

[18] Bollerslev, T. (1988), "On the Correlation Structure for the Generalized Autoregressive Conditional Heteroskedastic Process," Journal of Time Series Analysis 9, 121-131.

[19] Bollerslev, T. (1990), "Modeling the Coherence in Short-run Nominal Exchange Rates: A Multivariate Generalized ARCH Model," The Review of Economics and Statistics 72, 498-505.

[20] Bollerslev, T., R.Y. Chou and K. Kroner (1992), "ARCH Modeling in Finance: A Review of the Theory and Empirical Evidence," Journal of Econometrics 52, 5-59.

[21] Boothe, P. and D. Glassman (1987), "The Statistical Distribution of Exchange Rates," Journal of International Economics 22, 297-319. 
[22] Boswijk, H.P. (1992), Cointegration, Identification and Exogeneity: Inference in Structural Error Correction Models, Thesis, Tinbergen Institute Research Series 37, Amsterdam.

[23] Broyden, G. (1965), "A Class of Methods for Solving Nonlinear Simultaneous Equations," Mathematics of Computation 19, 577-593.

[24] Bruneau, C., H. Dauphin, E. Jondeau and J.-P. Nicolaï (1992) "FranceAllemagne: Asymétries et Convergences," Document de Travail. Caisse des Dépôts et Consignations 1992-19/E, Paris.

[25] Campbell, J. and P. Perron (1991), "Pitfalls and Opportunities: What Macroeconomists should know About Unit Roots," NBER technical Working Paper 100.

[26] Campbell, J. and P. Perron (1992), "Racines Unitaires en Macroéconomie: le Cas Multidimensionnel," Annales d'Economie et de Statistique 27, 1-50.

[27] Cavaglia, S.M.F.G., C.G. Koedijk and P.J.G.Vlaar (1994), "Exchange Rate Expectations and Risk Premia in the European Monetary System: 1985-1991," Open Economies Review, Forthcoming.

[28] Chen, Z. and A. Giovannini (1993), "The Determinants of Realignment Expectations under the EMS: Some Empirical Regularities," NBER Working Paper 4291.

[29] Chernoff, H. and E. Lehmann (1954), "The Maximum Likelihood Estimate in $\chi^{2}$ Tests for Goodness of Fit," Annals of Mathematical Statistics 25, 579-586.

[30] De Ceuster, M. and D. Trappers (1992), "Diagnostic Checking of Estimation with a Student- $t$ Error Density," Paper presented at the ESEM conference, Brussels, August 1992.

[31] De Grauwe, P. (1992), The Economics of Monetary Integration, Oxford: Oxford University Press.

[32] De Grauwe, P. and W. Vanhaverbeke (1991), "Is Europe an Optimal ('urrency Area? Evidence from Regional Data," CEPR Discussion Paper 555.

[33] De Jong, F.C.J.M. (1993), "A Univariate Analysis of EMS Exchange Rates Using a Target Zone Model," Journal of Applied Econometrics, forthcoming. 
[34] Delors Committee (1989), Report on Economic and Monetary Union in the European Community, Committee for the Study of Economic and Monetary Union, chaired by Jacques Delors.

[35] Diebold, F.X. (1987), "Testing for Serial Correlation in the Presence of ARCH," Proceedings from the American Statistical Association, Business 8 Economics Section, 323-328.

[36] Dominguez, K.M. and P.B. Kenen (1992), "Intramarginal Intervention in the EMS and the Target-Zone Model of Exchange-Rate Behavior," European Economic Review 36, 1523-1532.

[37] Dornbusch, R. (1991), "Problems of European Monetary Integration" in A. Giovannini and C. Mayer (eds.), European Financial Integration, ('ambridge: Cambridge University Press.

[38] Dumas, B. and L.F.O. Svensson (1991), "How Long Do Unilateral Target Zones Last," NBER Working Paper 3931.

[39] Edin, P.A. and A. Vredin (1991), "Devaluation Risk: Evidence from the Nordic Countries," FIEF Working Paper, Stockholm.

[40] Eichengreen, B. (1992), "Is Europe an Optimal Currency Area?," in: S. Borner and H. Grubel (eds.), The European Community after 1992: Perspectives from the Outside, London: Macmillan, 138-161.

[41] Engle, R. (1982), "Autoregressive Conditional Heteroskedasticity with Estimates of the Variance of United Kingdom Inflation," Econometrica 50, 987-1007.

[42] Engle, R.F. and C.W.J. Granger (1987), "Co-integration and Error Correction: Representation, Estimating and Testing," Econometrica $\mathbf{5 5}, 251-276$.

[43] Engle, R.F., D.F. Hendry and J.-F. Richard (1983), "Exogeneity," Econometrica 51, 277-304.

[44] Feinstone, L.J. (1987), "Minute by Minute: Efficiency, Normality and Randomness in Intra-Daily Asset Prices," Journal of Applied Econometrics 2, 193-214.

[45] Flood, R.P., Rose, A.K. and D.J. Mathieson (1991), "An Empirical Exploration of Exchange-Rate Target Zones," Carnegie-Rochester Conference Series on Public Policy 35, 7-66. 
[46] Frankel, J.A. and K. Froot (1990), "Exchange rate Forecasting Techniques, Survey Data, and Applications for the Foreign Exchange Market," NBER Working Paper 3470.

[47] Frankel, J.A. and S. Phillips (1991), "The European Monetary System: Credible at Last?," NBER Working Paper 3819.

[48] Froot, K. (1990), "Short Rates and Expected Asset Returns," NBER Working Paper 3247.

[49] Gardeazabal, J. and M. Regúlez (1992), The Monetary Model of Exchange Rates and Cointegration: Estimation, Testing and Prediction, (Lecture Notes in Fconomics and Mathematical Systems, vol. 385), New-York: Springer Verlag.

[50] Geweke, J. (1986), "Modelling the Persistence of Conditional Variances: Comment," Econometric Reviews 5, 57-61.

[51] Giavazzi, F. and A. Giovannini (1989), Limited Exchange Rate Flexibility, Cambridge: MIT Press.

[52] Giavazzi, F. and M. Pagano (1988), "The Advantage of Tying one's Hands: EMS Discipline and Central Bank Credibility," European Econornic Review 32, 1055-1082.

[53] Giovannini, A. (1990), "European Monetary Reform, Progress and Prospects," Brooking Papers on Economic Activity 2, 217-291.

[54] Gouriéroux, C., A. Monfort and A. Trognon (1984), "Pseudo Maximum Likelihood Methods: Theory," Econometrica 53, 681-700.

[55] Heckman, J.J. (1984), "The $\chi^{2}$ Goodness of Fit Statistic for Models with Parameters Estimated from Microdata," Econometrica 52, 15431547.

[56] Henry, J. and J. Weidmann (1993), "Asymmetry in the EMS Revisited: Evidence from the Causality Analysis of Daily Eurorates," Mimeo, Banque de France.

[57] Hsieh, D.A. (1989), "Modeling Heteroskedasticity in Daily ForeignExchange Rates," Journal of Business \& Economic Statistics 7, 307317 . 
[58] Hodrick, R.J. (1987), The Empirical Evidence on the Efficiency of Forward and Futures Foreign Exchange Markets, Chur: Harwoord Academic Publishers.

[59] Hodrick, R.J. and S. Srivastava (1984), "An investigation of Risk and Return in l'orward Foreign Exchange," Journal of International Money and Finance 3, 5.29.

[60] Johansen, S. (1988), "Statistical Analysis of Cointegrating Vectors," Journal of Economic. Dynamics and Control 12, 231-254.

[61.] Johansen, S. (1991), "Estimation and Hypothesis testing of Cointegration in Vector Gaussian Autoregressive Models," Econometrica 59, $1551-1580$.

[62] Johansen, S. (1992), "Cointegration in Partial System and the Efficiency of Single Equation Analysis," Journal of Econometrics 52, 389 402.

[63] Johansen, S. and K. Juselius (1990), "Maximum Likelihood Estimation and Inference on Cointegration - With Applications to the Demand for Money," Oxford Bulletin of Economics and Statistics 52, 169-210.

[64] Jorion, P. (1988), "On Jump Processes in the Foreign Exchange and Stock Markets," The Review of Financial Studies 1, 427-445.

[65] Kendall, M. and A. Stuart (1967), The Advanced Theory of Statistics, vol.2, Inference and Relationship, New York: Haffner.

[66] Kodde, D.A. and F.C. Palm (1986), "Wald Criteria for Testing Equality and Inequality Restrictions," Econometrica 54, 1243-1248.

[67] Koedijk, C.G. and C.J.M. Kool (1993), "Betting on the EMS," Open Economies Review 4, 151-173.

[68] Koedijk, C.G. and P.C. Schotman (1990), "How to Beat the Random Walk: An Empirical Model of Real Exchange Rates," Journal of International Economics 29, 311-332.

[69] Koedijk, C.G., Stork, P.A. and C.G. de Vries (1993), "An EMS Target Zone Model in Discrete Time," Limburg Institute of Financial Economies, Working Paper 93-02. 
[70] Krasker, W.S. (1980), "The 'Peso Problem' in Testing the Efficiency of Forward Exchange Markets," Journal of Monetary Economics 6, 269-76.

[71] Krugman, P. (1991), "Target Zones and Exchange Rate Dynamics," Quarterly Journal of Economics 56, 669-682.

[72] Krugman, P. and M.H. Miller (1992), "Why have a Target Zone," Carnegie Rochester Series on Public Policy, forthcoming.

[73] Krugman, P. and J. Rotemberg (1990), "Target Zones and Limited Reserves," NBER Working Paper 3418.

[74] Lindberg, H. and P. Söderlind (1991), "Target Zones and the Intervention Policy: The Swedish Case," Mimeo Sveriges Riksbank and IIES, Stockholm.

[75] MacDonald, R. and M.P. Taylor (1992), "Exchange Rate Economics," IMF Staff Papers 39, 1-57.

[76] McFarland, J.W., R.R. Pettit and S.K. Sung (1982), "The Distribution of Foreign Exchange Price Changes: Trading Day Effects and Risk Measurement," Journal of Finance 37, 693-715.

[77] McFarland, J.W., R.R. Pettit and S.K. Sung (1987), "The Distribution of Foreign Exchange Price Changes: Trading Day Effects and Risk Measurement: A Reply," Journal of Finance 42, 189-194.

[78] Meese, R.A. and K.R. Rogoff (1983), "Empirical Exchange Rate Models of the Seventies: Do they Fit out of Sample," Journal of International Economics 14, 3-24.

[79] Meese, R.A. and A.K. Rose (1990), "Nonlineär, Nonparametric, Nonessential Exchange Rate Estimation," American Economic Review 80, 192-196.

[80] Mosconi, R. and C. Giannini (1992), "Non-causality in Cointegrated Systems: Representation, Estimating and Testing," Oxford Bulletin of Economics and Statistics 54, 399-417.

[81] Nelson, D.B. (1990), "Stationarity and Persistence in the GARCH( 1,1$)$ Model," Econometric Theory 6, 318-334.

[82] Nelson, D.B. (1991), "Conditional Heteroskedasticity in Asset Returns: A New Approach," Econometrica 59, 347-370. 
[83] Nelson, D.B. and C.Q. Cao (1992), "Inequality Constraints in the Univariate GARCH Model," Journal of Business 83 Economic Statistics 10, 229-235.

[84] Newey, W.K. and K.D. West (1987), "A Simple, Positive Semi-Definite, Heteroskedasticity and Autocorrelation Consistent Covariance Matrix," Econometrica 55, 703-708.

[85] Nieuwland, F.G.M.C., W.F.C. Verschoor and C.C.P. Wolff (1991), "EMS Exchange Rates," Journal of International H'inancial Markets, Institutions and Money 2, 2142.

[86] Obstfeld, M. (1991), "Destabilizing Effects of Exchange-Rate Escape Clauses," NBER Working Paper 3603.

[87] Pearson, K. (1933), "On a Method of Determining Whether a Sample of Sizen Supposed to have been Drawn from a Parent Population Having a Known Probability Integral has Probably been Drawn at Random," Biometrika 25, 379-410.

[88] Pesaran, M.H. and H. Samiei (1992), "An Analysis of the Determination of the DM/FF Exchange Rate in a Discrete-Time Target-Zone Model," The Economic Journal 102, 388-401.

[89] Phillips, P.C.B. and M. Loretan (1991), "Estimating Long Run Equilibria," Review of Economic Studies 58, 407-436.

[90] Rose, A.K. and L.E.O. Svensson (1991), "Expected and Predicted Realignments: the FF/DM Exchange Rate during the EMS," IIES Seminar Paper 485; NBER Working Paper 3685, CEPR Discussion Paper 552.

[91] Rose, A.K. and L.E.O. Svensson (1993), "European Exchange Rate Credibility Before the Fall," European Economic Review, forthcoming.

[92] Schwarz, G. (1978), "Estimating the Dimension of a Model," Annals of Statistics 6, 461-464.

[93] Schächter, A. and A.C.J. Stokman (1992), "Interest Rate Policy of the Deutsche Bundesbank: An Econometric Analysis for 1975 to 1992," Research Memorandum WO\&E 9223, De Nederlandsche Bank, Amsterdam. 
[94] Smith, J.Q. (1985), "Diagnostic Checks of Non-standard Time Series Models," Journal of Forecasting 4, 283-291.

[95] So, J.C. (1987), "The Distribution of Foreign Exchange Price Changes: Trading Day Effects and Risk Measurement - A Comment," Journal of Finance 42, 181-188.

[96] Svensson, L.E.O. (1991), "The Simplest Test of Target Zone Credibility," IMF Staff Papers $\mathbf{3 8 .}$

[97] Svensson, L.E.O. (1992a), "An Interpretation of Recent Research on Exchange Rate Target Zones," Journal of Economic Perspectives 6, $119-14 \%$.

[98] Svensson, L.E.O. (1992b), "The Foreign Exchange Risk Premium in a Target Zone with Devaluation Risk," Journal of International Economics 33, 21-40.

[99] Svensson, L.E.O. (1993), "Assessing Target Zone Credibility: Mean Reversion, and Devaluation Expectation in the ERM, 1979-1992," European Economic Review 37, 763-802.

[100] Tauchen, G. (1985), "Diagnostic Testing and Evaluation of Maximum Likelihood Models," Journal of Econometrics 30, 415-443.

[101] Tucker, A.L. and L. Pond (1988), "The Probability Distribution of Foreign Exchange Price Changes: Tests of Candidate Processes," The Review of Economics and Statistics 70, 638-647.

[102] Ungerer, H., J.J.Hauvonen, A. Lopez-Claros and T. Mayer (1990), "The European Monetary System: Developments and Perspectives," Occasional Paper 73, IMF, Washington.

[103] Urbain, J.-P. (1993), "Partial Versus Full System Modelling of Cointegrated Systems: An Empirical Illustration," Journal of Econometrics, forthcoming.

[104] Van Wijnbergen, S. (1984), "The 'Dutch Disease': a Disease after all?," The Economic Journal 94, 41-55.

[105] Vlaar, P.J.G. (1992), "Target Zones and Realignment Risk: An Integrated Approach," Research Memorandum 92-050, University of Limburg. 
[106] Vlaar, P.J.G. (1993), "Simple Diagnostic Tests for Likelihood Functions with an Application to Daily US Dollar Rates," Research Memorandum 93-004, University of Limburg.

[107] Vlaar, P.J.G. (1994), "German Interest Rates and the European Monetary System," LIFE Working Paper 94-15, University of Limburg.

[108] Vlaar, P.J.G. and F.C. Palm (1993a), "The Message in Weekly Exchange Rates in the European Monetary System: Mean Reversion, Conditional Heteroskedasticity and Jumps," Journal of Business 6 Economic Statistics 11, 351-360.

[109] Vlaar. P.J.G. and F.C. Palm (1993b), "Inflation Differentials and Excess Returns in the European Monetary System," LIFE Working Paper 93-10, University of Limburg; CEPR-ESF Working Paper Series of the Network in Financial Markets 38.

[110] Weber, A.A. (1991), "Reputation and Credibility in the European Monetary System," Economic Policy 12, 58-102.

[111] Willms, M. (1983), "The Monetary Decision Process in the Federal Republic of Germany," in: D.R. Hodgman (ed.), The Political Economy of Monetary Policy: National and International Aspects, FRB of Boston, Conference Series 26, 34-58.

[112] Wolff, C.C.P. (1987), "Forward Exchange Rates, Expected Spoi Rates and Premia: A Signal-Extraction Approach," Journal of Finance 42, 395-406.

[113] Wooldridge, J.M. (1990), "A Unified Approach to Robust RegressionBased Specification Tests," Econometric Theory 6, 17-43. 


\section{Author Index}

Akgiray, V., 6, 23, 31

Andrews, D.W.K., 130

Baillie, R.T., 6, 15

Ball, C.A., 21, 23, 28, 126

Bayoumi, T., 94

Beetsma, R.M.W.J., 9, 76

Bera, A.K., 5

Bertola, G., 7, 8, 9

Biltoft, K., 98

Black, S.W., 104

Blackburn, K., 9

Boersch, C., 98

Bollerslev, T., 5, 6, 15, 17, 22, 31, $38,43,60,68,113,125$

Boothe, P., 6, 23, 31

Boswijk, H.P., 100, 102, 103, 104

Broyden, G., 24

Bruneau, C., 98

Caballero, R.J., 8

Campbell, J., 99

Cao, C.Q., 24

Cavaglia, S.M.F.G., v

Chen, Z., 67

Chou, R.Y., 6

Chernoff, H., 128

Dauphin, H., 98

De Ceuster, M., 125

De Grauwe, P., 79, 94

De Jong, F.C.J.M., 9

Delors Committee, 4

De Vries, C.G., 36, 54, 57

Diebold, F.X., 37, 64

Dominguez, K.M., 48
Dornbusch, R., 87

Dumas, B., 9

Edin, P.A., 10

Eichengreen, B., 94

Engle, R.F., 5, 15, 99, 100

Feinstone, L.J., 23

Flood, R.P., 9

Frankel, J.A., 10, 35, 80, 86, 90

Froot, K., 60, 90

Gardeazabal, J., 101

Goweke, J., 6

Giannini, C., 100, 102

Giavazzi, F., 2, 3, 38, 61, 65, 110

Giovannini, A., 2, 38, 61, 67, 88

Glassman, D., 6

Gouriéroux, C., 126

Granger, C.W.J., 99

Hauvonen, J.J., 22, 38, 80, 137

Heckman, J.J., 126, 131

Hendry, D.F., 100

Henry, J., 98

Higgins, M.L., 5

Hsieh, D.A., 6, 15, 23

Hodrick, R.J., 61, 87

Johansen, S., 100, 101, 102

Jondeau, E., 98

Jorion, P., 6, 12, 15, 16, 23, 24

Juselius, K., 100

Kendall, M., 126

Kenen, P.B., 48

Kodde, D.A., 24

Koedijk, C.G., v, 36, 46, 54, 57

Kool, C.J.M., 36, 54, 57 
Krasker, W.S., 51, 55, 60, 87

Kroner, K, 6

Krugman, P., 7, 9, 85

Lehmann, E., 128

Lindberg, H., 8

Lopez-Claros, A., 22, 38, 80, 137

Loretan, M., 99

MacDonald, R., 60

Mathieson, D.J., 9

Mayer, T., 22, 38, 80, 137

McFarland, J.W., 6

Meese, R.A., 9, 36, 49, 51, 85

Miller, M.H., 9

Monfort, A., 126

Mosconi, R., 100, 102

Nelson, D.B., 5, 24, 26

Newey, W.K., 88

Nicolaï, J.-P., 98

Nieuwland, F.G.M.C., 7, 12, 16, 23, 24

Obstfeld, M., 38, 66

Pagano, M., 3, 65, 110

Palm, F.C., v, 24

Pearson, K., 128

Perron, P., 99

Pesaran, M.H., 8

Pettit, R.R., 6

Phillips, P.C.B., 99

Phillips, S., 10, 35, 80, 86

Pond, L., 6, 23, 30, 31

Regúlez, M., 101

Richard, J.-F., 100

Rogoff, K.R., 36, 49

Roma, A., 23

Rose, A.K., 9, 10, 51, 85, 88

Rotemberg, J., 9
Samiei, H., 8

Schotman, P.C., 46

Schwarz, G., 30

Schächter, A., 97, 104

Smith, J.Q., 128

So. J.C., 6

Sola. M., 9

Srivastava. S., 87

Stokman, A.C.J., 97, 104

Stork, P.A., 36, 54, 57

Stuart, A., 126

Sung, S.K., 6

Svensson, L.E.O., 7, 9, 10, 61, 76, $77,80,85,88$

Söderlind, P., 8

Tauchen, G., 130, 131

Taylor, M.P., 60

Torous, W., 21, 23, 28, 126

Trappers, D., 125

Trognon, A., 126

Tucker, A.L., 6, 23, 30, 31

Ungerer, H., 22, 38, 80, 137

Urbain, J.-P., 99

Vanhaverbeke, W., 94

Van Wijnbergen, S., 48

Verschoor, W.l'.C., 7, 12, 16, 23, 24

Vlaar, P.J.G., v

Vredin, A., 10

Weber, A.A., 35, 38, 80

Weidmann, J., 98

West, K.D., 88

Willms, M., 104

Wolff, C.C.P., 7, 12, 16, 23, 24, 88

Wooldridge, J.M., 89 


\section{Samenvatting (Summary in Dutch)}

Sinds 1979 worden de wisselkoersen van de lidstaten van de Europese Gemeenschap gecoördineerd binnen het Europees Monetaire Stelsel (EMS). Voor de munten die participeren in het wisselkoers mechanisme van het EMS zijn onderlinge middenkoersen (pariteiten) afgesproken waar de de werkilijke koersen slechts in beperkte mate van af mogen wijken. Slechts binnen een smalle fluctuatie band (de docl-zone) mag de koers bewegen. Als een wisselkoers buiten de doel-zone dreigt te geraken, zijn de monetaire autoriteiten verplicht om in te grijpen. Zij kunnen dit zowel doen door zelf de eigen munt aan te bieden of op te kopen (directe interventies) als door middel van rente beleid. In de economische literatuur, zoals besproken in hoofdstuk 1, heeft men vooral gekeken naar de stabiliserende effecten van zo'n band op de wisselkoers. Als alle EMS lidstaten ermee instemmen is het echter ook mogelijk om de pariteiten aan te passen. In dit proefschrift zijn vooral de gevolgen van deze mogelijkheid aan de orde gekomen.

Aangezien de wisselkoersen slechts mogen fluctueren binnen beperkte marges, leiden veranderingen in onderlinge concurrentie kracht niet onmiddellijk tot grote wisselkoers-aanpassingen. Wezenlijke wisselkoers veranderingen zijn alleen mogelijk als de pariteiten worden aangepast. Omgekeerd betekent dit ook dat voor de bepaling van de gewenste devaluatic grootte alle economische veranderingen sinds de laatste pariteits-aanpassing van belang zijn. Zeker als er weinig aanpassingen plaatsvinden of als de verschillen tussen de landen groot zijn kan dit leiden tot grote pariteits-aanpassingen. Aangezien bovendien het tijdstip van een devaluatie bijzonder moeilijk te voorspellen is zal men niet graag beleggen in een overgewaardeerde munt. De rente op deze munt zal dientengevolge relatief hoog moeten zijn. Bovendien zal de aankondiging van negatief "nieuws" omtrent deze munt snel leiden tot paniek-reacties in de markt, met een plotselinge waardevermindering van de munt (voor zover mogelijk binnen de band) en nog hogere rentestanden 


\section{tot gevolg.}

Deze plotselinge depreciaties binnen de band kunnen ook veroorzaakt worden door zogenaamde speculatieve aanvallen. Het bestaan van een officiële band maakt het mogelijk om sprongen in de wisselkoers tot op zekere hoogte te voorspellen, omdat de autoriteiten de verplichting op zich hebben genomen om de band te verdedigen. Als de speculanten in staat zijn om een devaluatie te forceren (door zeer veel van een munt aan te bieden) kunnen zij daar zeer grote winsten mee behalen. Deze speculatieve aanvallen waren zeer prominent aanwezig tussen september 1992 en augustus 1993 en hebben geleid tot het verbreden van de doel-zone.

In hoofdstuk 2 worden tijdreeks-modellen geschat voor verschillende EMS munten ten opzichte van de Duitse mark. Aangetoond wordt dat grote plotselinge depreciaties, als gevolg van devaluaties, paniek reacties of speculatieve aanvallen, gemodelleerd kunnen worden door middel van "sprongen". De statistische betekenis van een sprong is een extra trekking uit een normale verdeling met een positief gemiddelde (meestal een depreciatie) en een grote variantie (toename van de onzekerheid). Voor wat betreft de kans op een sprong zijn de Bernoulli en Poisson specificaties met elkaar vergeleken. Het model is verder gespecificeerd met een "Moving Average" (MA) en een "Gegeneraliseerd Auto Regressief Conditioneel Heteroskedasticiteit" (GARCH) specificatie. De MA term modelleert de stabiliserende effecten van de interventie politiek van de monetaire autoriteiten. De GAR('H specificatie beschrijft de tijds-variërende onzekerheid. De resultaten tonen aan dat de sprongen een zeer belangrijke invloed hebben op de MA-GARCH specificatie, waarbij de verschillen tussen de Bernoulli en Poisson specificaties verwaarloosbaar zijn.

In hoofdstuk 3 zijn aan deze modellen twee aspecten toegevoegd. Ten eerste is de afwijking van de huidige koers ten opzichte van zijn pariteit opgenomen als extra verklarende variabele in het model. Deze variabele beschrijft het feit dat de koersen meestal de neiging hebben om naar de pariteit terug te keren. Ten tweede is de kans op een sprong tijds-variërend gemaakt. Aangezien de sprongen het gevolg zijn van (verwachte) pariteitsaanpassingen, is de sprongkans afhankelijk gemaakt van economische variabelen die mogelijk de devaluatiekans beïnvloeden. Het blijkt dat zowel een positief inflatieverschil met Duitsland als een handelsbalans-tekort de kans op een sprong significant vergroot. De modellen zijn geschat over de periode 
1979-1990. Met de modellen blijken goede voorspellingen gemaakt te kunnen worden, ook voor de periode 1991 tot september 1992. Naast puntschattingen zijn ook voorspel-intervallen berekend met het model. De intervallen zijn veel kleiner in de latere jaren van het EMS, hetgeen de toegenomen betrouwbaarheid van het systeem weerspiegeld. Bovendien tonen de resultaten aan dat de meeste devaluaties vooraf gegaan zijn door een voorspel-interval dat gedecltelijk buiten de fluctuatie-band lag. Deze devaluatios waren dus voorspeld door het model. Als laatste toepassing van de modellen is onderzocht of het model bruikbaar is bij het voorspellen van winsten in de wisselkoersmarkt. Daarbij is gekeken naar een belegging in een van de zwakke EMS munten met geleende Duitse marken. Met behulp van het model zijn de weken bepaald waarin de te verwachten depreciatie kleiner zou zijn dan het renteverschil. Voor allc munten blijken met het model zeer goede resultaten te behalen.

Om een verklaring te vinden voor deze voorspelbare opbrengsten, zijn de resultaten van deze belegging (renteverschil minus gerealiseerde depreciatie) zelf gemodelleerd in hoofdstuk 4. Twre bronnen voor de opbrengsten zijn gevonden. De eerste is onzekerheid, weergegeven door de conditionele standaard-deviatie. Het inflatie verschil met Duitsland is een belangrijke bepalende factor voor deze maatstaf. De tweede bron is het continu veranderende verwachte devaluatie risico. Deze onzekerheid omtrent pariteitsaanpassingen zorgt voor een negatieve autocorrelatie van de opbrengsten en een positief verband tussen de opbrengsten en de huidige afwijking van de wisselkoers ten opzichte van zijn pariteit. De verwachte opbrengsten, die onder de veronderstelling van efficiënte markten en rationele markt participanten gelijk zijn aan risico premies, blijken zeer grillig en van substantiële omvang. Dit reflecteert de onzekerheid binnen het EMS.

De interpretatie van verwachte opbrengsten als risico premies is alleen geldig onder de veronderstelling van efficiënte markten en rationele verwachtingen. Om risico premies te scheiden van systematische voorspelfouten van deelnemers in de markt wordt in hoofdstuk 5 gebruik gemaakt van enquête gegevens betreffende wisselkoers verwachtingen. Allereerst wordt aangetoond dat deze verwachtingen, alsmede de verwachtingen gebaseerd op renteverschillen, voor de meeste wisselkoersen buiten de doel-zone lagen tot april 1990. Bovendien blijkt uit de enquête gegevens dat de verwachtingen zeer grillige patronen vertonen. Deze feiten stemmen overeen met de veronder- 
stelling van positief en continu veranderend verwacht devaluatie risico. Vervolgens is de ex-ante risico premie, gedefinieerd als het renteverschil met Duitsland minus de enquête verwachtingen, gemodelleerd. Hoewel de technieken en de gegevens totaal verschillen van die van hoofdstuk 4 , is een positief verband tussen de risico premie en het inflatieverschil met Duitsland opnieuw aanwezig.

In hoofdstuk 6 wordt ingegaan op de ontwikkelingen die hebben geleid tot het verbreden van de fluctuatie-marges in augustus 1993. Vanaf de zomer 1992 heeft het EMS onder zeer grote spanning gestaan als gevolg van speculatieve aanvallen. In september 1992 heeft dit reeds geleid tot het verlaten van het systeem van de Italiaanse lire en het Britse pond. Deze munten waren vermoedelijk overgewaardeerd. Sindsdien zijn echter ook vrijwel alle andere munten (op de gulden en de mark na) onder druk komen te staan. De reden voor deze speculatieve aanvallen was lang niet altijd duidelijk omdat verschillende van deze munten niet overgewaardeerd waren. In de financiële pers werden de aanvallen voornamelijk toegeschreven aan de hoge Duitse rente, die het gevolg was van de inflatoire krachten voortvloeiend uit de Duitse eenwording. Om deze hypothese te staven is een maatstaf nodig van wat als een redelijke rente kan worden beschouwd. Hiertoe is een reactie functie geschat van het Duitse rente beleid over de jaren tachtig, gebaseerd op het Duitse inflatie niveau en een conjunctuur indicator voor Duitsland. Als we dit rentebeleid toepassen op de jaren negentig blijkt dat de Duitse rente vanaf eind 1991 inderdaad $\pm 1.5 \%$ hoger te zijn dan verwacht. Dit kan verklaard worden uit de extra bron van inflatie die de Duitse eenwording met zich meebracht. Als de Duitse reactie functie wordt toegepast op de andere landen van het EMS zien we dat vanaf begin jaren negentig deze gesimuleerde rente, die kan worden geinterpreteerd als de gewenste rente van binnenlands perspectief gezien, continu daalt. De Duitse rente, die men minimaal moet voeren om de koers op peil te houden, steeg daarentegen juist. Deze asymmetrische ontwikkeling leidde ertoe dat de binnenlandse rente in veel Europese landen substantieel hoger $( \pm 3 \%)$ lag dan men gegeven de binnenlandse ontwikkeling zou wensen. Er was dus een economisch motief om het EMS te verlaten. Om de invloed van deze rente ontwikkelingen op de wisselkoersen te meten is het verschil tussen de Duitse rente en de gesimuleerde rente (indien positief) opgenomen als extra verklarende variabele die de kans op een sprong in de modellen van hoofdstuk 3 beïnvloedt. Voor twee van de vier onderzochte 
wisselkoersen blijkt dit verschil, dat geïnterpreteerd kan worden als een indicator van de kosten van deelname aan het EMS, een significante invloed te hebben op de sprongkans.

Tenslotte wordt in hoofdstuk 7 kort ingegaan op de recente ontwikkelingen in het EMS. Ondanks het feit dat de officiële fluctuatie-banden zijn opgerekt tot $\pm 15 \%$, bewegen vrijwel alle koersen zich weer binnen de oude smalle banden. De meeste landen prefereren dus nog steeds een stabiele wisselkoers boven een iets lagere binnenlandse rente. Door smalle banden officieel af te schaffen is de kans op een toekomstige speculatieve aanval echter aanzienlijk verminderd. Ten eerste is het politieke signaal van stabiele wisselkoersen veel duidelijker bij brede banden (men zou de rente immers kunnen verlagen zonder gezichtsverlies te lijden). Ten tweede makt de afwezigheid van een smalle officiële band een sprong in de koers een stuk minder voorspelbaar. Het failliet van het EMS blijkt dus verder af dan gedacht. 
156 


\section{Curriculum Vitae}

Peter Vlaar werd geboren op 22 september 1966 te Avenhorn. Van 1978 tot 1984 volgde hij het atheneum aan de scholengemeenschap Werenfridus te Hoorn, waarna hij economie ging studeren aan de Vrije Universiteit te Amsterdam. In augustus 1990 studeerde hij hier af in de algemene economie met kwantitatieve specialisatie. In december 1990 ging hij werken als onderzoeker in opleiding bij de vakgroep Kwantitatieve Economie van de Rijksuniversiteit Limburg, alwaar dit proefschrift werd geschreven. Sinds 1 juni 1994 werkt hij als onderzoeker bij De Nederlandsche Bank. 
